\title{
REPRESENTATIVE BUREAUCRACY: REPRESENTATION OF AMERICAN INDIAN TEACHERS AND THEIR IMPACT ON AMERICAN INDIAN STUDENT ACCESS AND PERFORMANCE
}

by

Selena M. Grace

\author{
A dissertation \\ submitted in partial fulfillment \\ of the requirements for the degree of \\ Doctor of Philosophy in Public Policy \& Administration \\ Boise State University
}

May 2019 
(C) 2019

Selena M. Grace

ALL RIGHTS RESERVED 


\title{
BOISE STATE UNIVERSITY GRADUATE COLLEGE
}

\section{DEFENSE COMMITTEE AND FINAL READING APPROVALS}

\author{
of the dissertation submitted by
}

\author{
Selena M. Grace
}

Dissertation Title: Representative Bureaucracy: Representation of American Indian Teachers and Their Impact on American Indian Student Access and Performance

Date of Final Oral Examination: $\quad 15$ March 2019

The following individuals read and discussed the dissertation submitted by student Selena M. Grace, and they evaluated her presentation and response to questions during the final oral examination. They found that the student passed the final oral examination.

Stephanie L. Witt, Ph.D. Chair, Supervisory Committee

Gregory Hill, Ph.D. Member, Supervisory Committee

Thaddieus W. Conner, Ph.D. Member, Supervisory Committee

The final reading approval of the dissertation was granted by Stephanie L. Witt, Ph.D., Chair of the Supervisory Committee. The dissertation was approved by the Graduate College. 


\section{DEDICATION}

This has been a journey that started almost thirty-years ago with the birth of my first child, Danniell. As a young teenage mother I believed education would change our lives and the lives of generations to come. There have been many sacrifices my children (Danniell, Nicole, Thomas, and Michael) have made with me on this journey. But, it is my husband to whom I owe the most. He has supported me in every way he possibly could - suffering through courses, comprehensive exams, many drafts of this research, and stressful and tearful days. I would also like to acknowledge my parents and their never-ending support of me. I have given all that I have in the hopes that this research can be part of making some level of difference in the policy decisions those of us who are deserving and entitled have benefited from. And, last but not least, for my grandchildren and their American Indian heritage, may they be proud of that, educate themselves, and make a difference for their people. 


\section{ACKNOWLEDGEMENTS}

I would like to thank my committee for their insights and support. Particularly, I want to thank my chair, Dr. Stephanie L. Witt. She has been enthusiastic and supporting of my research through this multi-year journey. She always believed in me and made me feel more capable than I believed I was. I also want to express sincere gratitude to the superintendents, principals, teachers, and tribal education directors/managers who gave up their precious time to meet with me. For their open and honest conversations, and for their commitment to making education for American Indian students more meaningful and relevant. Without their time and support, valuable insights I discovered through this process would still be hidden. 


\begin{abstract}
Using a cross-comparative, qualitative case study approach, my research seeks to determine whether the presence of American Indian teachers (passive representation) positively influences educational access and performance of American Indian students in two rural Idaho public school districts located within tribal reservations. One district has representation of American Indian teachers and the other does not. Representation of American Indian teachers is a form of passive representation which the theory of representative bureaucracy suggests should lead to active representation (implementation of culturally relevant curriculum and teaching practices). My research analyzes deidentified student- and district-level data on access and performance as well as interviews conducted with teachers, administrators and tribal education directors in both school districts. While the data elements I evaluate under access and performance are different than the theoretical model used in prior research, they were selected to provide a larger dataset to determine the impacts of American Indian teacher representation on American Indian student access and performance based on my case study model. The interviews were intended to assess perceptions of performance as well as capture whether passive representation lead to active representation. Both the statistical data analyzed and qualitative data captured from interviews appears to support that passive representation may lead to active representation. However, my research also revealed that passive representation is significantly more complicated for American Indians than for African American and Hispanics as a result of the federal government's use of education as a tool
\end{abstract}


for cultural destruction. The evidence of these impacts can be seen in American Indian student attendance. Further, my research revealed that tribes assuming a more direct role in administrative decisions in public schools serving American Indian students may act as a form of active representation. 
TABLE OF CONTENTS

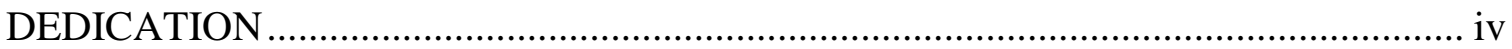

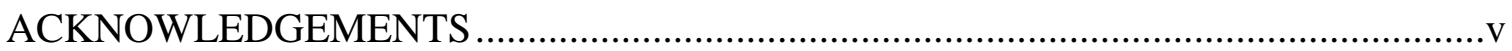

ABSTRACT ........................................................................................................... vi

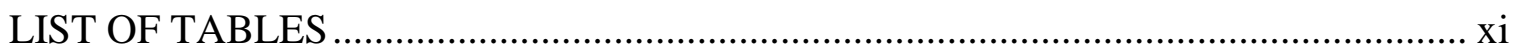

LIST OF CHARTS ……….....................................................................................

LIST OF ABBREVIATIONS .............................................................................. xiv

CHAPTER ONE: INTRODUCTION ......................................................................

CHAPTER TWO: A SOCIAL CONSTRUCTION LENS OF AMERICAN INDIAN EDUCATION POLICIES AND POLITICS ……………................................................15

CHAPTER THREE: WHY REPRESENTATIVE BUREAUCRACY MATTERS:

PASSIVE AND ACTIVE REPRESENTATION ……….............................................38

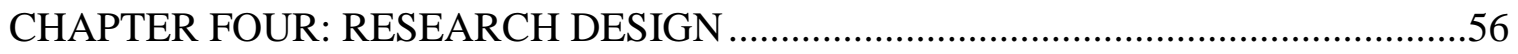

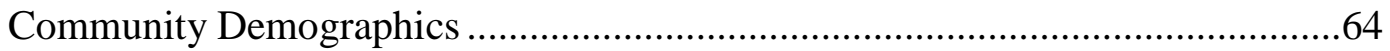

School Board Demographics ......................................................................66

Administrator Demographics........................................................................67

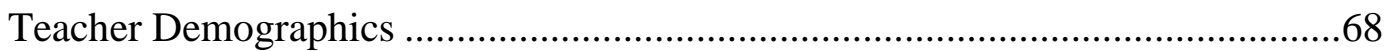

State Tribal Education Partnership (STEP) Grants ..............................................71

CHAPTER FIVE: RESULTS OF RESEARCH AND CONCLUSIONS .........................76

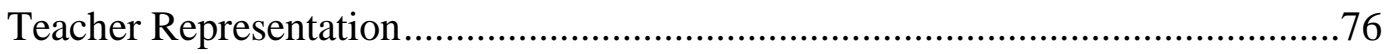

Student Access \& Performance Data .................................................................79 


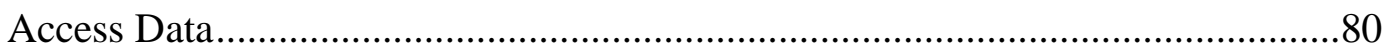

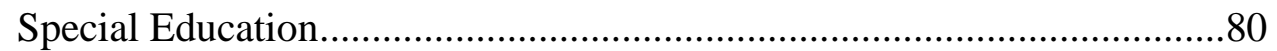

$4^{\text {th }}$ Grade Special Education.................................................................... 81

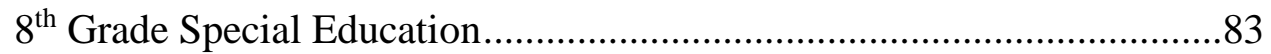

$11^{\text {th }}$ Grade Special Education....................................................................8

Gifted \& Talented Programs ................................................................86

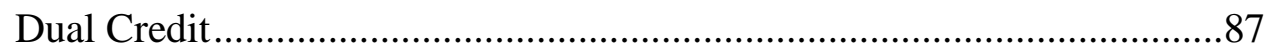

Middle/High School Math \& Science Course Availability ........................89

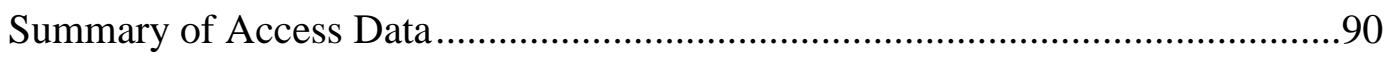

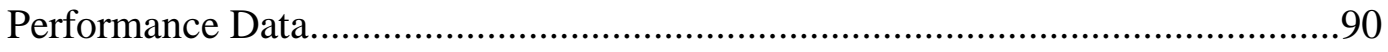

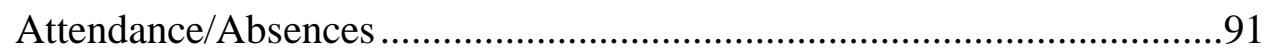

Idaho Standardized Assessment Test (ISAT) ……………………............95

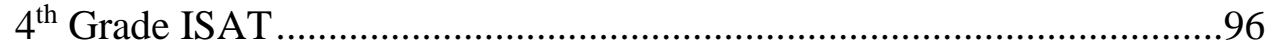

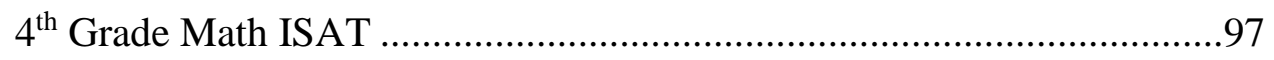

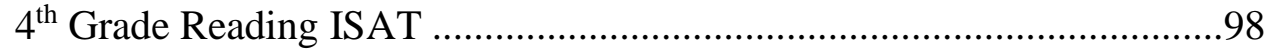

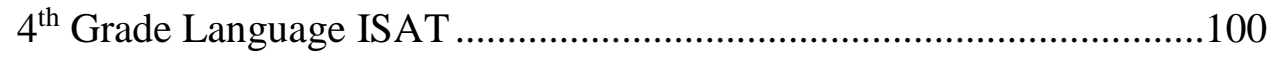

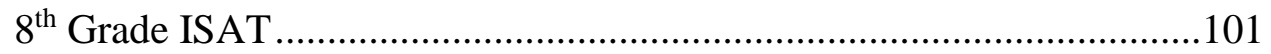

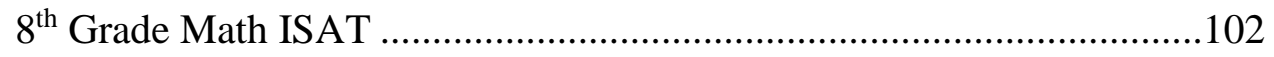

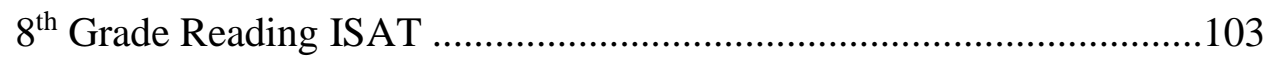

$8^{\text {th }}$ Grade Language ISAT .....................................................................104

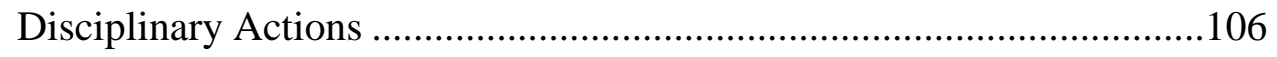

SAT/ACT College Entrance Exams ………………………………........109

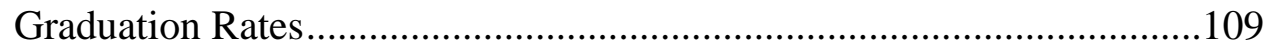


Summary of Performance Data...............................................................110

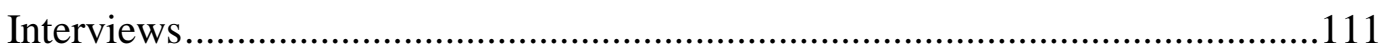

Tribal Education Department (TED) Interview Observations .........................112

Administrator Interview Observations .......................................................119

Teacher Interview Observations ........................................................ 124

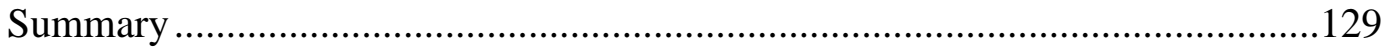

CHAPTER SIX: CONCLUSIONS AND POLICY RECOMMENDATIONS ...............132

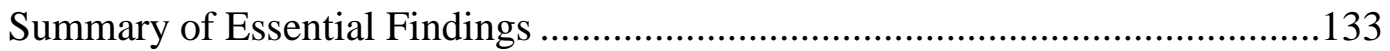

State and District-Level Policy Recommendations ......................................138

Recommendations for Further Research...............................................142

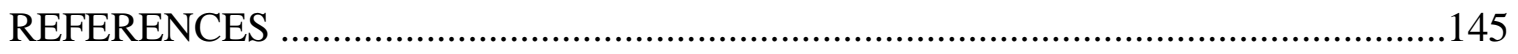

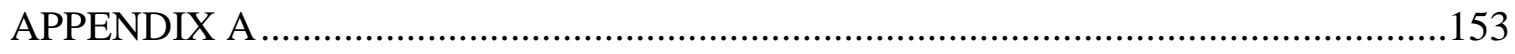

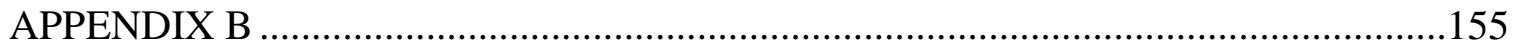

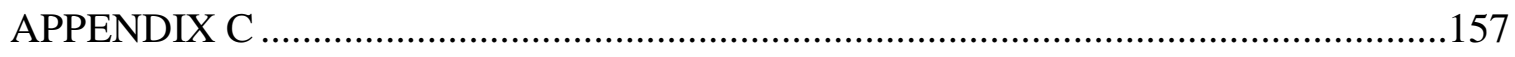




\section{LIST OF TABLES}

Table 2.1 History of Federal Policy Toward American Indians .............................. 17

Table 4.1 2010 CENSUS COMMUNITY DEMOGRAPHICS................................ 66

Table 5.1 Percent of American Indian Representation .......................................... 78

Table 5.2 2015 Federal Civil Rights Data............................................................ 80

Table 5.3 $\quad 4^{\text {th }}$ Grade Placement in Special Education by Race/Ethnicity .................. 82

Table 5.4 Rate of Placement in $4^{\text {th }}$ Grade Special Education by Race/Ethnicity ..... 82

Table 5.5 $\quad 8^{\text {th }}$ Grade Placement in Special Education by Race/Ethnicity .................. 83

Table 5.6 Rate of Placement in $8^{\text {th }}$ Grade Special Education by Race/Ethnicity ..... 84

Table 5.7 $11^{\text {th }}$ Grade Placement in Special Education by Race/Ethnicity ................ 85

Table 5.8 Rate of Placement in $11^{\text {th }}$ Grade Special Education by Race/Ethnicity ... 85

Table 5.9 Percent of $11^{\text {th }}$ Grade Students Enrolled in Dual Credit by Race/Ethnicity 88

Table 5.10 Percent of Students Enrolled in Calculus, Chemistry, or Physics ............ 89

Table 5.11 American Indian Student Access Represented Positively ........................ 90

Table 5.12 Percent of Students Chronically Absent by Type ……............................. 91

Table 5.13 $\quad 4^{\text {th }}$ Grade 2012-2013 Math ISAT Proficiency......................................... 97

Table 5.14 Rate of Proficiency for $4^{\text {th }}$ Grade 2012-2013 Math ISAT ……………..... 98

Table 5.15 $\quad 4^{\text {th }}$ Grade 2012-2013 Reading ISAT Proficiency ...................................... 99

Table 5.16 Rate of Proficiency for $4^{\text {th }}$ Grade 2012-2013 Reading ISAT .................. 99

Table 5.17 $\quad 4^{\text {th }}$ Grade 2012-2013 Language ISAT Proficiency .................................. 100 
Table 5.18 Rate of Proficiency for $4^{\text {th }}$ Grade 2012-2013 Language ISAT .............. 101

Table 5.19 $\quad 8^{\text {th }}$ Grade 2012-2013 Math ISAT Proficiency....................................... 102

Table 5.20 Rate of Proficiency for $8^{\text {th }}$ Grade 2012-2013 Math ISAT ..................... 102

Table 5.21 $\quad 8^{\text {th }}$ 2012-2013 Grade Reading ISAT Proficiency .................................. 103

Table 5.22 Rate of Proficiency for $8^{\text {th }}$ Grade 2012-2013 Reading ISAT ................ 104

Table 5.23 $\quad 8^{\text {th }} 2012-2013$ Grade Language ISAT Proficiency …............................ 105

Table 5.24 Rate of Proficiency for $8^{\text {th }}$ Grade 2012-2013 Language ISAT ............... 105

Table 5.25 Percent of Students Receiving Disciplinary Actions ........................... 106

Table 5.26 Special Education Students Receiving Disciplinary Actions by Race/Ethnicity ..................................................................... 107

Table 5.27 Percent of $11^{\text {th }}$ Grade Students Taking SAT/ACT by Type .................. 109

Table 5.28 American Indian Student Performance Represented Positively............ 110 


\section{LIST OF CHARTS}

Chart 1.1 Social Construction Quadrants (Ingram, et al., 2007) ……………........... 8

Chart 5.1 District 1 Teacher Race/Ethnicity (Three-Year Average: 2012 -2015).... 77

Chart 5.2 District 2 Teacher Race/Ethnicity (Three-Year Average: 2012 -2015).... 77

Chart 5.3 District 1 Chronic Absences by Enrollment Type …………………….... 92

Chart 5.4 District 2 Chronic Absences by Enrollment Type …………………...... 92

Chart 5.5 Days Missed Due to Out-of-School Suspensions by Race/Ethnicity ..... 108 


\section{LIST OF ABBREVIATIONS}

ACT

AP

AY

BIE

CLEP

CTE

EASI

ESSA

FTE

FY

IB

IDEA

IIEC

IRB

ISAT

JOM

LEA

NASTI

NCAI

NYCP
American College Testing

Advanced Placement

Academic Year

Bureau of Indian Education

College-Level Examination Program

Career Technical Education

Education Analytics System of Idaho

Every Student Succeeds Act

Full-Time Equivalent

Fiscal Year

International Baccalaureate

Individuals with Disabilities Education Act

Idaho Indian Education Committee

Institutional Review Board

Idaho Standardized Assessment Test

Johnson O’Malley

Local Education Agency

Native Serving Non-Tribal Institution

National Congress of American Indians

Native Youth Community Project 


$\begin{array}{ll}\text { PBIS } & \text { Positive Behavior Interventions \& Support } \\ \text { PLC } & \text { Professional Learning Communities } \\ \text { SAT } & \text { Scholastic Assessment Test } \\ \text { SBAC } & \text { Smarter Balanced Assessment Consortium } \\ \text { SBOE } & \text { State Board of Education } \\ \text { SEA } & \text { State Education Agency } \\ \text { STEP } & \text { State Tribal Education Partnership } \\ \text { TEA } & \text { Tribal Education Agency } \\ \text { TED } & \text { Tribal Education Department }\end{array}$




\section{CHAPTER ONE: INTRODUCTION}

For centuries, the naming of people and places has been a historical

demonstration of power, determining the viewpoint from which history will be recorded, and establishing where different groups of people and their culture fit within policy and politics. American Indians were targeted for assimilation to the Euro-American way of life in an attempt to eradicate their languages, traditions, and cultures (Calloway, 2016; Echo-Hawk, 2010; Nabokov, 1999; Weeks 2016). While most researchers argue that the primary tool for assimilation of American Indian children to the Euro-American way of life was education (Calloway, 2016; Fletcher, 2008; Reyhner \& Eder, 2004; Szasz, 1974; Wright, Hirlinger \& England, 1998), education was really a tool intended to destroy American Indian culture. Education of American Indian children was administered and controlled by secular and religious organizations, intentionally excluding American Indian parents and tribal leaders from the educational process, and in many cases moving American Indian children from their homes and sending them to boarding schools. The intentional exclusion of American Indian parents and tribal leaders from the education policy-making process supported and facilitated a lack of representation of American Indian teachers in the classroom. Further, it destroyed communities, alienated youth from their families and tribes, and created long-lasting intergenerational trauma ${ }^{1}$. Education

\footnotetext{
${ }^{1}$ Impacts of decades of decades of forced acculturation placed pressure and created stress on American Indian culture, their ways of knowing and epistemologies (Duran \& Duran, 1995).
} 
was less a tool to assimilate than it was a tool to destroy the American Indian way of life; thereby creating a long-standing and deep distrust about public education with American Indians.

Public administration theory of representative bureaucracy would argue that the presence of American Indian teachers should improve the education of American Indian students. Using a cross-comparative, qualitative case study approach, my research seeks to determine whether or not the presence of American Indian teachers positively influences educational access and performance of American Indian students in two rural, Idaho public school districts located within their local Tribe's reservation boundaries. I use the theory of representative bureaucracy (Selden, 1997; Meier, Stewart \& England, 1989; Wright et al., 1998) as the primary framework of my research. While a significant amount of research has been conducted using Meier's (1989) work on academic grouping and the impacts of second generation discrimination, I believe a more qualitative comparative case study approach provides additional insight into the lack of passive representation of American Indians in policy and politics, particularly in rural western communities. Further, my research focuses less on assessing second generation discrimination and more on whether the presence of American Indian teachers positively impacts access and performance of American Indian students. Representation of American Indian teachers is a form of passive representation that the theory of representative bureaucracy suggests should lead to active representation. It is active representation that should result in successfully implemented culturally relevant curriculum and teaching practices. Culturally relevant curriculum and teaching practices capture the local tribal history, culture, and community. The use of culturally relevant 
curriculum and teaching practices is the implementation and/or interpretation of policy, which is tied to active representation. While educational research proposes that implementation of culturally relevant curriculum and teaching practices leads to increased access and performance of American Indian students, I would propose that this cannot fully be realized without active representation of American Indian teachers in the schools and classrooms.

There is limited research that focuses on American Indians (see Wright et al., 1998) using Meier's (1989) work on academic grouping and second generation discrimination. Wright, Hirlinger, and England (1998) The Politics of Second Generation Discrimination: Incidence, Explanation, and Mitigating Strategies attempt to evaluate the impact of lack of representation of American Indian teachers and whether or not second generation discrimination exists, while taking both a qualitative and quantitative approach to their research.

While Wright et al. (1998) briefly touched on the political history of American Indian education, in addition to Meier's statistical model, they use qualitative research to understand why some school districts demonstrated better treatment of American Indian students; however, the research fails to attempt to answer the why. Without understanding why, is knowing the problem exists enough? In an attempt to answer the why, I use the theory of social construction to provide context for the unique historical relationship American Indians have with states and the federal government, particularly as it relates to educational policy matters.

From the time Europeans first made contact with Native peoples, American Indians were categorized into an oversimplified homogenous group of people seen 
through the lens of Euro-American social construction, thereby negatively affecting their representation in educational policy and politics. While social construction theory acknowledges the role values, perceptions of people, places, and objects play in how individuals view and understand the world, it also plays a role in determining how policy and politics are operationalized (Ingram, Schneider, \& deLeon, 2007). A simplified description of this theory categorizes individuals or populations of people into those who are deemed deserving and those who are deemed underserving of policy benefits (Berger \& Luckmann, 1966; Schneider \& Ingram, 1993 and 2005; Ingram et al., 2007). A review of U.S. policy toward American Indians illustrates the historical categorization of American Indians as undeserving of benefits and incapable of exercising authority and the ability to meaningfully participate in education policy and politics as it related to their people.

The demonstration of power can be seen from the earliest French, Spanish, and British contact with American Indians. Traders and explorers often came up with their own names for the tribes and their traditional landscapes without context or critical understanding of the local history. Many times, the names given to tribes were not the names they called themselves or their home landscapes. Rivers, established pathways, and mountains that had been incorporated into the various tribal histories were never acknowledged and these places were often given new Christian and European names. Tribal names assigned by the Europeans were often based only on immediate context or limited understanding of the distinctness of the many different tribes. Examples of the tremendous power and effect of naming can be seen in two Idaho tribal communities. Early French traders named one tribe the Nez Perce, meaning pierced noses in French. 
They reduced an entire organized tribal community with thousands of years of history to a group of people based on the French traders mistakenly connecting the Nez Perce with the nearby Chinook people. However, the Nez Perce refer to themselves as Nimíipuu (pronounced nimi:pu), which means the real people or we the people (Nez Perce Tribe, 2010).

Another example of the power and impact of naming took place in the late $18^{\text {th }}$ early $19^{\text {th }}$ century, when French traders and trappers named the Coeur d'Alene Tribe, meaning Heart of the Awl in French. The French selected this name because of "the sharpness of the trading skills exhibited by the tribal members in their dealings with visitors" (Coeur d'Alene Tribe, 2018). However, the Coeur d'Alene refer to themselves as Schitsu'umsh, meaning The Discovered People or Those Who Are Found Here (Coeur d'Alene Tribe, 2018). Notwithstanding the prior two examples, there were well over five hundred distinct tribes pre-European contact that were reduced into a singular group of people through the power of naming.

This power of naming can also be seen on a much larger scale with the use of the very term Indian. Therefore, it is important to provide historical context of the origins of the term Indian. The term Indian started as a European conception, and to a certain extent a misconception about the first Americans. When Columbus encountered the native inhabitants of a Caribbean island, he mistook them for inhabitants of India, and in believing he had discovered another route to India he called them los Indios (Calloway, 2016; Corntassel \& Witmer, 2008). It was then that the term first came into use, becoming a lasting designation for the first American peoples. However, since that time, the terms American Indians, Native Americans, native peoples, first peoples, and native 
nations have also been used (Calloway, 2016; Fredericksen, Witt, \& Nice, 2016; Grover, 2017; Wilkins \& Stark, 2011). In fact, the designation and use of terminology has widely become tribe or region-specific. From a tribal perspective, often their preference is the use of their individual tribal names. In my experience working on the Idaho Indian Education Committee (IIEC) for more than a decade, the consensus has been American Indian. For purposes of my research, I will use the term American Indian.

Using the lens of social construction, in Chapter 2, I will explain that how segments of the population view their relationship with the government is more legislatively complicated for American Indians than any other non-white American population because of their unique relationship with states and the federal government. This is due primarily to the role American Indian tribes have as domestic sovereign nations - sovereign yet still dependent on the federal government, and the role the federal government played in using education as a weapon to destroy tribal culture and communities rather than an opportunity to a better livelihood. I use social construction to frame the historical and contemporary policy and politics of states and the federal government toward American Indians. There are over five hundred active agreements and treaties between the U.S. government and individual tribes that establish the boundaries of policy and politics between tribes and the U.S. (Wilkins, 2002). These treaties and agreements generally guaranteed tribes:

...all the rights and resources (e.g., rights to water and lands; to hunt, fish and gather; to exercise criminal and civil jurisdiction; to tax) they had not ceded to the federal government when they sold or exchanged the majority of their land - most of North America (Wilkins, 2002, p. 44). 
American Indian rights are protected by the trust doctrine, which means that lands owned by American Indian tribes is held in trust by the U.S. government. Wilkins \& Lomawaima (2001) highlight that the trust doctrine, in its broadest sense, is about the federal responsibility to protect tribal assets through policy and management decisions (e.g., natural, human, cultural or financial). Through the trust doctrine, the federal government developed a different relationship with tribal governments than it did with the states. Much of the difference revolved, and still does, around the recognition that tribes were sovereign nations continuing to reside within the new boundaries of the U.S. The growth and expansion of states necessitated some level of federal protection of American Indians from states who were hungry for growth and asserting local power. While the U.S. government promised tribes provisions, money, healthcare, and education as part of the many treaties it executed and the removal of land that accompanied them, states retained a significant level of local control over education policies and decisions that directly impacted American Indian students - which has continued until present day. In states that do not work with their local tribes, American Indian representation in the policy decisions continue to be absent. In particular, this lack of representation in policy and politics limits the American Indian voice and authority in educational policy matters impacting their people.

From a social construction perspective, federal legislation and the negotiation of treaties was the policy design utilized to formally establish American Indians in a negative, undeserving social construct. The delineation of whether a target population is seen as deserving or undeserving determines where and how opportunities to participate in policy and politics exist. Ingram, Schneider, and deLeon (2007) devised a four 
quadrant matrix that consists of advantaged, contenders, dependents, and deviants to demonstrate where individuals fall with regard to political power and their degree of deservedness. Where a person falls within the quadrants of deservedness and power does not have hard delineations, but rather they may overlap in multiple quadrants, and while difficult, they can change over time. In a social construction framework, American Indians have consistently occupied the low power quadrant, and over time have oscillated between dependents and deviants, and from a Euro-American perspective supported an undeserved policy approach.

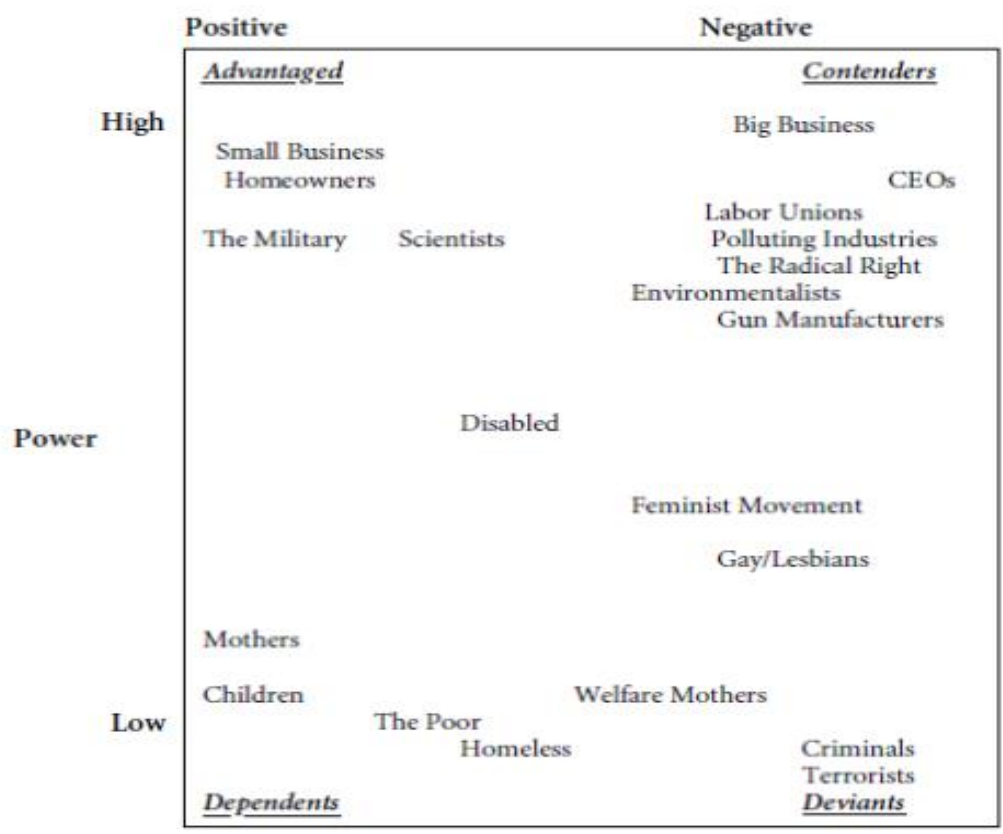

\section{Chart 1.1 Social Construction Quadrants (Ingram et al., 2007)}

Social construction theory proposes that policy designs are primarily driven by those who fall within the category of the deserving target population, and cultural values and social judgments drive policy design rather than dispassionate objectivity. Therefore, those who fall within the undeserving target population are much more likely to necessarily be viewed in a negative social construct - thereby unavoidably resulting in 
unequal access to benefits within the very same policy design. Social construction theory further proposes that policy designs and their operationalization, whether historical or contemporary, have long-term implications on target populations based on where they fall within the deserving and underserving categories (Ingram, et al., 2007).

While I use the theory of social construction in Chapter 2 to explain historical and contemporary American Indian and white relations and the educational policy designs that result, in Chapter 3 I explore how the operationalization of policy and politics is closely tied to representation, both passive and active. In Chapter 3, I more closely examine how policy and politics are operationalized in the passive representation of American Indian teachers in the classroom, or the lack thereof due to policy designs that created an adversarial relationship between states and the federal government regarding the treatment and position of power of American Indians. American Indians lacked access to the same educational opportunities as white Euro-Americans who in the position of deserving and entitled and the ones who were establishing the policy and framing the politics. Not only did American Indians lack access, but they were categorically denied a basic right to have a voice or determine how their children were educated.

The categorization of American Indians as an underserving population resulted in diminished access to participation in the political process, as a result of the message that it conveyed. As noted by Ingram et al. (2007) “[m]essages convey who belongs, whose interest[s] are important, what kind of 'game' politics is, and whether one has a place at the table" (p. 100). American Indians have had limited ability to participate in policy and politics, due to their status as an undeserving population which was deliberately 
established by the self-serving, deserving and entitled white European target population. In fact, much of the literature (Deloria \& Wilkins, 1999; Weeks, 2006 \& 2016; Wilkins \& Lamawaima, 2001; Nabokov, 1999; Biolsi, 2001; Calloway, 2016) references the Indian problem and a relationship between states and American Indians as one of deadliest enemies. This can be better illustrated in Table 2.1 History of Federal Policy in Chapter 2 where I review the contradictory and conflicting social construction of American Indians as seen through federal policy designs. The contradiction and conflict have limited the ability of American Indians to participate both passively and actively in educational policy and politics.

U.S. federal policy from the late 1870 s to present have been socially constructed in a manner that adversely impacted political orientation, participation, and therefore passive representation of American Indians in educational policy matters. My research seeks to determine if the passive representation of American Indians (the presence of American Indian teachers in the classroom) in education policy and politics leads to active representation. Which, if it does, may result in broader implementation of culturally responsive curriculum ${ }^{2}$ and teaching practices $^{3}$ in public schools that serve American Indian students.

Recognizing the educational needs and lower educational attainment level of American Indians in Idaho, my research seeks to determine the impacts of representation of American Indian teachers on student access and performance of American Indian

\footnotetext{
${ }^{2}$ Culturally responsive curriculum considers educational "materials, instructional techniques, and learning characteristics" that reflect the values of the communities/tribes (Swisher \& Tippeconic, 1999, p. 89). ${ }^{3}$ Culturally responsive teaching is a pedagogy that recognizes the importance of including cultural references of students in all aspects of learning. (Ladson-Billings, 1994).
} 
students. Chapter 4 presents the framework of my research, with greater detail on the public school districts and their community demographics. I selected public schools because the majority of American Indian students are enrolled in public schools, and yet there is limited research linking education and public policy theories as it relates to American Indians. According to the National Congress of American Indians (NCAI, 2015), nationally, $93 \%(620,000)$ of American Indian students attend public schools and only $7 \%(45,000)$ attend one of the 184 Bureau of Indian Education (BIE) schools that are located on 63 reservations in 23 states. The two school districts in my case study are rural and have an American Indian student enrollment between 40-80\% educated by all or predominantly white teachers and administrators.

Public schools are important from a policy perspective because nearly half of K12 funding comes from state taxes. States and local governments generate the majority of their revenue from taxes, which includes taxes on property, and because tribal lands are held in federal trust they cannot be taxed by the states or local governments.

Consequently, public school districts with a high American Indian population may be accompanied by an inadequate property tax base from which to draw and provide services. While these school districts receive federal Impact Aid dollars, those allocations are consistently underfunded and do not fill the financial void faced by these districts. According to the U.S. Department of Education (2017), Impact Aid was first approved by Congress in 1950 and is intended to offset lost property taxes for local school districts impacted by federally owned lands (which includes American Indian lands).

Therefore, the relationship between Tribes, their communities, and states, while incredibly important, is often in conflict because of resources. There are federal programs 
attempting to bridge the conflict related to education. One of those is the State-Tribal Education Partnership (STEP) grants. Chapter 4 includes an overview of the STEP grants received by the two tribes that were part of my research and their progress to date. The STEP grants are a significant accomplishment and a clear demonstration of increasing collaboration between tribal education agencies (TEA) and the state (SEA) and local (LEA) educational agencies. The primary goal of STEP is to increase capacity of TEAs in order to have a more direct role in administrative decisions impacting public school districts with predominantly American Indian students. In 2015, there were five, fouryear awards made, and Idaho received two of those. Because states' relationships with tribes are historically challenging, having been referred to as one of deadliest enemies (see Chapter 2), the existence of the two STEP grants are important factors included in my research. Due to the grants, there are signs of stronger collaborative relationships acknowledged by the LEAs and TEAs than in other districts in the state. The STEP grants are a demonstration of alternate approaches, or a mechanism, that may compensate for the lack of representation of American Indian leaders (teachers) in education policy and politics.

Chapter 5 presents the cross-comparative, qualitative case study of the two districts. The research includes a district with American Indian teachers and a district without. The case studies use state and federal data covering a two - three year period, focused on de-identified American Indian student-level data related to access and performance, as well as a summary of findings from interviews with teachers, administrators and tribal education leaders. I assess access using many of the traditional data elements identified as grouping (placement in special education and gifted and 
talented programs) of students into ability categories (Meier et. al., 1989). However, I also evaluated dual credit, and middle/high school math and science course availability to also assess access. While special education and gifted and talented programs are tied to ability grouping, the other two data elements assess student access to college-bound programs or opportunities and are more prevalent now than when the prior research was conducted. Ability grouping then establishes the academic pathways students follow for the majority of their educational careers, locking them into ability categories that are near impossible to remove - both personally and academically. To assess student performance, I look at standard metrics of educational assessment intended to capture progress and knowledge abilities, including attendance, disciplinary actions, standardized test scores, and graduation rates. I have included additional elements that were not part of prior research in order to more adequately to assess performance. Chapter 6 summarizes my research findings and implications of the study, provides policy recommendations, and provides areas for suggested future research.

This research is necessary and important because American Indians are indigenous to the land that now makes up the United States of America, and each tribe has their own unique histories and cultures that predate the existence of the U.S. by thousands of years. It matters because they have a unique historical experience and longstanding complex relationship with the federal government, unlike any other race or group of people, and they continue to be the only group to hold a politically sovereign status within the U.S. And, while they maintain this status, access to education and performance of American Indian students lags behind their white and non-white peers. It 
matters because we owe it to the native peoples we displaced, disadvantaged, and historically sought to destroy.

Ultimately, my goal is that this work can be used to inform policy recommendations by the Idaho Indian Education Committee (IIEC), of which I am a member, to the Idaho State Board of Education (SBOE). As a member of the IIEC, and someone who has been involved in American Indian education policy discussions in Idaho for more than a decade, I am professionally invested in this work. And, as a grandmother with two grandchildren who are American Indians, I am also personally invested. 


\section{CHAPTER TWO: A SOCIAL CONSTRUCTION LENS OF AMERICAN INDIAN EDUCATION POLICIES AND POLITICS}

In order to fully understand how social construction impacts public policy as it relates to American Indian representation in education, I will cover three main ideas in Chapter 2. In the first, I will look at the historical status/image of American Indians over time, to demonstrate the evolution of federal policies as seen through the lens of social construction. Second, I will look at two themes that run consistently throughout the literature review and how American Indians are represented in an undeserving and unentitled social construct. Finally, in order to better understand American Indian placement within education policy and politics, I will evaluate three major federal reports prepared during the last 100 years. I will highlight the social constructs and key findings and recommendations that consistently identify the need for representation of American Indian parents, elders, and tribal leaders in the education of their people.

As humans we have innate tendencies to group and categorize. Schneider and Ingram (2005) highlight the power to name, categorize, and group individuals into deserving and entitled in their work Public Policy and the Social Construction of Deservedness. While the Declaration of Independence says that all men are created equal, our natural tendencies to group and maximize the difference where we can distinguish ourselves from each other provides the government an avenue to exploit "people's tendency toward group categorization, positive group identification, and willingness to accept negative perceptions of undeserving groups" (Schneider \& Ingram, 2005, p. 3). 
Public policy is the mechanism that allows the government to institutionalize and perpetuate social constructions, and unchecked and unchallenged, social constructions allows for the marginalization of groups of people who become disadvantaged (Schneider \& Ingram, 2005).

American Indians have maintained sociocultural distinctness by tribe, occupied lands, and maintained governmental control over members of their tribes from preEuropean contact to the present time (Calloway, 2016; Nabokov, 1999; Weeks, 2016; Wilkins, 2002). However their current distinction from other minority groups is a result of their continued quasi-sovereign status, which provides tribal members a political status not held by any other minority group. American Indians hold citizenship in three categories: Tribal, State, and the United States. Officially, American Indians weren't granted U.S. citizenship until 1924, and many states refused to recognize American Indians as citizens of the state or federal government until well past the 1950's and 1970's (Calloway, 2016; Nabokov, 1999; Weeks, 2016; Wilkins, 2002). To further complicate identity and citizenship, identity and association with tribal membership became increasingly challenged as language and culture loss increased significantly across the many tribes. American Indians may hold three layers of citizenship, but those layers haven't always been clear, supported by other citizens within their own communities, and have a level of trauma that has impacted participation of many American Indians in policy and politics.

While tribal governments have been recognized since early European contact as having unique, independent responsibility for the political, cultural, and health and wellbeing of their members; the federal government maintained a level of control and 
responsibility due to the many federal treaties as well as federal and state policies. The federal responsibility was part of the negotiation of land removal and relocation agreements, and a way to ensure control and assimilation of American Indians.

Within the framework of social construction, early white Americans were seen as deserving and entitled, and American Indians were seen as underserving and unentitled (Berger \& Luckmann, 1966; Schneider \& Ingram, 1993 and 2005; Ingram et al., 2007). Since the early 1900s, in particular, education policy and politics centered on a philosophy of separation and assimilation. I have made adaptations to the following chart developed by the National Congress for American Indians (NCAI), to demonstrate the historical evolution of federal policies toward American Indians, and to demonstrate the status/image of American Indians as seen through the lens of social construction.

\section{Table 2.1 History of Federal Policy Toward American Indians}

\begin{tabular}{|l|l|l|}
\hline Time & Description/Federal Policy & Political Status/Image \\
\hline $1492-1828$ & $\begin{array}{l}\text { Colonial Period - Invasion of the } \\
\text { Americas, colonial acquisition of } \\
\text { American Indian lands under the doctrine } \\
\text { of discovery, establishment of Indian } \\
\text { tribes as foreign governments, } \\
\text { revolutionary war and an effort to } \\
\text { maintain peace between tribes and } \\
\text { colonial America. }\end{array}$ & $\begin{array}{l}\text { High power contenders } \\
\text { because of ability to ally } \\
\text { with warring nations, but } \\
\text { seen in a negative construct }\end{array}$ \\
$\begin{array}{l}\text { 1787 Northwest Ordinance } \\
\text { Seen as noble savages }\end{array}$ & $\begin{array}{l}\text { Negative construct } \\
\text { Growth in U.S. population and military } \\
\text { power, westward expansion and } \\
\text { relocation of American Indian tribes } \\
\text { further west but with the promise of } \\
\text { continued ability to self-govern. }\end{array}$ & $\begin{array}{l}\text { Slightly above low power, } \\
\text { with some advantage to } \\
\text { negotiate treaties, but also } \\
\text { seen as dependent }\end{array}$ \\
$\begin{array}{l}\text { 1830 Indian Removal Act } \\
\text { 1871 end of treaty making } \\
\text { 1885 Major Crimes Act }\end{array}$ & $\begin{array}{l}\text { Seen as domestic dependent } \\
\text { nations, blood thirsty } \\
\text { savages }\end{array}$ \\
\hline
\end{tabular}




\begin{tabular}{|c|c|c|}
\hline 1887-1934 & $\begin{array}{l}\text { Allotment \& Assimilation Period - Kill } \\
\text { the Indian save the man, defending the } \\
\text { west from continued encroachment of } \\
\text { non-Indian settlers, the Dawes Act, with } \\
\text { more than } 90 \text { million acres of tribal lands } \\
\text { taken and given to settlers. } \\
1887 \text { Dawes Act } \\
1928 \text { Meriam Report }\end{array}$ & $\begin{array}{l}\text { Low power, seen as } \\
\text { dependent and to some } \\
\text { degree as deviants } \\
\text { Seen as vanishing, wards in } \\
\text { need of protection } \\
\text { Negative construct }\end{array}$ \\
\hline 1934-1945 & $\begin{array}{l}\text { Indian Reorganization Period - End of } \\
\text { allotment, restoration of Indian lands and } \\
\text { reconstituted tribal governments. } \\
1934 \text { Indian Reorganization Act }\end{array}$ & $\begin{array}{l}\text { Low power, seen as } \\
\text { dependent and deviants } \\
\text { Seen as quasi-sovereigns, } \\
\text { noble savages } \\
\text { Negative construct }\end{array}$ \\
\hline 1945-1968 & $\begin{array}{l}\text { Termination Period - Public Law } 280 \\
\text { terminated more than } 100 \text { tribes, imposed } \\
\text { state criminal and civil jurisdiction of } \\
\text { tribes in five states, terminated federal } \\
\text { assistance, and relocation of Indians from } \\
\text { reservations to urban areas. } \\
1953 \text { Resolution } 108 \\
1953 \text { Public Law } 280\end{array}$ & $\begin{array}{l}\text { Low power, seen as } \\
\text { dependent and deviants } \\
\text { Seen as noble savages, } \\
\text { patriots }\end{array}$ \\
\hline 1968-1988 & $\begin{array}{l}\text { Self-Determination and Sovereignty } \\
\text { Period - favoring tribal control over their } \\
\text { destinies with control over land, } \\
\text { resources, and governance, revival of } \\
\text { cultures and societies. } \\
1968 \text { Indian Civil Rights Act } \\
1975 \text { Indian Self-Determination and } \\
\text { Education Assistance Act } \\
1976 \text { Report on Indian Education } \\
1978 \text { Indian Child Welfare Act } \\
1978 \text { Indian Religious Freedom Act }\end{array}$ & $\begin{array}{l}\text { Slightly above low power, } \\
\text { moderate dependence } \\
\text { Seen as domestic dependent } \\
\text { nations, with quasi- } \\
\text { sovereign status, militant } \\
\text { protestors, environmental } \\
\text { stewards } \\
\text { Positive construct }\end{array}$ \\
\hline
\end{tabular}




\begin{tabular}{|l|l|l|}
\hline $\begin{array}{l}\text { 1988- } \\
\text { present }\end{array}$ & $\begin{array}{l}\text { Mix of Self-Determination and Forced } \\
\text { Federalism Period - requiring state } \\
\text { compacts between tribes and states to } \\
\text { open a casino on Indian land. }\end{array}$ & $\begin{array}{l}\text { Moderate power, somewhat } \\
\text { contenders }\end{array}$ \\
$\begin{array}{l}1988 \text { Indian Gaming and Regulatory } \\
\text { Act } \\
1988 \text { Tribal Self Governance Act } \\
\text { 2000 Indian Economic Development } \\
\text { and Contract Encouragement Act }\end{array}$ & $\begin{array}{l}\text { Seen as domestic dependent } \\
\text { nations, quasi-sovereigns, } \\
\text { rich Indians, interest groups }\end{array}$ \\
\hline
\end{tabular}

National Congress of American Indians, Corntassel \& Witmer (2008) with my own adaptions

The social construction of American Indian power as depicted in Table 2.1

demonstrated the fluctuating perceptions over the last several centuries from a philosophy of extermination, to one of kill the Indian save the man, to perceptions of noble savages, to one of unique independent nations of rich Indians (Corntassel \& Witmer, 2008). These social constructs have not only "reduce[d] indigenous peoples to one-dimensional stereotypes [but] have become embedded in U.S. educational and governmental policymaking” (Corntassel \& Witmer, 2008, p. 27). Schneider and Ingram (2005) emphasize that persistent constructions of deservedness and entitlement can become stronger over time through policy re-enforcement, as well as through the undeserving and unentitled perpetuating their own subordination. American Indians were often at a disadvantage against Euro-Americans because of language barriers and a rapidly diminishing way of traditional life due to relocation and establishment of reservations.

Schneider and Ingram (2005) highlight that policies can have unintended consequences that adversely impact identity "[w] hen policies - backed by full authority of the state - embrace negative construction of groups[, thereby] help[ing] to spread them throughout society" (p. 21). Most significantly, public policy and politics sends messages that are "reflected in how people perform their role as citizens" (Schneider \& Ingram, 
2005, p.23). This participation can be in the form of voting, running for political offices or school boards, or working in public service roles such as teachers.

Schneider and Ingram (2005) propose that, in order for individuals to be good citizens, there must be participation, empathy, and recognition of the interests of public bureaucracies and private businesses, and that while citizenship is a legal category it also requires a sense of belonging. This sense of belonging requires involvement and participation, which ultimately leads to encouraging participation of some (those who are deserving and entitled) and discouraging participation of others (those who ware undeserving and unentitled). Participation in policy and politics by American Indians has been a particularly complicated and contradictory experience because of their unique political relationship with states and the federal government, and their sometimes contradictory levels of citizenship and the changing federal policies over time.

Within political social constructs, American Indians have oscillated between dependent and deviant status, which supported and reinforced their undeserving and unentitled position within society. The dependent and deviant status can been seen throughout two central ideas or themes consistently running through the American Indian historical literature review: one, the repeated reference to the Indian problem, and two, the acknowledgement that the relationship between states and tribes is often referenced as one of deadliest enemies (Weeks, 2006 \& 2016; Deloria \& Wilkins, 1999; Calloway, 2016; Biolsi, 2001; Steinman, 2004). I would argue these ideas or themes of the Indian problem and that of deadliest enemies are a demonstration of how the government has “exploited people's tendency toward group categorization, [negative] group identification and willingness to accept negative perceptions of undeserving groups" (Schneider \& 
Ingram, 2005, p. 3). The undeserving and unentitled status supported the federal government's ability to use education as a tool to assimilate the Indian. Because education policy and politics were the primary tools for assimilation and isolation from tribal culture and history, American Indians were intentionally placed in a position of low power and dependent status -thereby institutionalizing the perception of the Indian problem that created and escalated a deadliest enemies relationship between states and tribes.

American Indian writer and scholar N. Scott Momaday (1997) proposed that the idea of an Indian problem is dangerous as it presupposes there can be a solution (1997, p.58). Further, Momaday (1997) indicated that:

the immediate problems which arose out of colonial establishment are, with reference to the Indian, the common denominations of subsequent history: the question of Indian ownership of land, the development of natural resources, and the uncompromising determination on the part of the white man as either to "civilize" the Indian or to eliminate him (p. 60).

These ideas or themes are a direct result of the continued expansion of large numbers of non-Indian settlers' increased desires to move further and further west consuming more and more of the land and natural resources that had been governed by American Indian tribes for centuries; and one of an increasing number of states within the U.S. wanting control and authority over sovereign tribal entities (re)located within their boundaries (Weeks, 2006 \& 2016; Wilkins \& Lamawaima, 2001; Calloway, 2016). Because non-Indian, white Europeans were the deserving and entitled population, their 
goal has been to keep American Indians in an undeserving unentitled social construct where their political power could be limited and controlled.

Over the last century, this was accomplished by separating families and destroying tribal communities and local power (Corntassel \& Witmer, 2008). The origins of the U.S. provided that states would have a significant level of autonomy and authority within their borders. However, due to the federal government's recognition of American Indian tribes also maintaining a level of sovereignty that included governance over their own people, this created deep-seated tension between states and tribes. States were often apathetic or antagonistic towards the health, education, and overall well-being of American Indians, and frustrated by their lack of power and oversight over tribes and reservations (Weeks, 2006 \& 2016; Wilkins \& Lamawaima, 2001; Calloway, 2016). States also feared American Indian tribes gaining any power. Deloria \& Wilkins (1999) emphasized that,

[the] failure to look ahead and contemplate the real alternatives to the Indian problem [italics mine] was a great $\sin$ - but [also] one of omission, laziness, and allegiance. It created a situation in which the states and territories would frequently be opponents of the federal government when Indians were the subject of debate (p. 24).

This opposition often included citizenship and determining services the states or the federal government were responsible for providing to American Indians as well as the scope of the relationship between states, the federal government and American Indians.

Further, the complexity of the levels of American Indian citizenship has empowered exclusion and separation by white Euro-Americans, and ultimately states and 
the federal government. Review of the evolution of policy and politics between American Indians, early Europeans, and ultimately the U.S. Government clearly depicts the significance of socially constructed policies impacting the historical representation of American Indians in policy and politics. The centuries capture a complex and contradictory "unalterable reality of white dominance over the continent and the lives and destinies of its indigenous peoples" (Weeks, 2016, p. 3). Calloway (2016) captured the reality of civilization in that “...one people's triumph often means another's tragedy; that building a new nation often entails destruction or displacement of other, older nations; and that the expansion of one civilization often brings chaos and suffering to another" ( $p$. 4). Not only were many early American Indian civilizations irreversibly altered or destroyed, but in the process, the centuries consisted of failed American Indian policies unable to devise a solution to the Indian problem of how to assimilate American Indians into the Euro-American way of life (Weeks, 2016). In this process, hundreds of communities continue to experience intergenerational trauma today because of loss of language and culture. This marginalization has further alienated American Indians from trusting that education can be the great equalizer.

The history of federal educational policies in the United States demonstrate a philosophy to eliminate American Indian communities and cultural identity, and to enculturate American Indian students into the predominant Anglo culture. The federal government's goal of education of American Indians was certainly cultural assimilation, but the reality is that it had a more negative, long-lasting consequence than could have been imagined (American Indian Policy Review Commission, 1976; Deloria \& Wildcat, 2001; Fletcher, 2008; Nuby \& Smith, 2012; Wright et al., 1998). Because American 
Indians were perceived as an undeserving unentitled population, they lacked representation in the policy and politics imposed on them (Reyhner \& Eder, 2004; Weeks, 2006, 2016; Nabokov, 1999; Biolsi, 2001; Calloway, 2016). As Leiding (2006) emphasizes, "Indian education sprang from the misguided notion that assimilated Indians would be happy Indians" but the reality was that "they would not be Indians at all" (p. 43). Beginning with the boarding schools, the social construction of American Indians as an underserving unentitled population can be seen through evaluating three federal reports in particular. But first, it's important to understand a central element of the federal government's philosophy of education for American Indians. In the mid to late 1800's, the federal government determined that not enough American Indians were attending school. Believing that the only way to civilize the Indian and address the Indian problem was to remove the children from their parents and communities, they created a system of Indian boarding schools.

The most damaging act of assimilation played out during the boarding school era in the late 1800's, where American Indian students were removed from their homeland, families, and traditions. In 1877, Congress appropriated \$20,000 for Indian Education, and by 1900 that reached nearly $\$ 3$ million (Calloway, 2016). During that same period enrollment increased from 3,598 American Indian students in 1878 to 21,568 American Indian students in 1900, with attendance mandatory (Calloway, 2016). In 1891, for parents who refused to send their children, Congress authorized the Indian office to withhold rations and annuities, and in 1894 nineteen Hopi leaders were arrested and sent to Alcatraz for refusing to send their children to school (Calloway, 2016). Reyhner (2018) shares a memory from Willard Beatty who was the director of the Office of Indian 
Affairs education program from 1936 to 1952, when Indian police and government officials would steal children under the pretense of being ordered by Congress.

Whereupon the Navajo policeman stood up in the buckboard and fired a shotgun into the air to scare the children and make them stop running - if possible. Then he jumped out of the wagon and ran after the children. If he caught them (and many times he didn't), he wrestled them to the ground, tied their legs and arms, and with the help of Mr. Blair [the Superintendent of the Albuquerque Indian School] put them in the back part of the wagon, where they lay until Blair had gathered in the quota for the day. Then they returned to the Albuquerque school and enrolled the children they had captured (Beatty, 1961, as cited in Reyhner, 2018, p. 61).

Once at the boarding school, young men and women were stripped of their tribal names, clothes, language, and culture. The young men's hair was cut, both male and female students were given white European clothing, given Christian names, and prevented and punished for speaking their native language. In addition, the living conditions at the boarding schools were often more sufferable than the reservations. One teacher at the Crow Creek Indian School documented that:

students 'dressed in a frigid room, washed in icy water in an unheated washroom' and 'drank coffee three times daily. For there was neither sugar nor milk. Butter, cheese, fresh fruit, and vegetables were never seen in that dining room.' A 'daily diet of bread and molasses, coffee, meat and gravy' included eggs on rare occasions (Brown, 1952, cited in Reyhner 2018, p. 60). 
Many kids ran away on multiple occasions. Dennis Banks, an American Indian Movement leader recounts:

We all ran away from those schools from time to time, not really knowing where we were running to. In a way it was our own survival instincts telling us to go, and so we went. But the price for getting caught was the 'hot line.' That was when the older boys would form two lines facing each other - ten boys on either side and they would hit you with belts, sticks, and straps as you ran through the 'line.' Can you imagine? A government policy that encouraged kids to punish other kids. But we all survived, though at times the Indianness was almost beaten out of us. Then there were books we had to learn from. Books about white people. White heroes. White presidents. All the stories were about how the white settlers settled this land among the savage Indians, and how Indians came marauding, stealing, scalping, and killing innocent babies. All our teachers were white (1994, cited in Reyhner, 2018, p. 59).

Often when American Indian children returned to their families and communities five to ten years had passed, and they were isolated and seen as outsiders or betrayers of their heritage - leaving these young American Indians caught in the middle of two cultures and lifestyles creating further distrust and isolation (Calloway, 2016; Reyhner \& Eder, 2004; Reyhner, 2018). It's important to note that not all American Indians resisted education or sending their children to boarding schools. Some parents believed it would help their children survive in the white man's world, and perhaps by educating their children, they would be able to come back and help their own tribes. Reyhner (2018) shares the memories of a missionary who recalled "three adult Yankton (Sioux) warriors 
who rode forty miles every week to learn to read and write their own language" (Hinman, 1869, cited in Reyhner, 2018, p.62).

By 1920, Congress closed non-reservation boarding schools with less than 80 students, reservation boarding schools with less than 45 students, and day schools with less than eight (Reyhner \& Eder, 2004). As noted by Calloway (2016), the era of boarding schools "left a legacy of bitterness, confusion, and heartbreak that continues to affect Indian people as they struggle to restore languages that were almost destroyed and to restore pride in a heritage that was denied any worth for so long" (p. 397). This was observed significantly in the communities that are part of my research. The Tribe in District 1 had recently lost their last fluent native speaking elder. And while I was conducting interviews in District 2, a tribal elder who spent regular time teaching the Tribe's native language in the District 2 public schools passed away.

The legacy of bitterness, confusion, and heartbreak referenced by Calloway (2016) can be seen in the challenges of attendance of American Indian student in public school education today. I would propose that attendance challenges are the result of frustration towards an educational system that was created to destroy American Indian communities and culture, and the lack of representation of American Indian parents and tribal leaders in education policy has only exacerbated the disenfranchisement from participation. In many of the interviews, administrators and teachers expressed confusion and frustration by the attendance challenges for their students, and only one of the school districts discussed being a trauma informed and trained school.

As noted by Weinberg (1977), American Indian education "was based on the destruction of tribal economy and society, the civic powerlessness of Indian people, and a 
federal school bureaucracy marked by a strong sense of culture superiority" (p. 202). The rural nature of the reservations and the states and territories they were located in further isolated American Indians. Because of the flow of federal annuities and reservation payrolls there was substantial local investment in the reservation organizational structure, and local businesses invested themselves politically statewide and nationally to protect their financial interests. The use of education as a tool for colonization remained under government control, and "the goal of cultural obliteration was pursued consistently" (Weinberg, 1977, p. 225-26). The boarding school era had not had the degree of success of enculturation and assimilation that the federal government had hoped, rather it increased the tension and frustration between states and tribes.

American Indian and white relations have been carved into the American psyche over several centuries. A Lakota woman in South Dakota observed that the racial tensions in her state "reflect a vast cultural divide and a gulf of suspicion and mistrust between Indians and whites in a state that historically was one of the bloodiest battlegrounds between the races during the great westward expansion" (Sincangu Sun Times 1999, cited in Biolsi, 2001, p.4). These feelings and sentiments are true for many western states, and many towns that located on or near reservations, reinforcing a sentiment of deadliest enemies between states and tribes. The consistent perceptions by states and the federal government of an Indian problem and the division between tribes and states has not had positive contributions to American Indian education policy and politics. In Seymour Lipset's Bureaucracy and Social Change, he acknowledges the roles of social construction in that "[c]ivil servants...do not operate in a social vacuum. Their opinions about relative 'right' and 'wrong' are determined...by pressures existing in their social 
milieu" (cited in Dolan \& Rosenblom, 2003, pg. 80). When American Indians are underrepresented, or not represented at all, they become marginalized as undeserving of benefits and viewed as incapable of exercising authority, thereby negatively impacting their representation and ability to meaningfully participate in education policy and politics.

The federal government's philosophy and resulting history towards education of American Indian has led Congress and various federal committees to generate numerous federal reports. Three of which are most significant in this discussion: The Meriam Report (1928), the Kennedy Report (1969), and the Indian Nations at Risk Task Force Report (1991). These reports provide a window into the social constructs of the time, but also a consistently identified theme: the importance of and need for representation of American Indian parents, elders, and tribal leaders in the education of their people.

The 1928 Institute for Government Research report: The Problem of the Indian Administration (hereinafter referred to as the Meriam Report) was the first qualitative and statistical analysis of any real significance on the condition of American Indian reservations and boarding schools. The Meriam Report (1928) directly confronted the Indian problem by evaluating Indian Affairs and the adequacy of support being provided by federal Indian Services as it related to health, education, community, economic, and legal aspects. The Meriam Report (1928) highlighted under the education analysis section that [t]he Indian problem [emph. mine] is essentially one of education and social welfare, rather than that of land, property, or business" (p. 424) and that "[i]n the long run, the nation will settle the Indian problem or not by its willingness to take hold of the issue in a responsible and business-like way" (p. 429). They recommended a new viewpoint in 
American Indian education; one that did not remove American Indian children from their homes and communities (Meriam, 1928, p.346). The Meriam Report was the first recognition that, beyond acknowledging the administratively unqualified management and gross underfunding of boarding schools, there was a fundamental lack of representation of American Indian tribes' voice in the education of their people. The report acknowledged that:

- Indian tribes and individual Indians within the tribes vary so much that a standard content and method of education, no matter how carefully they might be prepared, would be worse than futile (p. 347);

- The Indian school course of study is clearly not adaptable to different tribes and different individuals; ... instead of being created out of the lives of Indian people, as it should be (p. 371);

- The government has in effect destroyed Indian tribal and community life without substituting anything valuable for it. Tribal councils are seldom utilized by the superintendent of an Indian reservation, though they are one of the best natural training schools for citizenship (p. 400); and

- We have learned, in the case of children from foreign homes, that there are values in the customs of other peoples that ought to be preserved and not destroyed; so with Indians; there is a contribution from Indian life that likewise needs to be safe-guarded and not sacrificed to unnecessary standardization (p. 412).

The Meriam Report (1928) further acknowledged that American Indians were placed in a "twilight zone" of sorts between states and the federal government because of 
their status as "a ward of the federal government" (p. 415). Ultimately while states had the responsibility to educate all citizens, they did not view American Indians as citizens. The continued resistance by many states to acknowledge the 1924 Indian Citizenship Act was further demonstration to American Indians of their undeserving status in state policy and politics. The Indian Citizenship Act granted citizenship to the remaining one-third of American Indians, who had not already received citizenship through obtaining land allotments or serving in World War I (Wright, et al., 1998; Calloway, 2016). As more than wards of the federal government, American Indians had now gained a constitutional right to attend public schools, further supporting the elimination of boarding schools and increasing the burden of responsibility on states (Wright, et al., 1998).

While citizenship may have been granted to American Indians, many states resisted allowing them the right to vote, in particular as it related to education policy and politics. In Wright, et al.'s (1998) research they highlight two state Supreme Court cases (Allen v. Merrell, Utah Supreme Court, 1956; and Prince v. Board of Education, New Mexico Supreme Court, 1975) where the American Indians were denied the right to vote by local governments. The denial of their right to vote required American Indians to bring forward litigation in those states. In Prince v. Board of Education (1975), while the local county had denied American Indians in New Mexico the right to vote, the New Mexico Supreme Court ruled that while American Indians were not taxed on bond repayments for local school boards they still maintained a right to vote (cited in Wright, et al., 1998, p. 10). Even in the last forty-years, states have been resistant in supporting or providing paths for American Indians to have a voice or role in policy and politics. This is not a non-existent, non-issue, but rather a lingering example of how states maintain 
power, and place American Indians in a lower undeserving social construct with little or no ability to vote or have representation in education policy and politics. While there are other educational policies that on the surface support American Indian students, in reality American Indian leaders continue to have little to no real voice in the expenditure and use of the state and federal dollars school districts receive. One prominent program as an example that supports this statement is the Johnson O’Malley funding.

The Johnson O’Malley (JOM) Act from 1934, provides financial assistance to states and local schools where 10 or more American Indian students are enrolled. The amount of the funding increases based on the size of American Indian student enrollment, so school districts with larger percentages of American Indian students receive more dollars. The intent was to provide financial assistance to public school districts where funds could not be generated from American Indians who lived on land the state, and thereby local school districts, could not tax (Wright, et al., 1998). Often JOM funds are used to supplement operational costs, rather than targeting the support mandated in the Act. While the JOM Act requires parent councils with the intent of parental and tribal engagement in the educational process, these have not historically been as effective or fully implemented to the intent of the Act. The parent councils have no real authority in the actual distribution of funds, they are nothing more than advisory ${ }^{4}$. In addition to JOM funding sources, in the mid-50's Congress passed P.L. 874 (also known as impacted-area legislation) to provide funding for state supported public schools that could go toward general operating needs in schools where taxes could not be collected (Szasz, 1974).

\footnotetext{
${ }^{4}$ These statements are based on ten years of experience and observation working with Tribal Education Department Directors and Tribal leadership regarding their lack of representation on the use of JOM funds.
} 
In April of 1965, Congress passed the Elementary and Secondary Education Act, with specificity that acknowledged the special needs of certain children, specifically through Title I (Szasz, 1974). By the 1960s, impacted-area legislation received a $\$ 505.9 \mathrm{M}$ appropriation, JOM awards to states totaled $\$ 11.5 \mathrm{M}$, and Title I funding was $\$ 9 \mathrm{M}$, with the funds being used at the local level to cover operating expenses rather than programs targeting American Indian students as they had been intended (Szasz, 1974). Perhaps an increased representation of American Indian administrators and teachers would impact how these funds are targeted.

Forty years after the Meriam Report, in 1969, the U.S. Senate Committee on Labor and Public Welfare commissioned a report by its Special Subcommittee on Indian Education: Indian Education: A National Tragedy, A National Challenge (hereinafter referred to as the Kennedy Report). Clearly we had not learned from the messages and heartfelt recommendations of the 1928 Meriam Report. The Kennedy Report (1969) highlighted a lack of participation or authority to participate by the tribes; curriculum that failed to recognized American Indian history, culture and language; anti-Indian sentiments by teachers and administrators; and made 60 recommendations related to policy and support for American Indian education. The Kennedy Report (1969) references the U.S. efforts at educating the American Indian as one of a "national tragedy and a national disgrace" (Congress, p. x). The Report highlighted that drop-out rates for American Indians were more than two times the national average, with some school districts nearing $100 \%$, and observed that "the Indian child falls progressively further behind the longer he stays in school" in that the quality of the educational support they received progressively stagnates or worsens (Congress, 1969, p. ix). The report 
acknowledged that while the federal government has a significant responsibility for American Indian children in public schools, in 1968, the education of American Indian children in California, Idaho, Michigan, Minnesota, Nebraska, Oregon, Texas, Washington, and Wisconsin was the total responsibility of the state and not the federal government (Congress, 1969, p. xii).

Consistent with recommendations in the Meriam Report (1928), the Kennedy Report (1969) notes that "[o]ne theme running through all our recommendations is increased Indian participation and control of their own education programs. For far too long, the Nation has paid only token heed to the notion that Indians should have a strong voice in their own destiny" (Congress, 1969, pp. xiii-xiv). There continued to be a lack of culturally sensitive curriculum materials, and little if any effort to demonstrate that progress was being made, not only in the representation of American Indian parents, community members, and tribal leaders, but to increase access and performance of American Indian students. The Kennedy Report (1969) succinctly captures how the social construction of U.S. education policy and politics was shaped toward American Indians.

Regretfully, one must conclude that this Nation has not faced up to an "American dilemma" more fundamental than the one defined so persuasively for us by Gunnar Myrdal in 1944. The "Indian problem" [emph. mine] raises serious questions about this Nation's most basic concepts of political democracy. It challenges the most precious assumptions about what this country stands for cultural pluralism, equity and justice, the integrity of the individual, freedom of conscience and action, and the pursuit of happiness. Relations with the American 
Indian constitute a "morality play" of profound importance in our Nation's history (Congress, 1969, p. 10).

The Kennedy Report (1969) reinforced that “[t]wo stereotypes still prevail[ed] 'the dirty, lazy, drunken' Indian and, to assuage our conscience, the myth of the 'noble savage"" thereby supporting a negative undeserving and unentitled social construct of American Indians (Congress, 1969, pp.9-10). While the Kennedy Report (1969) demonstrated empathy and provided and strong recommendations towards equality and accountability, as well as increased representation of American Indians in the education policy and politics, it highlights that as a country we continued to fail to take action addressing the lack of representation of American Indians in education policy and politics.

In 1975, the Indian Self-Determination and Education Act provided tribes more direct control in the management and implementation of social programs and services (e.g. healthcare, education, housing) within their communities (Deloria \& Wilkins, 1999; Conner, 2014; Calloway, 2016; Swisher \& Tippeconnic, 1999). This allowed tribal governments the ability to determine whether or not to allow the federal government to continue managing these services through the Bureau of Indian Affairs, or whether tribes would contract these services at the local level. This gave tribal governments explicit authority to work with local school boards and state education agencies (Conner, 2014; Wilkins \& Lomawaima 2001). However, the states and local school boards still maintained a significant amount of control and authority, and nothing in the Act forced states or school boards to work more proactively with their local tribes. In fact, based on working at the state policy level, I have seen there is often a disconnect from what the 
state requires of local school districts and what local tribes would like from an educational perspective for their students. This position was also supported in interviews with school district administrators and tribal education department directors/managers.

In March 1990 the U.S. Department of Education convened the Indian Nations at Risk Task Force. They were charged with evaluating the status of American Indian education and making recommendations for improving the quality and performance of American Indian education. They held regional meetings in Alaska, Arizona, Minnesota, Montana, North Carolina, Oklahoma, and Washington; received testimony from hundreds of citizens; interviewed parents, teachers, superintendents, board members, tribal leaders; and held special sessions at the National Indian Education Association's annual conference (Indian Nations, 1991, pp.xiii-xiv). They found that 35\% and as high as 50$60 \%$ of American Indian students drop-out of school, and that American Indian students had the highest dropout rate in the nation (Indian Nations, 1991, p. 7). They continued to find that curriculum was presented from only a Western perspective and American Indian stories and voices were absent from the curriculum; there continued to be unqualified teachers without appropriate training; "low expectations and relegation to low ability tracks;" lack of American Indian teachers and administrators as role models; a need for greater opportunities for parent and community involvement; major funding challenges for buildings and technology; and "overt and subtle racism" in schools that lacked any multicultural curriculum (Indian Nations, 1991, p. 8). The Indian Nations Task Force (1991) established 10 goals with benchmarks; identified eight areas of best practice supported by research that should be used by tribal leaders, education policymakers, and 
educators; and ultimately recommended five strategies for implementing their recommendations.

Generations of national reports (1928 Meriam, 1969 Kennedy, and 1991 Indian Nations at Risk Task Force) have repeatedly concluded that our nation's educational policies intended to meet the educational needs of American Indian students have been an abysmal failure of epic proportions. One could easily place the findings and recommendations of the Meriam Report (1928), the Kennedy Report (1969), Indian Nations at Risk Task Force (1991), and observations from my own research, side-by-side in columns and see that we have made very little progress in nearly 100 years when it comes to American Indian education. Why? Perhaps part of the challenge is we fail to look deeper into the feelings American Indians have towards education. In the Kennedy Report (1969), one Ponca Indian testifying before the subcommittee indicated that, "from the standpoint of the Indian student 'School is the enemy!'" (Congress, 1969, p. 9). The history and use of education to assimilate and destroy tribal culture, and the resulting lack of representation of American Indians in educational policy and politics have made it difficult to build trust that education is the great equalizer and one of the single greatest influences on upward mobility in shifting from one social class to another in the U.S. 


\section{CHAPTER THREE: WHY REPRESENTATIVE BUREAUCRACY MATTERS:}

\section{PASSIVE AND ACTIVE REPRESENTATION}

While early researchers such as Weber, Kingsley, and Mosher struggled with whether or not a bureaucracy can actually be representative and still be a legitimate bureaucratic organization, Krislov (1974) argued that bureaucracies can and should be representative as they provide counter balance to the lack of representation in the courts and legislatures (Dolan \& Rosenbloom, 2003). In Frederick Mosher's (1968) Democracy and the Public Service, he proposed that administrators of bureaucracies played a significant role in determining how policies are actually implemented, and the execution of such policies are significantly shaped by their individual values, backgrounds, education, and associations (social constructions). The significance of social constructions were demonstrated in Chapter 2 where I focused on how social construction shaped public perceptions and ultimately educational policy and politics toward American Indians. In this chapter, I will review the literature on representative bureaucracy, both in an active and passive form, with a primary focus on school systems as the bureaucracy.

Like earlier researchers, Fredrickson and Smith (2003) proposed that central to the foundations of the theory of representative bureaucracy is the notion that public agencies are organized in an undemocratic way by design, and "these undemocratic agencies exercise considerable political power" (Fredrickson \& Smith, 2003, p. 62). They are designed to protect those in positions of deserving and entitled and maintain their 
status of power within the social construction of policy and politics. However, it is the latitude and power bureaucracies possess that make true representation so important. The theory of representative bureaucracy requires acceptance of two essential elements: 1) that public agencies represent the interests and values of the public they serve, and 2) those values and interests are reflected in the policy decisions made (Fredrickson \& Smith, 2003; Dolan \& Rosenbloom, 2003; Selden, 1997; Meier et al., 1989; Wright et al., 1998). Ultimately, the truest test of the representation of a bureaucracy is the extent to which their demographics mirror that of the communities they serve (Meier \& Nigro, 1976; Fredrickson \& Smith, 2003; Dolan \& Rosenbloom, 2003; Selden, 1997; Meier et al., 1989; Wright et al., 1998).

There are two forms of representation: passive and active. Much of the research on representative bureaucracy over the last 40-50 years has been focused on the links between the two (Fredrickson \& Smith, 2003). Frederick Mosher (1968) was the first to distinguish between passive and active representation. Passive representation is the degree to which the bureaucracy mirrors the society they are serving in demographic characteristics such as level of education, income, social class, race, and religion (Fredrickson \& Smith, 2003; Dolan \& Rosenbloom, 2003; Selden, 1997; Meier et al., 1989; Wright et al., 1998). Analyzing the impact of passive representation then requires the consideration of whether some demographics are more important, or have greater impact. Selden (1997) underscores that the overall literature has supported the position that race and ethnicity are two of the most important demographics in analyzing bureaucracy and its representation in the United States. In many ways, passive representation is symbolic and demonstrates access and equality (Mosher, 1968 cited in 
Dolan \& Rosenbloom, pg. 21). The presence of American Indian teachers would be a form of passive representation.

Active representation then is the degree to which individuals within the bureaucracy advocate for the interests of those with similar demographics (Selden, 1997). While passive representation demonstrates equality and access to bureaucracy, and is largely symbolic, active representation requires the assessment of the policy outputs and outcomes with the conclusion that passive representation leads to active representation (Fredrickson \& Smith, 2003). It is the passive representation of American Indian teachers that may lead to positive policy outputs such as culturally responsive curriculum and teaching practices in public schools (active representation) with American Indian student enrollment. School systems are often the largest employers at the state and local bureaucratic levels, and therefore a logical place to conduct a case study of representation and the impacts of such (Meier \& Bohte, 2007). As noted by Meier, Wrinkle, and Polinard (1999), because schools are one of the largest employers, discretion is localized, and because they also generate a tremendous amount of data they are the ideal organization to evaluate in terms of representative bureaucracy theory.

Meier et al. (1999) indicated that because schools use 'an education production function' that takes student performance as a function of inputs into the organization and policies, they "add measures of representative bureaucracy to determine if it matters, giving controls for other factors that affect performance" (p. 1027). Meier, et al.'s (1999) research on representative bureaucracy revealed that a statistically significant difference exists between white and minority students. In schools with lower levels of minority representation among teachers, minority student performance was impacted in a negative 
direction, and in higher levels of minority teacher representation the impact on student performance was positive. Meier et al.'s (1999) research also revealed that "[t]aking the first derivative of these terms and setting them equal to zero predicts that the impact of minority teachers on all students will become positive at approximately $32.3 \%$ minority teachers, a somewhat higher critical mass than Meier (1993) found is his nonlinear analysis" (p. 1032).

Meier (1984) proposed that while teachers likely have minimal impact on school district policies at the macro level, their daily interaction with students and their ability to support or discourage students had a significant positive impact on student performance. Additionally, because teachers were responsible for interpreting and implementing disciplinary polices, their capacity for discretion put them in a "key position to affect a phenomenon known as 'second generation discrimination'” (Meier, 1984, p. 253). Essentially, second generation discrimination is the continued use of segregation through the practice of ability grouping and disciplinary actions. These practices disproportionately place minority and American Indian students in lower academic pathways and they also face significantly higher rates of disciplinary actions compared to their white peers. Meier's (1984) research proposed that second generation discrimination was particularly tied to educational inequalities in tracking (academic paths or groups) and discipline (Weinberg, 1977).

Tracking discrimination consists of limiting access to advanced programs and directing minority and American Indian students into remedial and dead-end curriculum and educational paths. Such restrictions and manipulation increases the academic gap between minority and American Indian students with white students being provided 
access to college opportunities. Further, research by Meier et al. (1989) supported the theory that schools use tracking or academic grouping to sort students into similar subgroups. The research by Meier et al. (1989) revealed that ability grouping often sorts students based on what teachers determine to be the student's academic potential. The high end of the grouping consists of honors and gifted classes, while remedial and special education classes occupy the lower end (Meier et al., 1989). In addition, there is a significant amount of literature that standardized tests, one of the critical tools used for placement of students into remedial or college-bound pathways are inherently biased against minority students (Wright et al., 1998; Reyhner \& Eder, 2000; Weinberg, 1977; Leiding, 2006; Fox, 1999).

Research by Roch, Pitts, and Navarro's (2010) Representative Bureaucracy and Policy Tools: Ethnicity, Student Discipline, and Representation in Public Schools supported that "the growing body of research suggests that social constructions are more likely to influence the choice of policy tools in some instance rather than others" (p. 43). This is particularly true given the autonomy and local discretion teachers have in implementation of curriculum and in applying disciplinary actions. Their research primarily focuses on the representational differences of teachers in public schools and how that impacts whether teachers implement punitive versus learning-oriented disciplinary policies. Roch et al. (2010) indicated that the "social constructs of student are more likely to be positive when bureaucrats match students by race and ethnicity" (p. 44). Further, the role of discretion is key in the transition from passive to active representation as "minority students are more likely to be disciplined when teacher...discretion must be used to impose order on an ambiguous behavioral problem" (p. 46). Ultimately their 
research concluded that the ethnic representation of teachers, due to their social constructions impacts the choice of policy tools (punitive versus learning-oriented disciplinary actions) in schools.

Meier et al. (1989) proposed that policy-making entities in the 1950's defined equal education as desegregated education; however, by not acknowledging that significant resistance to desegregated education existed, it allowed for other methods of limiting access to occur. Meier et al.'s (1989) research revealed that through the disproportionate sorting of African American students into lower academic courses, and the use of disciplinary actions, schools successfully circumvented desegregation by placing white students in higher academic courses and taking significantly fewer disciplinary actions against whites. Meier's (1984) research revealed that African American students who were perceived to pose potential disciplinary problems were more likely to be placed in special education programs than white students, resulting in higher dropout rates for minority students. When tracking and academic grouping fails to place minority students, Meier et al. (1989) discovered that indeed schools used disciplinary actions to sort students. Students were tracked by types of punishment, suspensions, and expulsions (Meier et al., 1989). However, as Meier et al. (1989) noted, the "[v]ariation in discrimination is linked directly to the political process," particularly "[i]n school districts with a politically powerful black community, with a large population of lower-class white students, and with a large percentage of black teachers, black students experience less second-generation discrimination" (p. 6). Research has revealed the teachers of similar race is the single greatest factor in limiting second 
generation discrimination against minority students (Meier et al., 1989; Meier et al., 1999; Meier \& Stewart, 1991; Wright et al., 1998).

Research by Meier et al. (1989) indicated that the practice of placing students in special education, advanced coursework, and disciplinary actions are some of the largest obstacles for minority students to receive an education equal to their white peers. Meier et al. (1989) believed that integration is necessary, but not in a traditional understanding of integration. Meier et al. (1989) proposed that integration is "the interaction of students in a multiracial learning environment both in and outside the classroom" (p. 4). This level of integration provides minority students with an equal status and opportunities, and by extension an equal capacity to excel (Meier et al., 1989). From an educational research perspective, multi-racial learning environments are a form of cooperative learning and teaching culturally, which supports improved peer engagement and interactions. Further, Meier et al. (1989) proposed that education is the "most important civil rights issue affecting blacks in the United States" (p. 4). It is an issue of access and equality also affecting Hispanic and American Indian students.

Meier (1984) concluded, the greater numbers of African American teachers resulted in reduction of discrimination against African American students, and that fact "held even under controls for black political resources, education, income, and region" (Meier, 1984, p. 260). As a result, Meier (1984) concluded that passive representation can lead to active representation, in that more African American teachers resulted in less second generation discrimination against African American students. While Uslaner and Weber criticized the link between representation and policy responsiveness, in Meier's (1984) research the link holds true for three reasons. First, Meier (1984) indicated that the 
"background variable, race, is directly linked to the policy in question," as the link between race and discrimination is obvious to those involved, as teachers are able to distinguish "actions favorable to people similar to themselves" (p. 261). This same observation was noted by Wright, et al. (1998) in their case studies in the one Alabama school district. They believed that one of the reasons that American Indians were treated better was because their race was indistinguishable from that of their teachers. Second, Meier (1984) indicated that race is the one demographic that persists, regardless of social experiences. This factor has been supported by many subsequent research studies (see Selden, 1997; Meier et al., 1989; Meier et al., 1999; Meier \& Stewart, 1991; Wright et al., 1998; Roch et al., 2010). Finally, Meier (1984) concluded that because all teachers work in the same type of organizations, and their policy values are based on the organization for which they are employed "...a major source of variation in attitudes and thus behavior is held constant" and therefore, "[a]s a result, race becomes even more significant" (Meier, 1984, p. 262). Schools and particularly rural school districts are tight knit communities and teachers often discuss student needs, behaviors, and family situations with each other.

Meier, et al.'s (1989) research noted that the patterns of racial difference which “disproportionately sort black students into lower academic groups also disproportionately subject these students to the schools disciplinary practices" while "white students gain better access to gifted classes, are less likely to drop out of school, and are more likely to graduate" (p. 5). Further, their analysis of disciplinary practices did not demonstrate that increased usage of disciplinary actions diminished or decreased behavior problems, and therefore concluded if it is not deterring behavior then "it must 
have other goals" (Meier, et al. 1989, p. 5). Meier, et al. (1989) ultimately proposed that their analysis demonstrated African American students were being denied access to the same educational opportunities as their white peers.

While Meier et al. (1989) acknowledged that their work didn’t necessarily apply to other minority populations, including American Indian students, Meier \& Stewart (1991) later replicated the work with Hispanic students. As proposed by Meier, et al. (1989), increased empirical work on the consequences of sorting and grouping minority students and their lack of representation is needed because of the complicated interracial and interethnic political tensions. However, the gaps in analytical research with regard to the American Indian student population were still significant. A decade later, Wright et al. (1998) conducted a similar study in The Politics of Second Generation Discrimination in American Indian Education: Incidence, Explanation, and Mitigating Strategies, which did provide more definition to the issues related to second generation discrimination of American Indian students. Building upon the work of Meier et al. (1989) and Meier \& Stewart (1991), the work by Wright et al. (1998) used both statistical and qualitative case study analysis which confirmed the findings of Meier's prior work.

The research by Wright et al. (1998) sought to determine whether American Indian occupation of positions on school boards, administrative, and teaching positions resulted in educational policies that benefited American Indian students. Essential was access to school board seats, through voting and availability of viable candidates. The research by Wright et al. (1998) recognized that while school board members were elected and they then hired administrators who then hired the teachers, their research focused on three "political variables: American Indian political resources (including 
population and education), social class, and American Indian access to other decisionmaking positions" (p. 24). As with prior research, minority administrators were more likely to consider the hiring of other minority teachers, but that was not a primary element in Wright et al.'s (1998) analysis.

In Meier et al. (1989), Meier \& Stewart (1991), and Wright et al. (1998) they note that social class discrimination is just as likely to adversely affect poor whites as African American, Hispanic, or American Indian students. To positively affect social class, educational attainment is an essential element. As discussed in Chapter 2, educational attainment for American Indians is particularly challenging because of its fundamental use by the federal government as tool to destroy American Indian culture and communities. The works of Meier et al. (1989), Meier \& Stewart (1991), and Wright et al. (1998) do not adequately address this critical reality. While Wright et al. (1998) provided a high level overview of American Indian education, there was no discussion on the use of education as a tool for tribal culture and community destruction. This is an important element that distinguishes American Indian educational history from that of African American or Hispanic educational experiences that will be further explored in Chapter 5 .

The dataset used in the research by Wright et al. (1998) included 128 public school districts in the U.S. with minimum enrollments of 1,000 students, and a 5\% minimum American Indian enrollment. Their research used student enrollment data from the Office of Civil Rights, the 1992 Elementary and Secondary School Civil Rights Survey to measure academic grouping, disciplinary actions, enrollment, and educational attainment, and the 1990 Bureau of Census, Housing and Population Survey to look at 
education, poverty, and other community demographic data (Wright et al., 1998). In addition, they conducted surveys, which included follow-up mailings and telephone calls, to identify school board representation. While the response rates were generally high (97\%), they received varied responses from 124 of the 128 school districts (Wright et al., 1998, p 51).

The research by Wright et al. (1998) concluded that American Indians were "significantly overrepresented in policy representation ratios - measures of second generation discrimination - that negatively affect students" in particular, special education and disciplinary actions such as suspensions; and they were "substantially underrepresented in representation policy ratios that positively affect students" in areas such as gifted and talented programs or graduation pathways (Wright et al., 1998, p. 70). In essence, there were higher proportions of American Indian students in special education and receiving disciplinary actions than their peers, and much lower proportions of American Indians in college-bound pathways. Their research revealed that whether analyzed through intercorrelation or factor analysis, "measures of second generation discrimination for American Indians converged or clustered together[,]" indicating a relationship among all factors demonstrating support of second generation discrimination (Wright et al., 1998, p. 70). Response rates, while high, were inconsistent across schools and school districts for the different types of positions (school board representation, administrators, and teachers) from which data was sought, due to the fact that data from some offices was more readily accessible than others.

Wright et al.'s (1998) data revealed that American Indians held $11.49 \%$ of the total school board positions in the 78 districts reporting data, and with their theoretical 
model, "hold only $46[\%]$ of the total number of school board seats they should hold based on their population" (p. 77). And, when using American Indian student enrollment as the base, American Indian representation dropped to $36 \%$ of the "total number of seats American Indians should occupy" (p. 77). For administrative positions, American Indians held only $7.46 \%$ of all administrative positions in their dataset. Using Wright et al.'s (1998) theoretical model, of the 120 school districts reporting, American Indian teachers held only " $62[\%]$ of the administrative positions they should hold based on the number of American Indians in the districts," and only 29\% using American Indian student enrollment as the comparison base (p. 77). The results of Wright et al.'s (1998) analysis revealed that American Indian administrators were underrepresented in the school districts by $71 \%$, and compared to the research by Meier et al. (1989), African Americans were underrepresented by $73 \%$, and the research by Meier \& Stewart (1991), Hispanics were underrepresented at 39\% (p. 78). These data support a significantly higher underrepresentation of American Indian and African American administrators.

Analyzing teacher representation, American Indians also face significant underrepresentation. Of the 124 school districts reporting, American Indian teachers made up $6.10 \%$ of all teaching positions (Wright et al., 1998, p. 78). For American Indian teachers, using Wright et al.’s (1998) theoretical model, they showed “an underrepresentation of 50[\%] when American Indian population is used as the comparison base, and 73[\%] underrepresentation when American Indian school enrollment is used as the comparison base" (p. 78).Wright et al.'s (1998) research revealed "[a] strong positive relationship exists between administrator representation and teacher representation" (p. 86). 
Wright et al. (1998) sought to determine if passive representation (the presence of American Indian school board members, administrators, and teachers) had an impact on the educational policies (active representation) affecting American Indian students. While Wright et al.'s (1998) research supported the proposition that the presence of American Indian teachers decreased American Indian special education class ratios and increased gifted and talented class ratios, the level of American Indian education in the community "did not significantly influence any of the policy ratio measures" (p. 97). In other words, the level of community education did not impact their ratios positively or negatively as one might have predicted. An interesting finding by Wright et al. (1998) was that school district size did not reliably predict influence on second generation discrimination; however, larger school districts demonstrated a lower proportionate suspension of American Indian students than did smaller districts. This was believed to be as a result of greater awareness of civil rights laws in the larger school districts. Ultimately, Wright et al. (1998) concluded that of all the factors, American Indian teachers have the greatest impact on second generation discrimination, which was consistent with earlier research (Meier et al., 1989; Meier \& Stewart, 1991). In an effort to expand on the scope of the current research, and seeking to validate the quantitative findings, Wright et al. (1998) conducted five case studies that included interviews of administrators, teachers, and students, and conducted classroom observations.

The case studies conducted by Wright et al. (1998) included two school districts from Oklahoma and three counties in Alabama. The school districts in Oklahoma ranged in population from 4,584 - 10,386 (Wright et al., 1998, p. 104). Watonga, the smaller of the two, had a population mix that was $80 \%$ white, $8 \%$ American Indian, $3 \%$ Hispanic, 
and 8\% African American; Watonga school district had three schools; and employed 68 teachers (Wright et al., 1998, p. 105). The larger district, Clinton, had a population mix that was 74\% white, $8 \%$ American Indian, 10\% Hispanic, and 7\% African American; Clinton school district had five schools; and employed 133 teachers (Wright et al., 1998, p. 104).

The three counties in Alabama consisted of DeKalb, Jackson, and Lawrence. The counties in Alabama ranged in population from 32,000 - 56,000 (Wright et al., 1998, p. 106). Of the three counties in Alabama, $70 \%$ of the approximate 56,000 people residing DeKalb County lived in rural areas (Wright et al., 1998, p. 106). In both DeKalb and Jackson counties Wright et al. (1998) did not provide a breakdown of race/ethnicity, but rather the total percentage of the population that was white and the percentage claiming American Indian ancestry. In DeKalb County $77 \%$ of the population was white and 30\% claimed American Indian ancestry. In Jackson County, which had a population of 50,000, 92.5\% were white and 20\% of those claimed American Indian ancestry. DeKalb County had 12 schools with a district enrollment of 7,300 students and nearly 400 teachers. Jackson County had 17 schools with a district enrollment of 6,600 students and more than 400 teachers. Lawrence County had the smallest population of 32,000, 77\% of which were white, 7\% American Indian, 1\% Hispanic, and 15\% African American. Lawrence County had seven schools with a population of 6,500 students and nearly 400 teachers.

Wright et al., (1998) used open-ended questions in their interviews, asking superintendents, administrators, and teachers "to suggest factors or variables that might explain, or at least influence, the school district's treatment of American Indians" (p. 107). For those who struggled to answer, Wright et al. (1998) provided prompting 
questions about representation of American Indian teachers (or minority teachers), cooperative learning strategies, the presence of American Indian Education programs, and how the community might influence the school district's treatment of American Indian students. Wright et al. (1998) grouped the aforementioned categories and tracked both spontaneity of responses and whether responses were to prompted questions in order to determine their significance.

In the two case studies in Oklahoma, Wright et al. (1998) indicated that in both school districts, those interviewed responded more spontaneously that "American Indian teachers, counselors, and minority teachers are important factors in the treatment of American Indian students" (p. 115). In addition to representation of American Indian teachers, cooperative learning was another key factor that had a high spontaneous response rate as being influential in impacting treatment of American Indian students. Wright et al. (1998) argued that this was significant because it was a reflection of streetlevel bureaucracy; school districts could more easily implement cooperative learning strategies than they could increase the number of American Indian teachers and counselors they had on staff. While cooperative learning increases interaction among students with different ethnic or racial backgrounds, in Wright et al.'s (1998) research, teachers responded that using it allowed them to group lower ability students with higher ability students - changing the classroom dynamic to one of a group rather than a competitive environment.

In addition to interviews, Wright et al. (1998) conducted direct observations as a mechanism to validate or confirm their interview research results. Their observations supported the use of cooperative learning strategies in many of the classrooms. 
Additionally Wright et al. (1998) found that American Indian students were more engaged in classes with American Indian or minority teachers, and appeared "solemn and reserved in classes taught by non-American Indian teachers and non-minority teachers"which supported findings from their interviews (p. 119).

In the three case studies in Alabama, Wright et al. (1998) observed that neither cooperative learning nor the presence of American Indian teachers was spontaneously mentioned at any of the schools, where it had been the two most important explanatory factors for lack of second generation discrimination in the schools in Oklahoma. In the three Alabama case studies, the highest spontaneous response rate as being significant in explaining the treatment of American Indian students was the existence of an American Indian Education program. Another noteworthy observation by Wright et al. (1998) in the three Alabama case studies was that American Indian teachers and American Indian students were not easily identifiable as being American Indian, and Wright et al. (1998) ultimately believed that was perhaps one of the reasons why second generation discrimination against American Indian students did not exist in those districts.

Ultimately, Wright et al. (1998) confirmed the need for and validity of conducting further case studies as significant findings may emerge as a result, and findings that would not otherwise have been identified simply through a quantitative regression analysis. Wright et al. (1998) noted that "different factors are important in different school districts in mitigating the impact of second generation discrimination on American Indian students" (p. 125). Their case studies not only supported their quantitative findings on the significance of representation of American Indian and other minority teachers. They also discovered other factors that may act as a form of active representation, such as 
the use of cooperative learning strategies, community support, and the existence of American Indian Education programs in the school districts (Wright, et al., 1998).

As noted in Chapter 2, understanding the complexities of the historical relationship that exists between American Indians, states, and the federal government is a necessary component of any analytical research evaluating passive and active representation of American Indians in education policy and politics. While the research by Meier et al. (1989), Meier \& Stewart (1991), and Wright et al. (1998) provided significant evidence to support the notion that second generation discrimination exists in the education of African American, Hispanic, and American Indian students, the prior research fails to capture an essential distinction with regard to American Indians.

Education was a tool for cultural destruction for American Indian communities; whereas, for African American and Hispanic students education was more benignly intended as a tool that could lead to opportunity. Notwithstanding that, second generation discrimination in other forms may have continued as a practice to separate and withhold opportunities for African American and Hispanic students, education was still viewed as a vehicle for opportunity and advancement to a better life for those minority groups.

For American Indians, education has meant isolation, destruction of language, culture, families, and their communities. It created a vicious cycle of poverty and disenfranchisement. Further, there is a fundamental lack of trust by American Indians about the U.S. education system, or that it is one of fairness that can create a path for a better way of life for American Indian students (Corntassel \& Witmer, 2008; Calloway, 2016; Reyhner \& Eder, 2004; Reyhner, 2018). And, the way education has been used to 
destroy American Indian culture necessarily impacts American Indian participation and representation in the U.S. education system. 


\section{CHAPTER FOUR: RESEARCH DESIGN}

In this chapter I will lay the foundation for conducting a qualitative cross comparative case study of two rural, Idaho, public school districts (one with American Indian teachers and one without); provide background and context for the two communities and school districts; and provide an overview of the federal program known as the State Tribal Education Partnership (STEP) grant. The two public school districts selected were District 1 located on the Coeur d'Alene reservation and District 2 located on the Nez Perce reservation.

I developed a qualitative cross comparative case study of two, rural Idaho public schools because it allows for more in-depth analysis and the ability to provide greater context (Goodrick, 2014; Creswell, 2009). While there is a significant amount of quantitative research on African American (Meier 1984; Meier, et al., 1989) and Hispanic (Fraga, Meier, and England, 1986; Meier \& Stewart, 1991) representation of teachers, administrators, and school boards, and limited research related to American Indians (Wright et al., 1998), the prior research is focused on whether or not the representation of teachers, administrators and school board members mitigates second generation discrimination. Further, the data has been primarily aggregated at an organizational level (Atkins, Fertig, and Wilkins, 2014). The prior research fails to address the impacts of social construction or political history of American Indians. When assessing American Indian representation in education, their representation should be assessed through a different lens due to their unique quasi-sovereign status and the resulting relationship 
tribes have with states and the federal government. In addition, education itself has been a tool for destruction of American Indian communities and culture, which has not been the case for African American and Hispanic populations. Additionally, only in Wright et al.'s (1998) research is there any attempt to understand the unique elements of local school districts. Prior research is constrained by having minimal enrollments of minority populations or classifications such as urban or rural using aggregated organizational level data. While urban and rural classifications are helpful for purposes of grouping, lumping all rural schools categorically together fails to address the regional nuances of eastern, southern, or western rural, let alone capturing the unique community elements (Monk, 2007; Barton, 2012).

Rural public schools located on reservations face additional and unique challenges beyond that of geography. There are legal limitations and historical relationships and perceptions that impact community support. Because both school districts in my research have enrollments that are now predominantly American Indian students, and they are both located within the reservation boundaries, they are often perceived as being part of their local tribe. A historical review of the year books and athletic photos in the district offices show a larger white enrollment in the preceding 20-40 years. Commentary in the local paper when the school districts were trying to pass bonds and supplemental levies included things such as the tribes had plenty of money and they needed to use their casino money (Cotterell, 2014). These sentiments support the discussions from Chapter 2 regarding the social construction of the rich Indian and therefore American Indians being in a position of undeserving and unentitled for positive policy actions. There were also comments that the school district was teaching things that were unnecessary, such as Nez 
Perce language. So, while the community would support French or Spanish, they were unwilling to support the local tribal language being part of the public school curriculum. These comments demonstrate a continued sentiment that American Indians and their culture are not part of the social construction of deserving and entitled.

While District 1 and District 2 are located on reservations, they are public school districts. Nearly half of K-12 funding comes from the state, and the inability of the local school districts to collect taxes on property has been detrimental. Because tribal lands are held in federal trust they cannot be taxed by the states or local governments, therefore public schools with a high American Indian population are often accompanied by an inadequate tax base from which to draw and provide crucial support services for students. Rural communities often face significantly higher transportation costs for busing students long distances (Barton, 2012, p. 2). And, because local bonds and levies are often more difficult to pass in rural communities, rural schools are often put at greater disadvantage and have less financial flexibility.

To pass a general obligation bond in Idaho requires a two-thirds majority of voters to approve. District 1 made three attempts to pass a bond to build a new elementary school before the 73 year old building they were located in was condemned by the State Division of Building Safety in July 2009. In December 2009 they again attempted to pass a bond, but it also failed. In the meantime, students who were enrolled in the elementary school in one community were moved to the middle school in the community where the district middle and high schools were located. At that point, District 1 was forced to apply for assistance directly through the state, putting the oversight of the building of the new school in receivership by the State Board of 
Education while the school was being built. Once the construction of the school was completed, oversight and responsibility returned to the local school board. Ultimately, while the local tax payers did not approve the bond, because the state had to intervene, local taxpayers were forced to pay back the $\$ 11.3$ million state loan. In addition to state funds, school districts that receive federal Impact Aid can apply for federal funds to support building projects; however, they are competing with Bureau of Indian Education (BIE) schools. According to the National Indian Education Association (2017), more than $\$ 1.3$ billion would be needed just to make the BIE schools safe and meet modern standards. Therefore, there is continued backlog and need for financial resources to support aging infrastructure and buildings.

In order to provide property owners property tax relief, the state of Idaho shifted the cost of school maintenance and operations to the state sales tax in 2006. Failure of the state to sustain adequate funding has led to many districts passing supplemental levies. These widespread levies, which require a 50\% majority approval by voters, have worsened inequality of funding across districts. According to the Idaho Center for Fiscal Policy (2018), in 2006 very few school districts had supplemental levies, but in FY2017 93 out of 116 school districts were using them (Investments in education). The growth in supplemental levies have increased the disparities across districts. The Idaho Center for Fiscal Policy (2018) reported that revenue generated from a $0.16 \%$ supplemental levy can generate significantly different revenue based on location and property values (Investments in education). For example, Blaine County would be able to generate $\$ 4,319$ in per student spending and Lake Pend Oreille would be able to generate $\$ 1,962$ in per 
student spending, but Blackfoot school district would only be able to generate $\$ 321$ in per student spending all based on the same $0.16 \%$ supplemental levy rate.

In spring 2013, the District 1 School Board approved the elimination of funding for sports, moved kindergarten to half days, implemented three days of furlough, and were contemplating going to a four-day school week. That fall voters approved a two year $\$ 550 \mathrm{~K}$ per year supplemental levy to reverse those decisions. Since then, the local communities have supported a supplemental levy every two years. The Superintendent affirmed that support from the local Tribe was a crucial element in passing the supplemental levy. District 2 made two attempts to pass a supplemental levy in 2014, and both failed. They were forced to eliminate music and were contemplating making physical education an on-line class. These data support the funding disparities and impact that has on providing equal education for students across the state, particularly in rural areas.

The scope of this research includes data collected from the Idaho State Board of Education's Education Analytics System of Idaho (EASI), the Idaho State Department of Education's school district financial data, the Federal Civil Rights data, and from interviews with teachers, principals, superintendents, and tribal education directors/managers from both school districts. The Boise State University IRB approval was granted May 16, 2018. De-identified student level data collected through EASI was for $4^{\text {th }}, 8^{\text {th }}$, and $11^{\text {th }}$ grades for academic years $2012-2015$. The purpose of focusing on $4^{\text {th }}, 8^{\text {th }}$, and $11^{\text {th }}$ grades was for the ability to use consistent assessments across school districts, and to capture disaggregated student-level data for one grade in each of the academic levels (elementary, middle and high). Grade-level data included race/ethnicity 
and gender, and was intended to capture student access and performance. Access, for purposes of my research, was intended to capture elements of academic grouping (following the work of Meier et al., 1989; Meier et al., 1999; Meier \& Stewart, 1991; Wright et al., 1998) and consisted of:

- Placement in special education

- Placement in gifted and talented programs

- Students participating in dual credit

- Availability of middle/high school math and science courses

I intentionally broadened the scope of my research beyond what has been included by others (Meier et al., 1989; Meier \& Stewart, 1991; Wright et al. 1998) to include availability of dual credit, and middle/high school math and science courses. Because I chose not to approach my research using a regression analysis model, and used a qualitative approach supported by descriptive statistics of student-level data, evaluating these additional data elements provides greater insight into academic grouping and tracking of students into college-bound and non-college-bound pathways. Further, there has been a phenomenal growth in dual credit opportunities for students and a greater focus on access to college-bound opportunities since the research by Meier et al. (1989), Meier \& Stewart (1991), and Wright et al. (1998) was conducted. This growth is especially true in Idaho.

Performance, for purposes of my research, was intended to capture educational outputs that demonstrate the impacts of academic grouping. Data elements collected consisted of:

- Attendance/absenteeism

- $\quad 4^{\text {th }} \& 8^{\text {th }}$ Grade Idaho Standardized Assessment Test (ISAT)

- Disciplinary actions

- $11^{\text {th }}$ grade students taking SAT/ACT

- Graduation rates 
I also broadened the data elements I evaluated under performance to include attendance and state standardized testing. Prior research by Meier et al. (1989), Meier \& Stewart (1991), and Wright et al. (1998) did not evaluate attendance or standardized state assessments in this manner. Because I determined to also evaluate de-identified studentlevel data at the granular grade-level rather than only at the organizational-level, looking at these additional data elements increased my ability to understand whether teacher representation in the school could singularly impact student access and performance in grades without representation.

In addition to student data, teacher data collected for both school districts included race/ethnicity and the areas they were certified, and was obtained through EASI from 2012-2015. Other data specific to school district enrollment and finances from 2012 - 2018 was obtained from the State Department of Education's Public School Finance website. Additional data on the school districts was obtained from the 2013 and 2015 Federal Civil Rights data. I also spent three to five days in each of the communities in 2018 conducting 18 interviews with teachers at the elementary and middle/high schools, all four principals, both superintendents, and both tribal education directors/managers in both school districts. I spent time driving throughout the communities and visiting local café's or libraries whenever possible.

I pre-determined meetings with all administrators and tribal education directors/managers in both districts. Interviews with teachers were slightly more random, but with the intent to capture generalized representation in core academic areas in elementary and middle/high school grades. All interviewees were sent an email with an overview of the scope of the research and provided the option to participate in my 
research. All administrators and tribal education directors/managers agreed to be part of the study in advance of receiving approval from the Boise State University Institutional Research Board (IRB); and of the teachers solicited, approximately 50\% of them agreed to be interviewed. Teachers who agreed to be interviewed ranged from one year experience to ten or more years' experience. All interviewees were offered and received a \$25 Amazon gift card for their time. Interviews were all conducted in the interviewee's classroom, district or administrative offices and lasted 45 minutes to $1 \frac{1}{2}$ hours. In some instances students were present in the classroom during the interviews, but were not part of any interviewing.

Interview questions were primarily directive, with the option for each interviewee to provide any additional information they felt significant, but that I may not have asked. Interview questions were developed to qualitatively assess the links between passive representation (presence of American Indian teachers) leading to active representation (the use of culturally relevant curriculum and teaching practices). There were approximately fifteen interview questions for principals and administrators, and they were centered around three themes: 1) recruitment and retention of American Indian teachers; 2) curriculum development processes and cultural relevance; and 3) tribal and community engagement in district decisions (see Appendix A for a full list of questions). The focus on these three themes was to ascertain awareness and intentionality regarding recruiting and retaining American Indian teachers; awareness and active engagement in the use and development of culturally relevant pedagogy and curriculum; and level of engagement with tribes and the community in hiring and implementation of policies impacting American Indian students. 
There were approximately twelve interview questions for teachers, and they were centered around three themes: 1) use and development of culturally relevant curriculum and teaching culturally - including cooperative learning strategies; 2) perceptions of American Indian student performance and success; and 3) levels of tribal and community engagement (see Appendix B for a full list of questions). The focus of the three themes was to ascertain teacher awareness, understanding, and use of culturally relevant curriculum and teaching strategies; trying to gauge perceptions and use of academic grouping; and significance of tribal and community engagement.

There were approximately ten interview questions for the tribal education directors/managers, with a focus on three themes: 1) collaboration with the school district in hiring, curriculum, student performance, and assessment needs; 2) perceptions of American Indian student success and ability to succeed in the school districts; and 3) perceptions of teachers and administrator engagement with the tribes and communities (see Appendix $\mathrm{C}$ for a full list of questions). The focus of the three themes was to ascertain perceptions of their ability to influence policies that impact members of their tribe and other American Indian students; perceptions of the use of academic grouping of American Indian students; and perceptions of teacher and administrator investment in the communities. While Chapter 5 will cover the results of my research, it's important to first provide community demographics and school district composition.

\section{Community Demographics}

District 1 is a consolidated school district (two school districts jointed together in 1990), and student enrollment is comprised of four small, rural communities covering a two county region and is located within the local Tribe's reservation boundaries. In the 
2015 Federal Civil Rights Data District 1 reported that 47\% of their students were American Indian, 25\% White, 13\% Hispanic, and 15\% two or more races. District 1 elementary and middle school enrollment is also impacted by the presence of a K-8 tribal school located in one of the four communities that make up the joint school district. The tribal school does not restrict enrollment to only American Indian students, any students in the area may apply to attend, impacting enrollment in District 1 . The tribal school and associated data are not included in the public school data presented for District 1. According to the 2010 U.S. Census, the four combined communities that make up joint school District 1 had a population of slightly over 1,800. The closest communities with populations greater than joint school District 1 are two communities: one with a population of 44,137 which is 33.5 miles (36 minutes) away, and one with a population of 2,402 and is 19 miles (30 minutes) away.

District 2 is made up of the city of one small rural community and surrounding area, and within a single county, located within the local Tribe's reservation boundaries. In the 2015 Federal Civil Rights Data, they reported that $80 \%$ of their students were American Indian, 9\% White, 5\% Hispanic, and 5\% two or more races. According to the 2010 U.S. Census, the community in District 2 had a population of nearly 1,400. The closest community has a population larger than them, is 15 miles (20 minutes) away, and has a population of 31,894 .

According to the 2010 U.S. Census, $35 \%$ of individuals live below poverty in District 1 and 19\% in District 2, whereas the state average is only 15\%. The median household income in Districts' 1 and 2 are \$10-20,000 lower than the state median of 
$\$ 50,985$, and those who have a high school degree or higher is $2-4 \%$ lower than the state average of $90 \%$.

Table 4.1 2010 CENSUS COMMUNITY DEMOGRAPHICS

\begin{tabular}{|l|r|r|r|}
\hline & District 1** & \multicolumn{1}{l|}{ District 2 } & \multicolumn{1}{l|}{ Idaho } \\
\hline Median Age & 36.9 & 31.5 & 35.9 \\
\hline Median Household Income & $\$ 30,526$ & $\$ 40,000$ & $\$ 50,985$ \\
\hline Individuals Below Poverty & $35 \%$ & $19 \%$ & $15 \%$ \\
\hline High School Graduates or Higher & $87 \%$ & $88 \%$ & $90 \%$ \\
\hline Race/Ethnicity American Indian & 721 & 880 & 21,323 \\
\hline Race/Ethnicity White & 831 & 237 & $1,507,880$ \\
\hline Race/Ethnicity Hispanic & 185 & 147 & 201,978 \\
\hline Race/Ethnicity Two or More & 82 & 124 & 43,914 \\
\hline
\end{tabular}

** District 1 is a consolidated school district that is made up of four towns, the data presented are the means

\section{School Board Demographics}

District 1 has a total of seven school board members, two of which are American Indian (28\%). American Indians make up $40 \%$ of the total population within the school district according to the 2010 U.S. Census data, and $47 \%$ of the total student population within the elementary and middle/high schools according to the 2015 Federal Civil Rights Data. The school board meets monthly, and their agendas and most meeting minutes are posted on their website.

District 2 has a total of five school board members, four of which are American Indian (80\%). American Indians make up $63 \%$ of the total population within the school district according to 2010 U.S. Census data, and $80 \%$ of total student population within the elementary and middle/high schools according to the 2015 Federal Civil Rights Data. The school board meets monthly and their agendas and meeting minutes are posted on their website. 


\section{Administrator Demographics}

District 1 has one superintendent who has been in the school district for approximately 18 years. When the Superintendent first came to the school district they worked in special education for a few months, and then as the interim middle school principal before becoming the Superintendent. There is no assistant superintendent. There are two principals, one at the elementary school, who was in their first year as an administrator in that school district, and was a fourth/fifth grade teacher the prior year. The elementary principal had been a teacher and principal in other Idaho school districts in prior years, but this was only their second year in District 1 . The other principal is a middle/high school principal who has been in that role for approximately five years. Prior to that they were a middle school math teacher, and have been in the district for 23 years. None of the administrators in the school district are American Indian.

District 2 has one superintendent who has been in the school district for 19 years. They began as a fifth-grade teacher for six years and then taught third-grade. They have been the superintendent for the last nine years. There is no assistant superintendent. There are two principals, one at the elementary and one at the middle/high school level. The elementary principal has been in the school district for nearly 20 years. They taught fifth and sixth grade, were a curriculum director, and middle school principal before becoming the elementary principal. The middle/high school principal has been in the school district for 15 years, four as the middle/high principal, and prior to that, they taught fifth grade in the elementary school. One administrator is American Indian. 


\section{Teacher Demographics}

District 1 has faced significant challenges with teacher retention. The 2015 Federal Civil Rights data reported that $15 \%$ were in their first year of teaching and $9 \%$ were in their second year of teaching. District 2 reported in their 2015 Federal Civil Rights data that $0 \%$ of their teachers were in their first or second year of teaching. They reported that $94 \%$ of their teachers had been employed in the District for at least two years.

In the 2015 Federal Civil Rights data, District 1 reported a student to teacher FTE ratio of approximately $10 / 1$. They also reported $31 \%$ of teachers were chronically absent ${ }^{5}$ during the school year. During interviews with administrators in District 1, they reported difficulty finding substitute teachers and that often teachers came to school ill because they knew the ripple affect a teacher absence would have on their colleagues. Teacher absences meant dividing and shuffling students into other classes, or having multiple paraprofessionals cover a classroom, meaning the students who were supported by the paraprofessionals were then shuffled to another teacher or administrator in the school. District 1 had a 1.5 total counselor FTE and a .5 total psychologist FTE. District 2 reported a student to teacher FTE ratio of approximately 14/1.They also reported $89 \%$ of teachers were chronically absent during the school year. District 2 reported 2 total counselor FTE and 1.0 total psychologist FTE.

The average teacher salary reported in the 2015 Federal Civil Rights data was $\$ 36,996.42$ for District 1 . None of the teachers live in the community where the school is located, and only one administrator and a handful of paraprofessionals live in the

\footnotetext{
${ }^{5}$ Teachers are considered chronically absent if they miss 10 or more days during the school year.
} 
community. The vast majority of teachers and administrators commute anywhere from 30 minutes to $1 \frac{1 / 2}{2}$ hours, one way. For District 2 , the average teacher salary reported in the 2015 Federal Civil Rights data was $\$ 41,172.49$. One administrator and several teachers and paraprofessionals live in the community. The other teachers and administrators live in the next town over and commute approximately 20 minutes, one way.

Interviews with District 1 administrators revealed lack of available housing in the community, and that a building ban had been in place in the community for several years, making the availability of affordable housing non-existent. The lack of available housing options certainly contributed to the fact that more than $90 \%$ of teachers and administrators in District 1 commute one to three hours each day. Being located on a reservation with limited ability to collect property taxes to address facility needs is not the only challenge District 1 and District 2 face, but the rural nature of the communities also impacts their ability to recruit and retain teachers. Because of lack of flexibility and lower budgets, teachers in rural communities often make less than their peers in larger communities. Not only do rural teachers make less, but teachers in Idaho are also paid less than surrounding states. According to the Idaho Center for Fiscal Policy's Teacher Compensation (2018), Idaho ranks $43^{\text {rd }}$ in the nation for teacher compensation and Idaho teachers earn $\$ 12,420$ less than the national average.

Adding to the challenges, District 1 faces steep competition on teacher salaries with the surrounding communities, particularly those in Washington. The Superintendent shared that while their top teacher makes $\$ 53 \mathrm{~K}$ that is the starting salary for teachers in Washington, where many of District 1 teachers are commuting from. While beginning teacher salaries in Idaho have increased by nearly $\$ 10 \mathrm{~K}$ with the implementation of the 
five-year phased Career Ladder (beginning teacher salaries will increase from $\$ 31,750$ to $\$ 37,000$ in $2019-20)$, teacher salaries are woefully lower than nearly all surrounding states. According to research by The Hamilton Project (2018) Where Work Pays: Occupations \& Earnings across the United States, salaries for teachers in nonmetropolitan areas in surrounding states are all higher than Idaho $(\$ 36,588)$. Wyoming is the highest at $\$ 49,459$, with Washington at $\$ 44,307$ and Utah and Oregon between $\$ 41$ $\$ 42 \mathrm{~K}$. Montana $(\$ 38,260)$ showed the closest salary for non-metropolitan areas to Idaho.

District 1 administrators voluntarily shared that nearly half of the elementary school teachers turned over in one year. According to the Idaho Center for Fiscal Policy (2018), Idaho's teacher turnover rate is almost 4\% higher than the national average, and that low-performing and high-poverty school districts struggle the most with retention (Teacher compensation).

Professional development was an area where teachers and administrators in District 2 voluntarily highlighted a strong commitment to educator professional development and the use of learning communities by grades and subject matter within the school district. In fact, District 2 allocated one hour every Wednesday from 7:00-8:00am, and two hours every Friday afternoon, as students were granted early release. While teachers and administrators had an increased amount of time devoted to professional development, many shared that lack of time was one of the biggest challenges they faced. District 1 administrators shared having leadership teams at the district and school level that look at school data and professional development, but did not have the same emphasis and focus as District 2. 


\section{State Tribal Education Partnership (STEP) Grants}

Both school districts have a significantly high enrollment of American Indian students, higher than the research conducted in the case studies of Wright, et al. (1998), and both tribal education departments are recipients of federal STEP grants. The federal STEP program is intended to promote increased collaboration between tribal education agencies (TEA) and the state (SEA) and local (LEA) educational agencies, and to increase capacity of TEAs to have a more direct role in administrative decisions impacting public school districts with predominantly American Indian students. This grant is an example of the federal government's attempt to address the many federal reports referenced in Chapter 2. Because states' relationships with tribes have been historically challenging, the significance of the two STEP grants are important factors that must be included in this research. Due to the grants, there is the demonstration of stronger collaborative relationships between the LEAs and TEAs than in other districts with high American Indian student enrollments but do not have STEP grants. Wright, et al. (1998) found in the three Alabama counties' case studies that the presence of American Indian education programs played a significant role in reducing second generation discrimination against American Indians and positively impacted the treatment of American Indian students.

The STEP grants go beyond having American Indian programs in the schools in that local Tribes have a direct and specific voice on education policies at the local level in their communities. The STEP grants could be an alternate approach that might compensate for the lack of representation of American Indian administrators and teachers. In 2015, there were five, four-year awards made, and Idaho received two of 
those awards. The Tribe in District 2 are recipients of a second round of the grant (first round was awarded in 2012), and the Tribe in District 1 received their first round of funding in 2015.

In 2015 the Tribe in District 2 was awarded \$330,000, and was their second round as a recipient of the STEP grants. The focus of their current grant was to expand on the partnerships established with the two local school districts on the reservation (LEAs) which have 10-80\% American Indian enrollment. They proposed to continue their work with the Academic Development Institute, a non-profit organization to assist with evaluation, and Mathematize Inc. to support the development of culturally-responsive education strategies. Their STEP project supports the Tribe's education department staff being trained to provide technical assistance to partner LEAs and SEA staff, related to Title I, Part A; School Improvement Grant; and Improving Teacher Quality State Grants (Title II, Part A). Their focus was meeting the unique educational and cultural needs of American Indian students, including expansion of strategies to provide culturally responsive curriculum and environment, family engagement, instruction, and leadership. They have been heavily focused on building community engagement and increasing the representation and perspective of the tribe in education decisions impacting American Indian students in the school districts on the local reservation. They meet monthly with district leadership in those school districts.

The Tribe's STEP project in District 2 was recognized by the National Indian Education Association as an example of best practices for strengthening control of tribal education. In addition, they have seen a number of other successes:

- Development and use of the Tribe's Cultural Standards 
- Collaborated with the LEA and SEA to determine how the Tribe's pedagogy aligns with the state assessment standards

- Provided teacher training programs on the integration of cultural pedagogy, tribal education standards that aligns with the state's teacher evaluation model

- Established family engagement models that recognize the role of the family as the first educator

The Tribe in District 1 received $\$ 330,000$ in the 2015 awards, and was their first STEP grant. The primary focus of their grant was to articulate, align, and integrate culture, history and language in K-12 Idaho Social Studies standards through developing and integrating the Tribe's Social Studies Units for grade 4 Idaho History in their local school district. In addition they proposed to focus on the development of three high school Social Studies dual credit or high school credit courses, and to provide pre-service and in-service teacher education programs to promote Indigenous knowledge and culturally-responsive pedagogy for all LEA and Tribal School teachers, administrators, and paraprofessionals. Through the establishment of an advisory group of local postsecondary curriculum experts, teachers in the school district, and tribal education staff, they would develop and then pilot use of culturally relevant curriculum that is specific to the Tribe in District 1.

The Tribe in District 1 is seeing positive successes as a result of their efforts on the STEP grant. They are able to provide training to teachers and administrators professional development on culturally responsive pedagogy, and believe this has resulted in administrative support to create culturally responsive schools and classrooms. Their relationship with the State Department of Education (SEA) has been strengthened 
and continues to provide pathways for conversations about the Tribes and their role in educational decisions in schools that serve their students. They also acknowledge an increase in $4^{\text {th }}$ and $5^{\text {th }}$ grade student engagement where the curriculum is being piloted. And most significantly, the STEP grant is strengthening the Tribe's voice and ability to be partners in education of their people.

The fundamental research question is whether the presence of American Indian teachers (passive representation) positively impacts access and performance of American Indian students in two rural, public school districts, thereby leading to active representation which should result in culturally relevant curriculum and teaching practices. This research seeks address the lack of research on American Indian students in representative bureaucracy theory and the disconnection between education and policy research. From an educational research perspective, there is a fair amount of literature regarding culturally relevant curriculum as a strategy for improving education for American Indian (and minority) students. However, there is a lack of research on 1) whether passive representation of American Indian teachers in the classroom positively impacts access and performance of American Indian students; and 2) whether the passive representation of American in Teachers leads to active representation thereby resulting in an increased presence of culturally relevant curriculum and teaching practices.

Teaching culturally is not sufficient to positively impact American Indian student access and performance, nor can it be fully realized in absence of passive representation of American Indian teachers. Ladson-Billings (1995) is a well-known theorist on culturally revenant pedagogy. In the article "But that's just good teaching! The case for culturally relevant pedagogy" two of her three examples underscore the impact of 
representation. In those examples where culturally relevant curriculum is used in minority serving schools, two of the three examples include representation of parents, mentors, or other community leaders sharing the same demographics as the students in the delivery of the curriculum and teaching. Ladson-Billings' (1995) research, however, is focused solely on the pedagogical aspects of the teaching, thus missing the role of representation. I propose that a closer look at the data in these two school districts, supported by interviews, will reveal that the representation of American Indian teachers in the schools impacts access and performance through passive representation, and that through active representation culturally relevant curriculum and teaching practices are more fully realized. Ultimately, it is the representation that matters.

Ultimately, the representation matters. Whether that representation happens through the presence of American Indian teachers or administrators, or through the tribes having a voice in educational policy decisions at the local level through application of the STEP grants. 


\section{CHAPTER FIVE: RESULTS OF RESEARCH AND CONCLUSIONS}

Using a cross comparative case study of two rural Idaho public school districts, I examine whether the presence of American Indian teachers positively impacts access and performance of American Indian students. Which if it does, may result in broader implementation of culturally responsive curriculum and teaching practices in public schools that serve American Indian students. I have organized this chapter in three overarching sections. The first section reviews teacher representation data by district. The second section compares both districts' student data related to access and performance. Finally, the last section provides a summary of interviews with tribal education directors/managers, school district administrators, and teachers. All data have been rounded up to the nearest value.

\section{Teacher Representation}

Data retrieved from the Education Analytics System of Idaho (EASI) showed District 1 had a three-year average (AYs 2012-2015) of 30 regular classroom teachers and supplemental/mentor specialists. District 1 had one American Indian teacher in 2013-14 and one Hispanic teacher in 2014-15. 


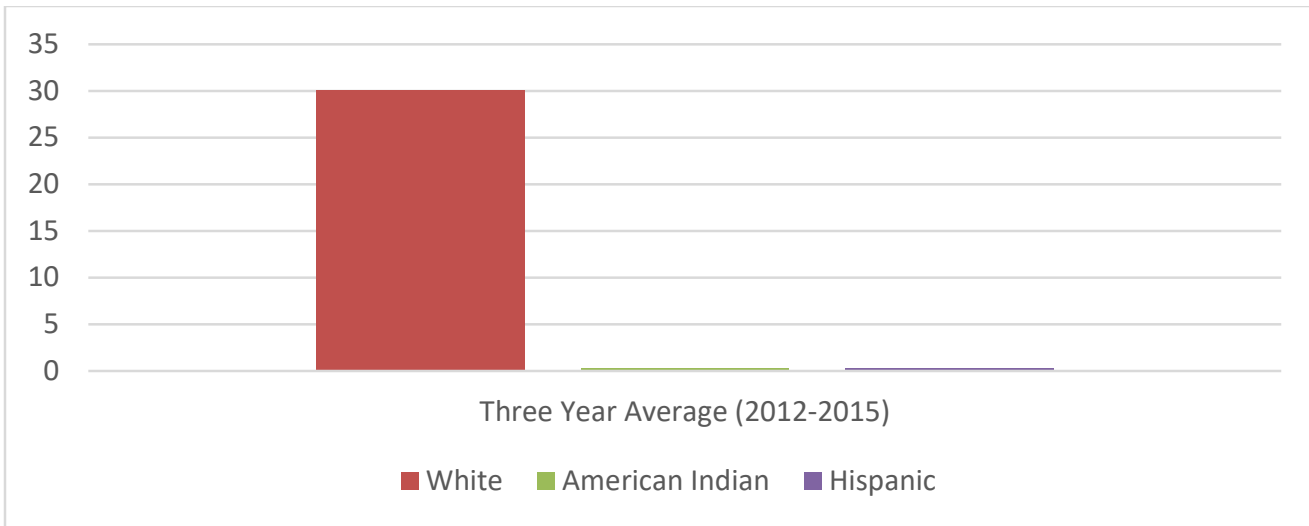

Source: Education Analytics System of Idaho (EASI)

Chart 5.1 District 1 Teacher Race/Ethnicity (Three-Year Average: 2012 -2015)

At the time of the interviews, District 1 did not have any minority certified teachers. The administrators indicated that there were classified staff and paraprofessionals in the school district who were American Indian. During the three-year period evaluated, the number of teachers supporting multiple grade levels (grades 6-12 or $\mathrm{K}-12$ ) in District 1 increased from three to five.

Data retrieved from EASI showed a three-year average (AYs 2012-2015) of 23 teachers/proctors in District 2. During the three-year period the number of proctors declined dramatically, and the number of teachers supporting multiple grade levels in District 2 (grades 6-12 or K-12) fluctuated between eight and eleven.

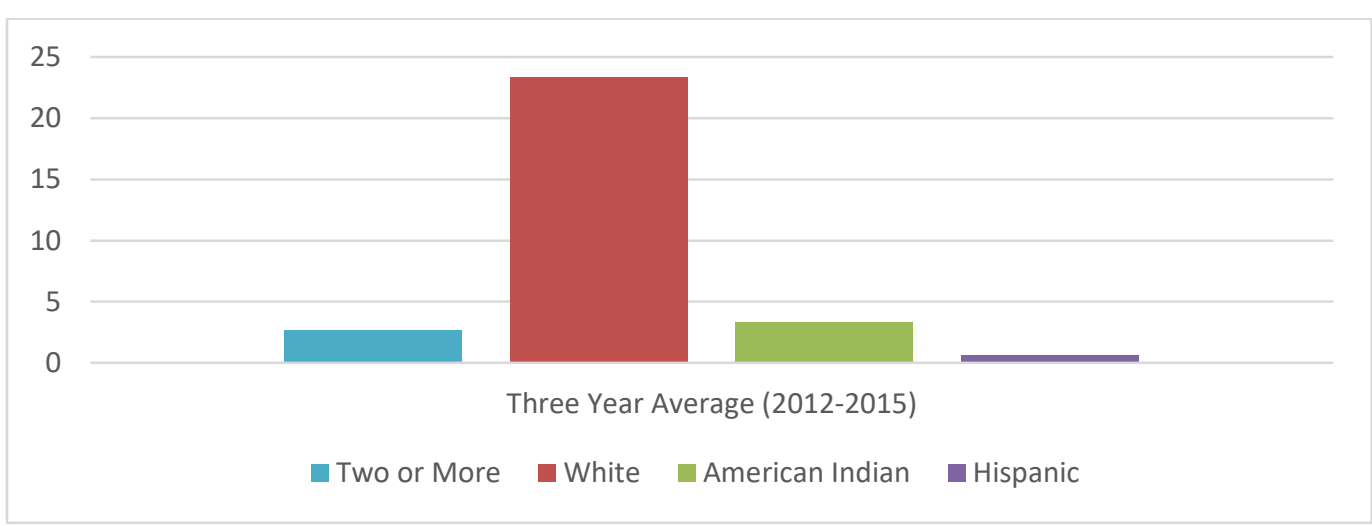

Source: Education Analytics System of Idaho (EASI)

Chart 5.2 District 2 Teacher Race/Ethnicity (Three-Year Average: 2012 -2015) 
Teacher demographics in District 2 showed a decline in the representation of American Indian teachers and/or proctors from seven to two during the three-year period. In addition, the number of Hispanic teachers went from two to none, while the number of teachers who identified as two or more races held fairly constant. District 2 reported having proctors, whereas District 1 did not report having proctors but identified having supplemental/specialists.

District 2 had an overall larger American Indian representation across all populations (see Table 5.1), with teacher representation (11\%) being the smallest. The theory of representative bureaucracy would indicate that American Indian students in District 2 should demonstrate more positively access and performance educational outputs when compared to American Indian students in District 1.

Table 5.1 Percent of American Indian Representation

\begin{tabular}{|l|r|r|}
\hline \multicolumn{1}{|c|}{ American Indian } & District 1 & District 2 \\
\hline Community Population $^{1}$ & $40 \%$ & $63 \%$ \\
\hline Student Population $^{2}$ & $47 \%$ & $80 \%$ \\
\hline Teachers $^{3}$ & $0 \%$ & $11 \%$ \\
\hline Administrators & $0 \%$ & $33 \%$ \\
\hline School Board Members & $28 \%$ & $80 \%$ \\
\hline
\end{tabular}

${ }^{1}$ Using the American Indian 2010 Census population in the school district as the comparison base

${ }^{2}$ Using the 2015 Federal Civil Rights American Indian student enrollment data as the comparison base

${ }^{3}$ Using 2014-15 EASI teacher data

As demonstrated in Table 5.1, American Indian representation for administrator and school board positions in District 2 is also higher than District 1 . While the focus of this research is on teacher representation, prior research (Meier, 1989; Meier \& Stewart, 1991; Wright et al., 1998) would support that administrator and school board representation also play a vital role in reducing second generation discrimination. 


\section{Student Access \& Performance Data}

I provide descriptive statistics that include snapshots in time of three grades at each educational level (elementary, middle, and high) of American Indian student access and performance data compared to their peers over a three-year period. There are limitations with this approach. I found that while the targeted grades I was looking at $\left(4^{\text {th }}\right.$, $8^{\text {th }}$, and $\left.11^{\text {th }}\right)$ may not have had any disciplinary actions, there still may be disciplinary actions for other grade levels in the school district that were not captured. I have attempted to counter balance this incongruence by using aggregate school-level data. Another way of managing this in future research would be to evaluate all grade levels over time.

Student data is organized by access and performance. I use access as a demonstration of academic grouping, and data elements evaluated were special education, gifted and talented, dual credit, and middle/high school math and science availability. I broadened these data from prior research based on my primarily qualitative approach, as well as my focus on student and grade-level performance. I use performance to capture educational outputs that are often a result of academic grouping, and data elements evaluated were attendance, Idaho Standardized Assessments (ISAT) for $4^{\text {th }}$ and $8^{\text {th }}$ grades, disciplinary actions, SAT/ACT test taking, and graduation rates. The data selected for performance were also broadened as a result of my methodological approach.

As demonstrated in Table 5.2, both District 1 and District 2 have a high free and reduced lunch population. District 2 had almost $20 \%$ higher of the total student population eligible. Both school districts provide free breakfast and lunch to all students 
in their school districts. In addition, students who attend their afterschool programs receive a free meal.

Table 5.2 2015 Federal Civil Rights Data

\begin{tabular}{|l|r|r|}
\hline & District 1 & District 2 \\
\hline Free \& Reduced Lunch Eligibility & $79 \%$ & $90 \%$ \\
\hline $\begin{array}{l}\text { Individuals with Disabilities Education Act } \\
\text { (IDEA) }\end{array}$ & $22 \%$ & $21 \%$ \\
\hline Disabilities under Section 504 & $1 \%$ & $2 \%$ \\
\hline
\end{tabular}

While District 2 had a higher Free \& Reduced Lunch student population, data reveal that both districts have a similar percentage of their overall student population receiving special education (see Table 5.2).

\section{Access Data}

In my research, I used access as a demonstration of academic grouping, where students are grouped into academic categories based on real or perceived notions of ability (Meier et al., 1989; Meier et al., 1999; Meier \& Stewart, 1991; Wright et al., 1998). Academic grouping establishes permanent academic paths students follow for the majority of their educational careers, and locks students into ability categories that are nearly impossible to remove - both personally and academically. I reviewed six data elements under access: $4^{\text {th }}, 8^{\text {th }}$, and $11^{\text {th }}$ grade special education, gifted and talented, dual credit, and middle/high school math and science courses.

\section{$\underline{\text { Special Education }}$}

The Individuals with Disabilities Education Act (IDEA) is a federal law intended to ensure all children, regardless of ability, receive a free appropriate public education, and requires states and local education agencies (LEAs) to provide services and supports that meet individual student needs. Both formula and discretionary grants are available to states (SEA) and schools (LEAs). In addition, states are required to report on the status of 
their compliance with the implementation and performance of IDEA federal statutory requirements. In July 2018, Idaho was classified as Needs Assistance (two or more consecutive years) ${ }^{6}$ for Part B determinations (ages 3-21) (U.S. Dept. of Ed, 2018).

Looking at state-level data on special education across three years (AYs 2012$2015)$ in $4^{\text {th }}, 8^{\text {th }}$, and $11^{\text {th }}$ grades in the two districts, I found that American Indian students comprise the largest percentage of special education participation in all but one instance (District $1,11^{\text {th }}$ grade). This suggests that the higher percentage of placement in special education of American Indian students supports what we might expect from representative bureaucracy theory. However, when I evaluated at the rate of special education placement across ethnic groups, I found that American Indian student rates of placement were similar to or less than those of white and Hispanic students. Comparing District 1 and District 2, the theory would suggest that fewer American Indian students would be tracked in special education in District 2, since that district has American Indian teachers.

$\underline{4^{\text {th }} \text { Grade Special Education }}$

Looking at a three-year average (AYs 2012-2015) of the $4^{\text {th }}$ grade placement in special education in District $1,19 \%$ of the total $4^{\text {th }}$ grade population were in special education. In District 2, $29 \%$ of the total $4^{\text {th }}$ grade population were in special education. American Indian students make up the largest representation in both District 1 and District 2 of all ethnic groups in $4^{\text {th }}$ grade special education.

\footnotetext{
${ }^{6}$ This designation means Idaho has not met the procedure requirements of IDEA: https://www.ncd.gov/sites/default/files/NCD_Monitoring-Enforcement_Accessible.pdf
} 
Table 5.3 $\quad 4^{\text {th }}$ Grade Placement in Special Education by Race/Ethnicity

\begin{tabular}{|l|r|r|}
\hline \multirow{2}{*}{} & \multicolumn{1}{|c|}{ District 1 $\left(4^{\text {th }}\right.$ Grade $)$} & District 2 $\left(4^{\text {th }}\right.$ Grade $)$ \\
\cline { 2 - 3 } & Three-Year Average & Three-Year Average \\
\hline $4^{\text {th }}$ Grade Students in Special & 6 & 13 \\
Education (three-year average) & & $79 \%$ \\
\hline American Indian & $37 \%$ & $8 \%$ \\
\hline White & $0 \%$ & $8 \%$ \\
\hline Hispanic & $16 \%$ & $5 \%$ \\
\hline Two or More & & \\
\hline
\end{tabular}

Source: Education Analytics System of Idaho (EASI)

When comparing the rate of placement in $4^{\text {th }}$ grade special education by ethnic groups, American Indian students in District 1 are ten percentage points less than District 2.

\section{Table 5.4 Rate of Placement in $4^{\text {th }}$ Grade Special Education by Race/Ethnicity}

\begin{tabular}{|l|r|r|}
\hline & District 1 $\left(4^{\text {th }}\right.$ Grade $)$ & District 2 $\left(4^{\text {th }}\right.$ Grade $)$ \\
\hline American Indian & $19 \%$ & $29 \%$ \\
\hline White & $26 \%$ & $43 \%$ \\
\hline Hispanic & $0 \%$ & $43 \%$ \\
\hline Two or More & $16 \%$ & $15 \%$ \\
\hline
\end{tabular}

Source: Education Analytics System of Idaho (EASI)

During interviews with teachers in District 1, they shared frustrations that they believed more students would likely qualify for special education services, but students were unable to qualify as a result of too many absences. Missing too many days was impacting student learning time and the school's ability to determine if the students' academic challenges were as a result of a disability or as a result of missed instructional time.

District 2 has a higher $(79 \%)$ three-year average number of $4^{\text {th }}$ grade American Indian student placement in special education than in District $1(47 \%)$. In addition, the rate of placement for American Indian students in special education is higher in District 2 (29\%) than District $1(19 \%)$. These data would contradict the theory of representative 
bureaucracy in that the presence of American Indian teachers in District 2 does not appear to have positively impacted access in this category.

$\underline{8^{\text {th }} \text { Grade Special Education }}$

In the $8^{\text {th }}$ grade, American Indian students make up the majority of all students in special education in both districts. Looking at the three-year average (AYs 2012-2015) of the $8^{\text {th }}$ grade placement in special education in District $1,23 \%$ of the total $8^{\text {th }}$ grade population was in special education. In District $2,18 \%$ of the total $8^{\text {th }}$ grade population was in special education. In both districts, American Indian student representation in special education is the largest of all ethnic groups. The total $8^{\text {th }}$ grade special education participation across both districts are very similar, however District 2 has a much higher representation of American Indian student participation.

Table 5.5 $\quad 8^{\text {th }}$ Grade Placement in Special Education by Race/Ethnicity

\begin{tabular}{|l|r|r|}
\hline \multirow{2}{*}{$\begin{array}{l}8^{\text {th }} \text { Grade Students in Special } \\
\text { Education (three-year average })\end{array}$} & \multicolumn{1}{|c|}{ District 1 $\left(8^{\text {th }}\right.$ Grade $)$} & \multicolumn{1}{c|}{ District 2 $\left(8^{\text {th }}\right.$ Grade $)$} \\
\cline { 2 - 3 } & Three-Year Average & \multicolumn{1}{|c|}{ Three-Year Average } \\
\hline American Indian & 7 & 7 \\
\hline White & $65 \%$ & $82 \%$ \\
\hline Hispanic & $5 \%$ & $5 \%$ \\
\hline Two or More & $25 \%$ & $5 \%$ \\
\hline
\end{tabular}

Source: Education Analytics System of Idaho (EASI)

When comparing the rate of placement in $8^{\text {th }}$ grade special education across all three years (AYs 2012-2015) by ethnic group, American Indian students in District 1 make up a larger percentage of students in special education than in District 2. 
Table 5.6 Rate of Placement in $8^{\text {th }}$ Grade Special Education by Race/Ethnicity

\begin{tabular}{|l|r|r|}
\hline & District 1 $\left(8^{\text {th }}\right.$ Grade $)$ & District 2 $\left(8^{\text {th }}\right.$ Grade $)$ \\
\hline American Indian & $37 \%$ & $19 \%$ \\
\hline White & $4 \%$ & $9 \%$ \\
\hline Hispanic & $26 \%$ & $22 \%$ \\
\hline Two or More & $8 \%$ & $14 \%$ \\
\hline
\end{tabular}

Source: Education Analytics System of Idaho (EASI)

District 2 has a higher $(82 \%)$ three-year average number of $8^{\text {th }}$ grade American Indian student placement in special education than in District $1(65 \%)$. However, the rate of placement for American Indian students in special education in District 2 (19\%) is less than District $1(37 \%)$. When looking at the rate of placement for American Indian students, these data would suggest support for the theory of representative bureaucracy in that the presence of American Indian teachers in District 2 appears to have positively impacted access in this category.

\section{$11^{\text {th }}$ Grade Special Education}

In the $11^{\text {th }}$ grade, there are greater distinctions across the two districts. American Indian students make up almost the entire special education enrollment in District 2 across all three years (AYs 2012-2015). In District 1, 23\% of the total $11^{\text {th }}$ grade population was in special education, whereas only $13 \%$ of the total $11^{\text {th }}$ grade population in District 2 was in special education. The three-year average for District 2 revealed $87 \%$ of students enrolled in special education were American Indian. 
Table 5.7 $11^{\text {th }}$ Grade Placement in Special Education by Race/Ethnicity

\begin{tabular}{|l|r|r|}
\hline \multirow{2}{*}{} & \multicolumn{1}{|c|}{ District 1 $\left(11^{\text {th }}\right.$ Grade $)$} & District 2 $\left(11^{\text {th }}\right.$ Grade $)$ \\
\cline { 2 - 3 } & Three-Year Average & Three-Year Average \\
\hline Total $11^{\text {th }}$ Grade Students In & 6 & 5 \\
Special Education & & $87 \%$ \\
\hline American Indian & $39 \%$ & $0 \%$ \\
\hline White & $44 \%$ & $0 \%$ \\
\hline Hispanic & $11 \%$ & $13 \%$ \\
\hline Two or More & $6 \%$ & \\
\hline
\end{tabular}

Source: Education Analytics System of Idaho (EASI)

When comparing the rate of placement across all three years (AYs 2012-2015)

and across ethnic groups in $11^{\text {th }}$ grade special education, American Indian students in

District $1(23 \%)$ make up a higher percentage than District $2(16 \%)$.

Table 5.8 Rate of Placement in $11^{\text {th }}$ Grade Special Education by Race/Ethnicity

\begin{tabular}{|l|r|r|}
\hline & District 1 $\left(11^{\text {th }}\right.$ Grade $)$ & District 2 $\left(11^{\text {th }}\right.$ Grade $)$ \\
\hline American Indian & $23 \%$ & $16 \%$ \\
\hline White & $24 \%$ & $0 \%$ \\
\hline Hispanic & $29 \%$ & $0 \%$ \\
\hline Two or More & $11 \%$ & $20 \%$ \\
\hline
\end{tabular}

Source: Education Analytics System of Idaho (EASI)

District 2 has a higher $(87 \%)$ three-year average number of $11^{\text {th }}$ grade American Indian student placement in special education than in District 1 (39\%). However, the rate of placement for American Indian students in special education in District $2(16 \%)$ is less than District $1(23 \%)$. When looking at the rate of placement for American Indian students, these data would suggest support the theory of representative bureaucracy in that the presence of American Indian teachers in District 2 appears to have positively impacted access in this category.

Without tracking students over time and evaluating more grades, it's difficult to ascertain if more American Indian students are being placed in special education as a form of tracking and grouping. Given that two of the three grades evaluated had a higher 
rate of placement of American Indian students in special education in District 1 than in District 2 (the district with American Indian teachers), there are demonstrated patterns that support the theoretical model of representative bureaucracy in that the representation of American Indian teachers appears to have positively impacted access of American Indian students with regard to placement in special education, particularly for middle/high school American Indian students.

While prior research (Meier et al., 1989; Meier et al., 1999; Meier \& Stewart, 1991; Wright et al., 1998) proposes that placement in special education is a tool used to demonstrate second generation discrimination, and that minority students are often disproportionately placed or over identified for needing special education, there is also another important element that requires further research. Monk (2007) noted in his research that over-identification of minority students in special education isn't simply a tool for removing students from the classroom, but rather a mechanism for "qualifying a district for additional federal and state aid" (p.165). While there was no evidence of this in either school district, given the rural nature and the financial realities of both districts, this could prove to be a topic that requires additional research and analysis.

\section{$\underline{\text { Gifted \& Talented Programs }}$}

Neither school district has a prescribed gifted and talented program. However, District 1 reported two white students receiving gifted and talented services in their 2015 Federal Civil Rights Data. While prior research (Meier, 1984; Meier et al., 1989; Meier et al., 1999; Meier \& Stewart, 1991; Meier \& Bohte, 2007; and Wright et al., 1998) indicates that placement (or lack) of minority students in gifted and talented programs can be an indicator for tracking and grouping, neither school district has a prescribed 
gifted and talented program. The fact that both schools are rural and are considered high poverty schools, impacts their financial flexibility to serve students with varied programs. Unlike special education programs, where school districts can obtain additional federal funding through discretionary or competitive grants, funding options are generally limited or do not exist for gifted and talented services. Neither school district reported having students enrolled in $8^{\text {th }}$ grade Algebra, an indicator the U.S. Department of Education uses to evaluate access to courses that demonstrate student preparation for college-readiness. Because there was an absence of a formal gifted and talented program to assess placement across all ethnic backgrounds, I was unable to use this for purposes of my research.

\section{$\underline{\text { Dual Credit }}$}

The Idaho legislature created a program called Fast Forward. This program provides $\$ 4,125$ for every public high school student, and those funds can be used for any of Idaho’s Advanced Opportunities programs. These opportunities include International Baccalaureate (IB) Program, Dual Credit (academic and technical college credit), and Advanced Placement (AP) exams. In 2016, House Bill 458 expanded the use of the funds to cover grades 7-12, and can be used to pay for overload courses in high school (up to \$225), dual credit (up to $\$ 75$ per credit), and AP, College Level Examination Program (CLEP), IB, or Career Technical Education (CTE) exams.

Using data from EASI, the three-year average (AYs 2012-2015) dual credit participation in District 1 was $66 \%$ of the total $11^{\text {th }}$ grade student population participating in dual credit; whereas $22 \%$ of the total $11^{\text {th }}$ grade student population participated in 
District 2. However, District 2 had the highest percentage of American Indian participation across all ethnic groups.

Table 5.9 Percent of $11^{\text {th }}$ Grade Students Enrolled in Dual Credit by Race/Ethnicity

\begin{tabular}{|l|r|r|}
\hline & District 1 $\left(11^{\text {th }}\right.$ Grade $)$ & District 2 $\left(11^{\text {th }}\right.$ Grade $)$ \\
\cline { 2 - 3 } & Three-Year Average & Three-Year Average \\
\hline $11^{\text {th }}$ Grade Students Enrolled in & 23 & 8 \\
Dual Credit (three-year average $)$ & & $83 \%$ \\
\hline American Indian & $32 \%$ & $4 \%$ \\
\hline White & $45 \%$ & $0 \%$ \\
\hline Hispanic & $9 \%$ & $13 \%$ \\
\hline Two or More & $13 \%$ & \\
\hline
\end{tabular}

Source: Education Analytics System of Idaho (EASI)

Additionally, when looking at the mean number of credits earned by $11^{\text {th }}$ grade students over the three-year period (AYs 2012-2015), in District 1, American Indian students earned 11 of the 41 credits, whereas in District 2, American Indian students earned 8 of the 9 credits during the three-year period (AYs 2012-2015). During interviews with school district administrators, both districts expressed frustration about their inability to offer dual credit options to their students. This is particularly challenging for rural school districts because qualifications to teach dual credit are based on standards set by the college or university awarding the dual credit. In many instances, if high school teachers do not have a master's degree (or a minimum of 18 credits in the content area), they are not eligible to teach. At the time of interviews, District 2 had just hired two new, first-year teachers in math and science, and a new music teacher. The science teacher had their master's degree and was also certified to teach dual credit for the regional college. There are demonstrated patterns that support the theoretical model of representative bureaucracy theory, and the data appear to support that the presence of American Indian teachers in District 2 may positively impact access in this category. 


\section{Middle/High School Math \& Science Course Availability}

Challenges with teacher recruitment and retention also impact what courses districts can offer to students. Both school district administrators shared that music and art teachers served K-12 students, thereby limiting the number of electives that could be offered at the middle/high school levels. The limitation of available offerings extend beyond art and music classes. Under the College and Career Readiness categories of the 2015 Federal Civil Rights Data, District 1 indicated they provided calculus, chemistry, and physics, whereas District 2 did not offer any of the three courses.

Table 5.10 Percent of Students Enrolled in Calculus, Chemistry, or Physics

\begin{tabular}{|l|r|r|r||r|r|r|}
\hline & \multicolumn{3}{|c||}{ District 1 $(\mathrm{n}=166)^{*}$} & \multicolumn{3}{|c|}{ District 2 (n=188)* } \\
\cline { 2 - 7 } & Calculus & Chemistry & Physics & Calculus & Chemistry & Physics \\
\hline $\begin{array}{l}\text { Total } \\
\text { Students } \\
\text { Enrolled }\end{array}$ & 2 & 15 & 29 & 0 & 0 & 0 \\
\hline $\begin{array}{l}\text { American } \\
\text { Indian }\end{array}$ & & & & & & \\
\hline White & $10 \%$ & $27 \%$ & $14 \%$ & 0 & 0 & 0 \\
\hline Hispanic & $0 \%$ & $13 \%$ & $7 \%$ & 0 & 0 & 0 \\
\hline Two or More & $0 \%$ & $13 \%$ & $14 \%$ & 0 & 0 & 0 \\
\hline
\end{tabular}

Source: 2015 Federal Civil Rights Data

* 2014-2015 Net School Enrollment Report for middle/high school grades

Comparing District 1 and District 2, the theory of representative bureaucracy would suggest that District 2 would have a greater number of American Indian students enrolled in calculus, chemistry, or physics courses. However, in this instance the challenge is not placement of students or ability grouping, there was simply not the availability of qualified teachers in District 2 to teach the courses. The challenge of teacher retention, and the ability to hire qualified teachers of any ethnic background has been a challenge for both school districts. Therefore, the data could not conclusively be 
tied to grouping or tracking of students, but rather was a reflection of availability (or lack) of qualified teachers.

\section{Summary of Access Data}

Six data elements were evaluated under access over a three-year period, looking at district- and student-level data for $4^{\text {th }}, 8^{\text {th }}$ and $11^{\text {th }}$ grades. Two areas did not yield meaningful data as a result of lack of availability of a gifted and talented program and lack of availability of qualified teachers.

Table 5.11 American Indian Student Access Represented Positively

\begin{tabular}{|l|r|r|}
\hline Access Data Reviewed & District 1 & \multicolumn{1}{|c|}{ District 2 } \\
\hline $4^{\text {th }}$ Grade Special Education & Yes & No \\
\hline $8^{\text {th }}$ Grade Special Education & No & Yes \\
\hline $11^{\text {th }}$ Grade Special Education & No & Yes \\
\hline Gifted \& Talented & VOID & VOID \\
\hline Dual Credit & No & Yes \\
\hline Middle/High School Math and Science Courses & VOID & VOID \\
\hline
\end{tabular}

District 2 had three instances where data indicated access for American Indian students was positively impacted by the presence of American Indian teachers compared to only one instance in District 1 (see Table 5.11 below). Consequently, the data reviewed under access provides demonstrated patterns that support the theory of representative bureaucracy in that the presence of American Indian teachers appears to have positively impacted access for American Indian students in District 2.

\section{Performance Data}

I used performance as a way to evaluate the educational outputs that are often as a result of academic grouping. Assessing student performance traditionally consists of using standard metrics of educational assessment intended to capture progress and knowledge abilities. Data evaluated were attendance, $4^{\text {th }}$ and $8^{\text {th }}$ grade ISAT, disciplinary actions, SAT/ACT test-taking, and graduation rates. Based on the theory of representative 
bureaucracy, District 2 should see more positive performance of American Indian students than District 1, due to the presence of American Indian teachers.

\section{$\underline{\text { Attendance/Absences }}$}

According to the 2015 Federal Civil Rights data, both districts have a high percentage of students who are considered chronically absent, which means they are missing $10 \%$ or more of the school year. Research by Balfanz \& Byrnes (2012) noted that students in poor, rural areas can often miss up to a month of school, and that these absences are compounded over time. They also noted that the younger grades (kindergarten and first grade) and the older grades $\left(12^{\text {th }}\right.$ grade) generally have the highest rates of chronic absences, and they are most prevalent among low socioeconomic students (Balfanz \& Byrnes, 2012). In District 1, 43\% of all students are chronically absent, and 39\% in District 2.

Table 5.12 Percent of Students Chronically Absent by Type

\begin{tabular}{|l|r|r||l|r|}
\hline \multirow{2}{*}{} & \multicolumn{3}{|c||}{ District 1 (n=348) } & \multicolumn{2}{|c|}{ District 2 (n=496) } \\
\cline { 2 - 4 } & $\begin{array}{l}\text { Student } \\
\text { Enrollment }\end{array}$ & $\begin{array}{l}\text { Chronically } \\
\text { Absent }\end{array}$ & $\begin{array}{l}\text { Student } \\
\text { Enrollment }\end{array}$ & $\begin{array}{l}\text { Chronically } \\
\text { Absent }\end{array}$ \\
\hline All Students & & $43 \%$ & & $39 \%$ \\
\hline American Indian & $47 \%$ & $22 \%$ & $80 \%$ & $33 \%$ \\
\hline White & $25 \%$ & $10 \%$ & $5 \%$ & $1 \%$ \\
\hline Hispanic & $13 \%$ & $7 \%$ & $1 \%$ & $0 \%$ \\
\hline Two or More & $15 \%$ & $6 \%$ & $5 \%$ & $1 \%$ \\
\hline
\end{tabular}

Source: 2015 Federal Civil Rights Data

Chart 5.3 show that in District 1 American Indian students make up 50\% of the population with chronic absences. In District 2, American Indian students make up 91\% of the population of students with chronic absences (Chart 5.4). 


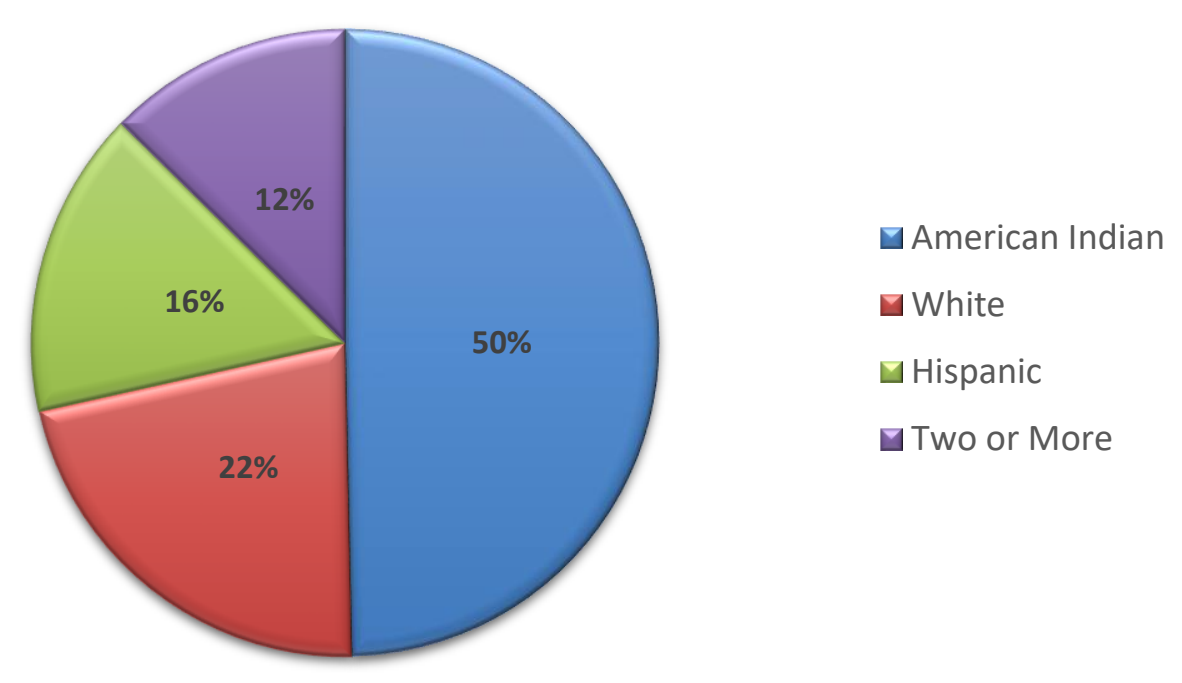

Source: 2015 Federal Civil Rights Data

Chart 5.3 District 1 Chronic Absences by Enrollment Type

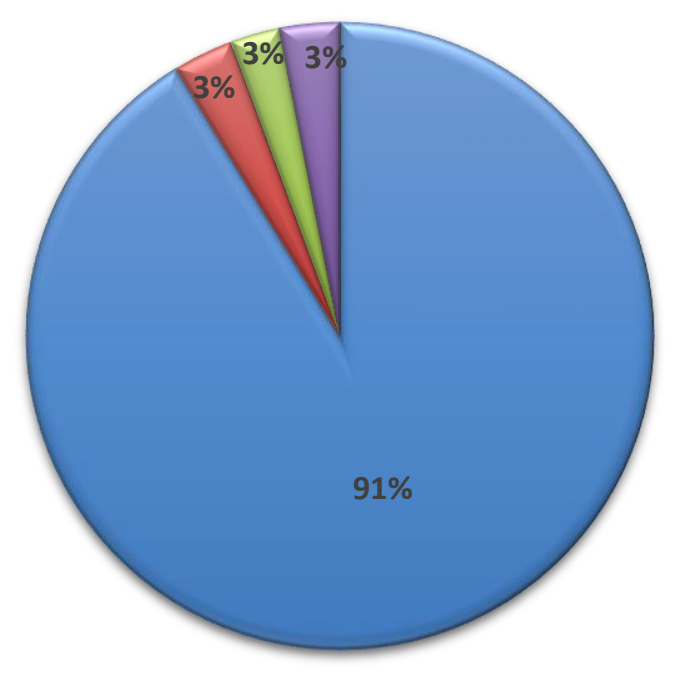

$\square$ American Indian

$\square$ White

$\checkmark$ Hispanic

口Two or More

\section{Source: 2015 Federal Civil Rights Data}

\section{Chart 5.4 District 2 Chronic Absences by Enrollment Type}

Because attendance is tracked by an average over an identified period of time,

actual enrollment and student needs are often not captured, particularly in rural districts with high poverty and minority populations. Research by Balfanz \& Byrnes (2012) described three reason why students miss school: 
- Students who cannot attend school due to illness, family responsibilities, housing instability, the need to work or involvement with the juvenile system.

- Students who will not attend school to avoid bullying, unsafe conditions, harassment and embarrassment.

- Students who do not attend school because they, or their parents, do not see the value in being there, they have something else they would rather do, or nothing stops them from skipping school (pp. 4-5).

These observations support the responses from interviewees in both districts. One teacher in District 1 indicated they had purchased an alarm clock for one of their elementary students because there was no one to wake up the student for school. In another example, the teacher rewarded a student with any book they wanted out of the book order if the student could maintain perfect attendance for 10 days in a row, which they were able to do. Administrators in District 2 shared having to drive to homes in the communities to pick up children whose parents did not have a vehicle to get their young children to school.

In another example of students in District 2, administrators shared that some of the students who do not have washing machines will bring their clothes in a bag each week and the school will wash them and send them home with the children. In some instances, the administrators are driving families to the local food bank to ensure they have food, otherwise the families would have no way to obtain necessary food. During one interview, a middle/high school student interrupted our interview to obtain homework from the teacher. The student shared with the teacher being interviewed that they were checking out of school for the day because they believed that another teacher 
had it out for them and that teacher was going to just provoke the student until they got angry and into trouble.

Data on absences reveal that while District 1 has a slightly higher percentage of their total population being chronically absent, District 2 has a higher percentage (and raw total numbers) of American Indian students chronically absent than District 1 . This would suggest that representation of American Indian teachers in District 2 appears not to have positively impacted performance in this category.

District 1 , teachers and administrators shared that they felt it was difficult to discern whether or not students genuinely needed special education support services, or if their learning challenges were as a result of attendance challenges. At nearly every interview, a key topic interviewees brought up in District 1 were challenges with attendance. While District 2 also faced attendance challenges, it was not brought up as frequently as a major challenge. That may be as a result of a new attendance policy implemented in District 2. Teachers and administrators in District 2 shared that this was the first year implementation of their new attendance policy, and they appeared to be seeing positive results.

The attendance policy changes created an early morning homeroom class for the middle/high school students, and for students in grades 9-12 who missed 12 or more classes in any given period in a semester they would lose credit for that class. For students in grades PreK-8, students who miss more than $40 \%$ of scheduled instructional minutes would automatically be required to repeat the grade. While there were mixed feelings and support for the plan, the Superintendent shared that it had been one of the most broadly vetted policy decisions the district had ever made. The Superintendent 
shared that it had been vetted with the Tribal Council, the Tribal Education Department, the Circle of Elders, community advisory groups, and teachers. District 2 shared they lost approximately $\$ 70 \mathrm{~K}$ in state funding in the prior school year because of attendance challenges. Based on preliminary data they were seeing promising results, and it appeared that not only would they recover the $\$ 70 \mathrm{~K}$, but potentially gain an additional $\$ 50 \mathrm{~K}$.

\section{$\underline{\text { Idaho Standardized Assessment Test (ISAT) }}$}

One data element that was not evaluated in prior research by Meier, et al. (1989), Meier \& Stewart (1991), and Wright, et al. (1998) was student performance on state standardized tests. State standardized tests were likely not included because there are significant differences in content and quality of these assessments across states. However, in recent years numerous states have collaborated to establish multi-state consortiums to develop common assessments that could be used to evaluate performance across multiple states. One of the consortiums was the Smarter Balanced Assessment Consortium (SBAC), for which Idaho became a member.

As part of the federal Every Student Succeeds Act (ESSA), all states are required to have a standardized state assessment, and the ISAT is Idaho's standardized assessment. Idaho was part of the SBAC efforts, and implemented the new assessment tool in 20142015. However the 2012-2013 ISAT data used in my research is based on the old assessment tool. The SBAC was first piloted by Idaho in pre-selected school districts in 2012-2013. Therefore standardized assessment data were not available from either the old or the new test for either school district in 2013-2014, as all school districts were allowed to bank the prior year's assessment results while the SBAC practice field test was conducted. Banking the scores of the practice field test was an effort to hold schools 
harmless as educators and state leaders were aware the new assessment was significantly different, and the number of students scoring proficient or better would likely see dramatic declines. In 2014-2015 the new SBAC assessment was fully implemented.

While part of the data I collected from EASI included ISAT data for 2014-2015, that was the first year of the full implementation of the new statewide testing standards. Results of those assessments across all subject areas in both districts for $4^{\text {th }}$ and $8^{\text {th }}$ grade revealed that $70-80 \%$ of students, regardless of ethnic group, scored below proficient. Therefore, I determined not to include data for those years in my analysis. Because the tests were so different there was no ability to make comparisons over time. It does however demonstrate that students were not prepared for the type of test (more hours on a computer-based assessment), or the content and style (less multiple choice and greater analytical question and answer) of the new state assessment.

\section{$\underline{4^{\text {th }} \text { Grade ISAT }}$}

In 2012-2013, American Indian students made up $45 \%$ of the $4^{\text {th }}$ grade enrollment in District 1, and $82 \%$ of the enrollment in District 2. In District 1, on average five students did not take the $4^{\text {th }}$ grade math, reading, or language ISATs, and of those students approximately $80 \%$ were American Indian students. While it has been implied that districts intentionally discourage some students from participating, particularly minority students, in taking state assessments that was not part of my research analysis. It may, however be an area for future research. In District 2, only one student did not take the $4^{\text {th }}$ grade math, reading, language ISATs, and that student was American Indian. These numbers explain the discrepancy in categories not always adding up to $100 \%$. 
$4^{\text {th }}$ Grade Math ISAT

Overall, District 2 had more students score proficient or better on the $4^{\text {th }}$ grade math assessment than District 1. However, in both school districts, American Indian students have the highest percentage of all ethnic groups scoring below proficient, with double-digit differences between American Indian students and all other ethnic groups.

Table 5.13 $\quad 4^{\text {th }}$ Grade 2012-2013 Math ISAT Proficiency

\begin{tabular}{|l|r|r||r|r|}
\hline & \multicolumn{2}{|c|}{ District 1 $(\mathrm{n}=34)^{*}$} & \multicolumn{2}{|c|}{ District 2 (n=32)* } \\
\cline { 2 - 3 } & $\begin{array}{l}\text { Proficient or } \\
\text { Better }\end{array}$ & $\begin{array}{l}\text { Below } \\
\text { Proficient }\end{array}$ & $\begin{array}{l}\text { Proficient or } \\
\text { Better }\end{array}$ & $\begin{array}{l}\text { Below } \\
\text { Proficient }\end{array}$ \\
\hline All 4 ${ }^{\text {th }}$ Graders* & $65 \%$ & $35 \%$ & $78 \%$ & $22 \%$ \\
\hline American Indian & $18 \%$ & $24 \%$ & $63 \%$ & $19 \%$ \\
\hline White & $12 \%$ & $0 \%$ & $6 \%$ & $0 \%$ \\
\hline Hispanic & $18 \%$ & $0 \%$ & $3 \%$ & $3 \%$ \\
\hline Two or More & $18 \%$ & $3 \%$ & $6 \%$ & $0 \%$ \\
\hline
\end{tabular}

Source: Education Analytics System of Idaho (EASI)

* Only includes students taking Math ISAT (between 1-4 students in each district did not take test)

In District1, American Indian students made up 18\% of the students scoring proficient or better, whereas in District 2 they made up 63\%.

In District 1, the rate of American Indian students scoring proficient or better on the math ISAT as a group was 43\%. In District 2, the rate of American Indian students scoring proficient or better on the math ISAT as a group was $77 \%$. Conversely, the rate of American Indian students scoring below proficient as a group in District 1 was 57\% compared to 23\% in District 2. 
Table 5.14 Rate of Proficiency for $4^{\text {th }}$ Grade 2012-2013 Math ISAT

\begin{tabular}{|l|r|r||r|r|}
\hline & \multicolumn{2}{|c||}{ District 1 $(\mathrm{n}=34)^{*}$} & \multicolumn{2}{|c|}{ District 2 $(\mathrm{n}=32)^{*}$} \\
\cline { 2 - 5 } & $\begin{array}{l}\text { Proficient or } \\
\text { Better }\end{array}$ & $\begin{array}{l}\text { Below } \\
\text { Proficient }\end{array}$ & $\begin{array}{l}\text { Proficient or } \\
\text { Better }\end{array}$ & $\begin{array}{l}\text { Below } \\
\text { Proficient }\end{array}$ \\
\hline American Indian & $43 \%$ & $57 \%$ & $77 \%$ & $23 \%$ \\
\hline White & $67 \%$ & $33 \%$ & $50 \%$ & $50 \%$ \\
\hline Hispanic & $100 \%$ & $0 \%$ & $100 \%$ & $0 \%$ \\
\hline Two or More & $86 \%$ & $14 \%$ & $100 \%$ & $0 \%$ \\
\hline
\end{tabular}

Source: Education Analytics System of Idaho (EASI)

* Only includes students taking Math ISAT (between 1-4 students in each district did not take test)

Evaluating the data by both the overall American Indian representation and the rate of representation by ethnic group, District 2 had a higher percentage of their $4^{\text {th }}$ grade American Indian students scoring proficient or better on the math ISAT, and a higher rate of American Indian students as a group scoring proficient or better than District 1 . These findings would suggest support for the theory of representative bureaucracy in that the presence of American Indian teachers in District 2 appears to have positively impacted performance of American Indian students in this category.

$\underline{4^{\text {th }} \text { Grade Reading ISAT }}$

A higher percentage of American Indian students in both districts scored proficient or better when compared to all other ethnic groups on the $4^{\text {th }}$ grade reading ISAT. Of the students scoring proficient or better on the $4^{\text {th }}$ grade reading ISAT, $59 \%$ of the students were American Indian in District 2, and 24\% were American Indian in District 1. American Indian students were the highest ethnic group of students scoring below proficient in both districts, making up $22 \%$ of the population scoring below proficient in District 2, and 15\% in District 1. 
Table 5.15 $\quad 4^{\text {th }}$ Grade 2012-2013 Reading ISAT Proficiency

\begin{tabular}{|l|r|l||l|r|}
\hline \multirow{2}{*}{} & \multicolumn{3}{|c|}{ District 1 (n=33)* } & \multicolumn{2}{c|}{ District 2 (n=32)* } \\
\cline { 2 - 5 } & $\begin{array}{l}\text { Proficient or } \\
\text { Better }\end{array}$ & $\begin{array}{l}\text { Below } \\
\text { Proficient }\end{array}$ & $\begin{array}{l}\text { Proficient or } \\
\text { Better }\end{array}$ & $\begin{array}{l}\text { Below } \\
\text { Proficient }\end{array}$ \\
\hline All 4 ${ }^{\text {th }}$ Graders* & $67 \%$ & $33 \%$ & $75 \%$ & $25 \%$ \\
\hline American Indian & $24 \%$ & $15 \%$ & $59 \%$ & $22 \%$ \\
\hline White & $9 \%$ & $3 \%$ & $6 \%$ & $0 \%$ \\
\hline Hispanic & $15 \%$ & $9 \%$ & $3 \%$ & $3 \%$ \\
\hline Two or More & $18 \%$ & $6 \%$ & $6 \%$ & $0 \%$ \\
\hline
\end{tabular}

Source: Education Analytics System of Idaho (EASI)

* Only includes students taking Reading ISAT (between 1-5 students in each district did not take test)

In District 1, the rate of American Indian students scoring proficient or better as a group was $62 \%$ on the reading ISAT, compared to $73 \%$ in District 2 . Conversely, the rate of American Indian students scoring below proficient as a group was 15\% in District 1, and $22 \%$ in District 2.

Table 5.16 Rate of Proficiency for $4^{\text {th }}$ Grade 2012-2013 Reading ISAT

\begin{tabular}{|l|r|r||r|r|}
\hline & \multicolumn{2}{|c|}{ District 1 (n=33)* } & \multicolumn{2}{c|}{ District 2 (n=32)* } \\
\cline { 2 - 3 } & $\begin{array}{l}\text { Proficient or } \\
\text { Better }\end{array}$ & $\begin{array}{l}\text { Below } \\
\text { Proficient }\end{array}$ & $\begin{array}{l}\text { Proficient or } \\
\text { Better }\end{array}$ & $\begin{array}{l}\text { Below } \\
\text { Proficient }\end{array}$ \\
\hline American Indian & $62 \%$ & $38 \%$ & $73 \%$ & $27 \%$ \\
\hline White & $63 \%$ & $38 \%$ & $50 \%$ & $50 \%$ \\
\hline Hispanic & $75 \%$ & $25 \%$ & $100 \%$ & $0 \%$ \\
\hline Two or More & $75 \%$ & $25 \%$ & $100 \%$ & $0 \%$ \\
\hline
\end{tabular}

Source: Education Analytics System of Idaho (EASI)

* Only includes students taking Math ISAT (between 1-4 students in each district did not take test)

Evaluating the data by both the overall American Indian representation and the rate of representation by ethnic group, District 2 had higher percentage of their $4^{\text {th }}$ grade American Indian students scoring proficient or better on the reading ISAT, and a higher rate of American Indian students as a group scoring proficient or better than District 1. These findings would suggest support for the theory of representative bureaucracy in that 
the presence of American Indian teachers in District 2 appears to have positively impacted performance of American Indian students in this category.

$\underline{4^{\text {th }} \text { Grade Language ISAT }}$

Most surprising when reviewing the $4^{\text {th }}$ grade language ISAT was that in both districts students scoring proficient or better were 10 percentage points less than those for the math and reading ISATs. In District 1, American Indian students made up 12\% of the students scoring proficient or better, compared to $47 \%$ in District 2. American Indian students in District 1 and District 2 made up the highest percentage of students scoring below proficient on the language IAST.

Table 5.17 $\quad 4^{\text {th }}$ Grade 2012-2013 Language ISAT Proficiency

\begin{tabular}{|l|r|l||l|r|}
\hline & \multicolumn{2}{|c|}{ District 1 $(\mathrm{n}=33)^{*}$} & \multicolumn{2}{|c|}{ District 2 (n=32)* } \\
\cline { 2 - 5 } & $\begin{array}{l}\text { Proficient or } \\
\text { Better }\end{array}$ & $\begin{array}{l}\text { Below } \\
\text { Proficient }\end{array}$ & $\begin{array}{l}\text { Proficient or } \\
\text { Better }\end{array}$ & $\begin{array}{l}\text { Below } \\
\text { Proficient }\end{array}$ \\
\hline All 4 ${ }^{\text {th }}$ Graders* & $52 \%$ & $48 \%$ & $63 \%$ & $38 \%$ \\
\hline American Indian & $12 \%$ & $27 \%$ & $47 \%$ & $34 \%$ \\
\hline White & $9 \%$ & $3 \%$ & $6 \%$ & $0 \%$ \\
\hline Hispanic & $15 \%$ & $12 \%$ & $3 \%$ & $0 \%$ \\
\hline Two or More & $15 \%$ & $6 \%$ & $6 \%$ & $3 \%$ \\
\hline
\end{tabular}

Source: Education Analytics System of Idaho (EASI)

* Only includes students taking Language ISAT (between 1-4 students in each district did not take test)

When evaluating the rate of proficiency by ethnic group on the language ISAT, only 24\% of American Indian students in District 1 scored proficient or better compared to $58 \%$ in District 2. 
Table 5.18 Rate of Proficiency for $4^{\text {th }}$ Grade 2012-2013 Language ISAT

\begin{tabular}{|l|r|r||r|r|}
\hline & \multicolumn{2}{|c|}{ District 1 $(\mathrm{n}=33)^{*}$} & \multicolumn{2}{|c|}{ District 2 (n=32)* } \\
\cline { 2 - 5 } & $\begin{array}{l}\text { Proficient or } \\
\text { Better }\end{array}$ & $\begin{array}{l}\text { Below } \\
\text { Proficient }\end{array}$ & $\begin{array}{l}\text { Proficient or } \\
\text { Better }\end{array}$ & $\begin{array}{l}\text { Below } \\
\text { Proficient }\end{array}$ \\
\hline American Indian & $24 \%$ & $53 \%$ & $58 \%$ & $42 \%$ \\
\hline White & $50 \%$ & $50 \%$ & $100 \%$ & $0 \%$ \\
\hline Hispanic & $75 \%$ & $25 \%$ & $100 \%$ & $0 \%$ \\
\hline Two or More & $71 \%$ & $29 \%$ & $67 \%$ & $33 \%$ \\
\hline
\end{tabular}

Source: Education Analytics System of Idaho (EASI)

* Only includes students taking Math ISAT (between 1-4 students in each district did not take test)

Evaluating the data by both the overall American Indian representation and the rate of representation by ethnic group and consistent with the results for the math and reading ISATs, District 2 had an overall higher percentage of American Indian students scoring proficient or better on the language ISAT, and a higher rate of American Indian students scoring proficient or better as a group than District 1. These findings would suggest support for the theory of representative bureaucracy in that the presence of American Indian teachers in District 2 appears to have positively impacted performance of American Indian students in this category. $\underline{8^{\text {th }} \text { Grade ISAT }}$

In 2012-2013, American Indian students made up 34\% of the total $8^{\text {th }}$ grade student population in District 1 , and $84 \%$ of the total $8^{\text {th }}$ grade student population in District 2. Overall, District 2 had 15 more $8^{\text {th }}$ grade students than District 1. In both Districts, an average of five students did not take the $8^{\text {th }}$ grade math, reading, or language ISAT; of those students 50\%-60\% across both districts were American Indian students. These numbers explain the discrepancy in categories not always adding up to $100 \%$. 
$\underline{8^{\text {th }} \text { Grade Math ISAT }}$

Overall, District 1 had a higher percentage of $8^{\text {th }}$ grade students scoring proficient or better on the math ISAT. However, a significantly higher percentage of American Indian students in District 2 scored proficient or better (41\%) when compared to District $1(14 \%)$. In District 1, 17\% of the students scoring below proficient were American Indian students, compared to $45 \%$ in District 2.

Table 5.19 $\quad 8^{\text {th }}$ Grade 2012-2013 Math ISAT Proficiency

\begin{tabular}{|l|r|r||r|r|}
\hline & \multicolumn{2}{|c||}{ District 1 $(\mathrm{n}=29)^{*}$} & \multicolumn{2}{|c|}{ District 2 (n=44)* } \\
\cline { 2 - 3 } & $\begin{array}{l}\text { Proficient or } \\
\text { Better }\end{array}$ & $\begin{array}{l}\text { Below } \\
\text { Proficient }\end{array}$ & $\begin{array}{l}\text { Proficient or } \\
\text { Better }\end{array}$ & $\begin{array}{l}\text { Below } \\
\text { Proficient }\end{array}$ \\
\hline All $8^{\text {th }}$ Graders* & $62 \%$ & $38 \%$ & $52 \%$ & $48 \%$ \\
\hline American Indian & $14 \%$ & $17 \%$ & $41 \%$ & $45 \%$ \\
\hline White & $14 \%$ & $7 \%$ & $2 \%$ & $0 \%$ \\
\hline Hispanic & $28 \%$ & $7 \%$ & $7 \%$ & $2 \%$ \\
\hline Two or More & $7 \%$ & $7 \%$ & $2 \%$ & $0 \%$ \\
\hline
\end{tabular}

Source: Education Analytics System of Idaho (EASI)

* Only includes students taking Math ISAT (between 5-6 students in each district did not take test)

While the rate of $8^{\text {th }}$ grade American Indian students scoring proficient or better as group on the math ISAT in District 2 (44\%) was higher than District $1(33 \%)$, American Indian students still have the lowest rate of proficiency compared to other ethnic groups.

Table 5.20 Rate of Proficiency for $8^{\text {th }}$ Grade 2012-2013 Math ISAT

\begin{tabular}{|l|r|r||r|r|}
\hline & \multicolumn{2}{|c||}{ District 1 $(\mathrm{n}=29)^{*}$} & \multicolumn{2}{c|}{ District 2 $(\mathrm{n}=44)^{*}$} \\
\cline { 2 - 3 } & $\begin{array}{l}\text { Proficient or } \\
\text { Better }\end{array}$ & $\begin{array}{l}\text { Below } \\
\text { Proficient }\end{array}$ & $\begin{array}{l}\text { Proficient or } \\
\text { Better }\end{array}$ & $\begin{array}{l}\text { Below } \\
\text { Proficient }\end{array}$ \\
\hline American Indian & $33 \%$ & $42 \%$ & $44 \%$ & $49 \%$ \\
\hline White & $67 \%$ & $17 \%$ & $60 \%$ & $20 \%$ \\
\hline Hispanic & $57 \%$ & $29 \%$ & $50 \%$ & $0 \%$ \\
\hline Two or More & $50 \%$ & $50 \%$ & $100 \%$ & $0 \%$ \\
\hline
\end{tabular}

Source: Education Analytics System of Idaho (EASI)

* Only includes students taking Math ISAT (between 4-6 students in each district did not take test) 
Evaluating the data by both the overall American Indian representation and the rate of representation by ethnic group, District 2 had an overall higher percentage of American Indian students scoring proficient or better on the $8^{\text {th }}$ grade math ISAT, and a higher rate of American Indian students scoring proficient or better than District 1. These findings would suggest support for the theory of representative bureaucracy in that the presence of American Indian teachers in District 2 appears to have positively impacted performance of American Indian students in this category.

$\underline{8^{\text {th }} \text { Grade Reading ISAT }}$

Both districts showed more than $86 \%$ of $8^{\text {th }}$ grade students scoring proficient or better on the reading ISAT. In both districts, American Indian students were the largest of all ethnic groups scoring below proficient. In District 2, American Indian students were the only students to score below proficient on the reading ISAT. In District 1 American Indian students made up $24 \%$ of the students scoring proficient or better, compared to $78 \%$ in District 2.

Table 5.21 $8^{\text {th }}$ 2012-2013 Grade Reading ISAT Proficiency

\begin{tabular}{|c|c|c|c|c|}
\hline & \multicolumn{2}{|c|}{ District $1(\mathrm{n}=29)^{*}$} & \multicolumn{2}{|c|}{ District $2(n=45)^{*}$} \\
\hline & $\begin{array}{l}\text { Proficient or } \\
\text { Better }\end{array}$ & $\begin{array}{l}\text { Below } \\
\text { Proficient }\end{array}$ & $\begin{array}{l}\text { Proficient or } \\
\text { Better }\end{array}$ & $\begin{array}{l}\text { Below } \\
\text { Proficient }\end{array}$ \\
\hline All $8^{\text {th }}$ Graders* & $86 \%$ & $14 \%$ & $91 \%$ & $9 \%$ \\
\hline American Indian & $24 \%$ & $7 \%$ & $78 \%$ & $9 \%$ \\
\hline White & $17 \%$ & $3 \%$ & $2 \%$ & $0 \%$ \\
\hline Hispanic & $34 \%$ & $0 \%$ & $9 \%$ & $0 \%$ \\
\hline Two or More & $10 \%$ & $3 \%$ & $2 \%$ & $0 \%$ \\
\hline
\end{tabular}

Source: Education Analytics System of Idaho (EASI)

* Only includes students taking Reading ISAT (between 4-6 students in each district did not take test)

In District 1 the rate of American Indian students scoring proficient or better was $58 \%$ compared to $85 \%$ in District 2. 
Table 5.22 Rate of Proficiency for $8^{\text {th }}$ Grade 2012-2013 Reading ISAT

\begin{tabular}{|l|r|r||r|r|}
\hline & \multicolumn{2}{|c||}{ District 1 $(\mathrm{n}=29)^{*}$} & \multicolumn{2}{c|}{ District 2 (n=45)* } \\
\cline { 2 - 4 } & \multicolumn{1}{|c|}{$\begin{array}{l}\text { Proficient or } \\
\text { Better }\end{array}$} & $\begin{array}{l}\text { Below } \\
\text { Proficient }\end{array}$ & $\begin{array}{l}\text { Proficient or } \\
\text { Better }\end{array}$ & $\begin{array}{l}\text { Below } \\
\text { Proficient }\end{array}$ \\
\hline American Indian & $58 \%$ & $17 \%$ & $85 \%$ & $10 \%$ \\
\hline White & $83 \%$ & $0 \%$ & $80 \%$ & $0 \%$ \\
\hline Hispanic & $71 \%$ & $14 \%$ & $50 \%$ & $0 \%$ \\
\hline Two or More & $75 \%$ & $25 \%$ & $100 \%$ & $0 \%$ \\
\hline
\end{tabular}

Source: Education Analytics System of Idaho (EASI)

* Only includes students taking Math ISAT (between 4-6 students in each district did not take test)

Evaluating the data by the overall American Indian representation and the rate of representation by ethnic group, a significant higher percent of American Indian students in District 2 scored proficient or better than in District 1. These findings would suggest support the theory of representative bureaucracy in that the presence of American Indian teachers in District 2 appears to have positively impacted performance of American Indian students in this category. $\underline{8^{\text {th }} \text { Grade Language ISAT }}$

District 1 had a higher percentage of the overall $8^{\text {th }}$ grade population scoring proficient or better (62\%) on the language ISAT than District $2(45 \%)$. However, District 2 American Indian students made up a higher percentage of students scoring proficient or better (36\%) than District $1(10 \%)$. In District 2 American Indian students made up 50\% of the students scoring below proficient and $21 \%$ of the students in District 1. 
Table 5.23 $\quad 8^{\text {th }}$ 2012-2013 Grade Language ISAT Proficiency

\begin{tabular}{|l|r|r||r|r|}
\hline & \multicolumn{2}{|c||}{ District 1 $(\mathrm{n}=29)^{*}$} & \multicolumn{2}{c|}{ District 2 $(\mathrm{n}=44)^{*}$} \\
\cline { 2 - 5 } & $\begin{array}{l}\text { Proficient or } \\
\text { Better }\end{array}$ & $\begin{array}{l}\text { Below } \\
\text { Proficient }\end{array}$ & $\begin{array}{l}\text { Proficient or } \\
\text { Better }\end{array}$ & $\begin{array}{l}\text { Below } \\
\text { Proficient }\end{array}$ \\
\hline All $8^{\text {th }}$ Graders* & $62 \%$ & $38 \%$ & $45 \%$ & $55 \%$ \\
\hline American Indian & $10 \%$ & $21 \%$ & $36 \%$ & $50 \%$ \\
\hline White & $7 \%$ & $14 \%$ & $2 \%$ & $0 \%$ \\
\hline Hispanic & $34 \%$ & $0 \%$ & $7 \%$ & $2 \%$ \\
\hline Two or More & $10 \%$ & $3 \%$ & $0 \%$ & $2 \%$ \\
\hline
\end{tabular}

Source: Education Analytics System of Idaho (EASI)

* Only includes students taking Language ISAT (between 5-6 students in each district did not take test)

In both districts, the rate of $8^{\text {th }}$ grade American Indian students scoring proficient

or better as a group on the language ISAT was less than the rate for all ethnic groups,

except in one instance. In District 1, the rate of American Indian students scoring proficient or better (39\%) as group was higher than District 2 (25\%). In both districts, the rate of American Indian students scoring below proficient was more than $50 \%$.

Table 5.24 Rate of Proficiency for $8^{\text {th }}$ Grade 2012-2013 Language ISAT

\begin{tabular}{|l|r|r||r|r|}
\hline & \multicolumn{2}{|c||}{ District 1 $(\mathrm{n}=29)^{*}$} & \multicolumn{2}{|c|}{ District 2 (n=44)* } \\
\cline { 2 - 4 } & \multicolumn{1}{|l|}{$\begin{array}{l}\text { Proficient or } \\
\text { Better }\end{array}$} & $\begin{array}{l}\text { Below } \\
\text { Proficient }\end{array}$ & $\begin{array}{l}\text { Proficient or } \\
\text { Better }\end{array}$ & $\begin{array}{l}\text { Below } \\
\text { Proficient }\end{array}$ \\
\hline American Indian & $25 \%$ & $50 \%$ & $39 \%$ & $54 \%$ \\
\hline White & $83 \%$ & $0 \%$ & $60 \%$ & $20 \%$ \\
\hline Hispanic & $26 \%$ & $57 \%$ & $50 \%$ & $0 \%$ \\
\hline Two or More & $75 \%$ & $25 \%$ & $0 \%$ & $100 \%$ \\
\hline
\end{tabular}

Source: Education Analytics System of Idaho (EASI)

* Only includes students taking Math ISAT (between 4-6 students in each district did not take test)

Evaluating the data by the overall American Indian representation, District 2 had a higher overall percentage, as well as the rate of proficiency as a group for American Indian students scoring proficient or better than District 1. These findings would suggest support for the theory of representative bureaucracy in that the presence of American Indian teachers in District 2 appears to have positively impacted performance of American Indian students in this category. 


\section{Disciplinary Actions}

Both school districts report using Positive Behavior Interventions and Support (PBIS) as a district-wide philosophy and practice. PBIS is a national model funded by the U.S. Department of Education's Office of Special Education Programs and the Office of Elementary and Secondary Education. Simplistically, PBIS is focused on the teaching and reinforcement of positive behavioral expectations, rather than waiting for misbehavior to occur and then punishing students for misbehavior.

In the 2015 Federal Civil Rights data, District 1 reported a much higher percent (43\%) of their total student population receiving in-school and out-of-school suspensions compared to District $2(9 \%)$. In both districts, American Indian students made up largest of all ethnic groups receiving in-school and out-of-school suspensions.

Table 5.25 Percent of Students Receiving Disciplinary Actions

\begin{tabular}{|c|c|c|c|c|}
\hline & \multicolumn{2}{|c|}{ District $1(n=348)$} & \multicolumn{2}{|c|}{ District $2(n=496)$} \\
\hline & $\begin{array}{l}\text { In-School } \\
\text { Suspensions }\end{array}$ & $\begin{array}{l}\text { Out-of-School } \\
\text { Suspensions }\end{array}$ & $\begin{array}{l}\text { In-School } \\
\text { Suspensions }\end{array}$ & $\begin{array}{l}\text { Out-of-School } \\
\text { Suspensions }\end{array}$ \\
\hline $\begin{array}{l}\text { Total Receiving } \\
\text { Suspensions }\end{array}$ & 96 & 55 & 15 & 29 \\
\hline American Indian & $42 \%$ & $66 \%$ & $87 \%$ & $66 \%$ \\
\hline White & $22 \%$ & $20 \%$ & $13 \%$ & $21 \%$ \\
\hline Hispanic & $4 \%$ & $0 \%$ & $0 \%$ & $0 \%$ \\
\hline Two or More & $32 \%$ & $15 \%$ & $0 \%$ & $14 \%$ \\
\hline
\end{tabular}

Source: 2015 Federal Civil Rights Data

According to the 2015 Federal Civil Rights Data, in addition to in-school and outof-school suspensions, District 1 reported ten student referrals to law enforcement: $40 \%$ were American Indian students, $40 \%$ were white students, and 20\% were two or more races. District 2 reported four student referrals to law enforcement, 100\% were American Indian students. 
Existing research (Meier et al., 1989; Meier et al., 1999; Meier \& Stewart, 1991; Wright et al., 1998) supports that students in special education may also face disproportionately higher disciplinary actions as a form of second generation discrimination. When evaluating the 2015 Federal Civil Rights data, both districts have more than double the percentage of American Indian students in special education who also received disciplinary actions when compared to all other ethnic groups.

Table 5.26 Special Education Students Receiving Disciplinary Actions by Race/Ethnicity

\begin{tabular}{|l|r|r||r|r|}
\hline & \multicolumn{2}{|c|}{ District 1 $(\mathrm{n}=71)^{*}$} & \multicolumn{2}{|c|}{ District 2 (n=105) } \\
\cline { 2 - 5 } & $\begin{array}{l}\text { In-School } \\
\text { Suspensions }\end{array}$ & $\begin{array}{l}\text { Out-of-School } \\
\text { Suspensions }\end{array}$ & $\begin{array}{l}\text { In-School } \\
\text { Suspensions }\end{array}$ & $\begin{array}{l}\text { Out-of-School } \\
\text { Suspensions }\end{array}$ \\
\hline Total Students** & 18 & 16 & 6 & 12 \\
\hline American Indian & $61 \%$ & $63 \%$ & $100 \%$ & $67 \%$ \\
\hline White & $11 \%$ & $13 \%$ & $0 \%$ & $0 \%$ \\
\hline Hispanic & $0 \%$ & $0 \%$ & $0 \%$ & $0 \%$ \\
\hline Two or More & $28 \%$ & $25 \%$ & $0 \%$ & $33 \%$ \\
\hline
\end{tabular}

*Total students in the district in special education

**Total students in the district in special education and also receiving a suspension Source: 2015 Federal Civil Rights Data

While District 2 had a smaller percentage of their overall special education population also receiving disciplinary actions than District 1, a slightly higher percentage of District 2 students are American Indian. In both districts, American Indian special education students make up the highest percentage of all ethnic groups receiving disciplinary actions. These findings would not demonstrate patterns that support the theory of representative bureaucracy in that the presence of American Indian teachers in District 2 appears to not have positively impacted performance of American Indian students in this category.

One data element not traditionally evaluated in prior representative bureaucracy research (Meier et al., 1989; Meier et al., 1999; Meier \& Stewart, 1991; Wright et al., 
1998 ) is the impact disciplinary actions have on attendance as a result of out-of-school suspensions. According to the 2015 Federal Civil Rights data District 1 shows students missing $68 \%$ more days of school due to out-of-school suspensions than District 2. As discussed previously, absences impact student performance and increased absences, regardless of reason, impact student retention and performance particularly in high school grades. District 1 data show that American Indian students are missing more days due to out-of-school suspensions than District 2.

Because both school districts use the same disciplinary model, disciplinary actions may more easily be tied to representation than if they were using different disciplinary models. Research by Roch, Pitts, and Navarro (2010) support that in schools where teachers are representative of the student population there are less frequent punitive disciplinary actions and teachers are more likely to implement practices that are more rehabilitatively focused.

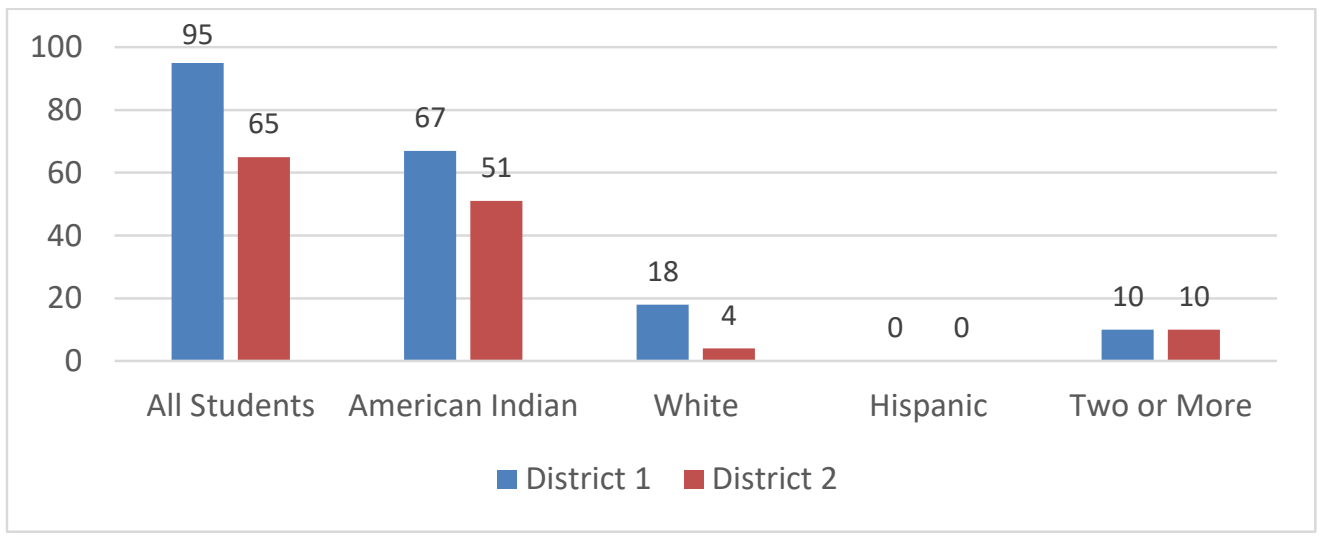

Source: 2015 Federal Civil Rights Data

\section{Chart 5.5 Days Missed Due to Out-of-School Suspensions by Race/Ethnicity}

These findings would suggest support for the theory of representative bureaucracy in that the presence of American Indian teachers in District 2 appears to limit both the number of and total days American Indian students miss for out-of-school suspensions 
thereby suggesting a positive impact for performance of American Indian students in this category.

\section{$\underline{\text { SAT/ACT College Entrance Exams }}$}

Idaho pays for every public high school junior to take the SAT, students may also choose to pay for and take the ACT. District 2 data reveal that a much higher percentage of American Indian students $(85 \%)$ take the SAT/ACT college entrance exams than District $1(27 \%)$.

Table 5.27 Percent of $11^{\text {th }}$ Grade Students Taking SAT/ACT by Type

\begin{tabular}{|c|c|c|c|c|}
\hline & \multicolumn{2}{|r|}{ District 1} & \multicolumn{2}{|r|}{ District 2} \\
\hline & $\begin{array}{l}\text { District } \\
\text { Enrollment }\end{array}$ & $\begin{array}{l}\text { Taking } \\
\text { SAT/ACT }\end{array}$ & \begin{tabular}{|l|} 
District \\
Enrollment
\end{tabular} & $\begin{array}{l}\text { Taking } \\
\text { SAT/ACT }\end{array}$ \\
\hline $11^{\text {th }}$ Grade Students & $23^{1}$ & $15^{2}$ & $30^{1}$ & $47^{2}$ \\
\hline American Indian & $47 \%$ & $27 \%$ & $80 \%$ & $85 \%$ \\
\hline White & $25 \%$ & $47 \%$ & $5 \%$ & $15 \%$ \\
\hline Hispanic & $13 \%$ & $13 \%$ & $1 \%$ & $0 \%$ \\
\hline Two or More & $15 \%$ & $13 \%$ & $5 \%$ & $0 \%$ \\
\hline
\end{tabular}

${ }^{1}$ Using 2014-15 State Department of Education Net Enrollment School Report

${ }^{2}$ Using the 2015 Federal Civil Rights SAT/ACT Enrollment data

These data would suggest support for the theory of representative bureaucracy in that the presence of American Indian teachers in District 2 appears to have positively impacted performance of American Indian students in this category.

\section{Graduation Rates}

Graduation rates are another important factor when evaluating student performance. The first year Idaho began using the federal four-year adjusted cohort graduation rate was 2013-2014. The four-year adjusted cohort graduation rate is based on the number of students who graduate in four years with a regular high school diploma, divided by the number of students who entered high school four years earlier, while adjusting for transfer students or those who emigrated or are deceased. In 2018, Idaho's 
four-year adjusted cohort graduation rate was $81 \%$. The four-year adjusted cohort graduation rate for District 1 was $59 \%$ and in District 2 was $84 \%$. The data by ethnic groups was not provided by the state, nor was it reported in the 2015 Federal Civil Rights data. Therefore, while important, these data were not part of my analysis.

\section{Summary of Performance Data}

Six data elements were evaluated under performance over a three-year period, looking at district and student-level data for $4^{\text {th }}, 8^{\text {th }}$ and $11^{\text {th }}$ grades. One data element selected (Graduation Rates) did not yield meaningful data due to lack of availability of student-level data. For the remaining five elements there were four areas in District 2 where data demonstrated patterns that support the theoretical model of representative bureaucracy in that performance for American Indian students appears to have been positively impacted by the presence of American Indian teachers. Consequently, the data reviewed under performance would appear to suggest that the theoretical model of representative bureaucracy (the presence of American Indian teachers) appears to have positively impacted performance for American Indian students in District 2.

Table 5.28 American Indian Student Performance Represented Positively

\begin{tabular}{|l|r|r|}
\hline Performance Data Reviewed & District 1 & \multicolumn{1}{|c|}{ District 2 } \\
\hline Attendance & Yes & No \\
\hline $4^{\text {th }}$ Grade ISAT (math, reading, language) & No & Yes \\
\hline $8^{\text {th }}$ Grade ISAT (math, reading, language) & No & Yes \\
\hline Disciplinary Actions & No & Yes \\
\hline SAT/ACT & No & Yes \\
\hline Graduation Rates & VOID & VOID \\
\hline
\end{tabular}

Through empirical analysis of the six data elements under access and the six data elements under performance, I sought to determine if the passive representation of American Indian teachers in the school districts positively impacted access and 
performance for American Indian students. In evaluating the metrics associated with access, the results suggests that American Indian students in District 2 were more positively impacted than American Indian students in District 1. In evaluating the metrics associated with performance, the results also suggest that American Indian students in District 2 appear to be more positively impacted by the presence of American Indian teachers, than American Indian students in District 1. If these data hold true, based on the theory of representative bureaucracy, passive representation should lead to active representation (policy outputs that positively impact American Indian students) and therefore likely lead to more culturally relevant curriculum and teaching practices within District 2.

\section{Interviews}

My interview questions were developed in advance and based on the American Indian literature reviews (Wilkins \& Lamawaima, 2001; Corntassel \& Witmer, 2008; Deloria \& Wildcat, 2001; Fletcher, 2008; Nuby \& Smith, 2012; Reyhner \& Eder, 2004; Reyhner, 2018). As a member of the Idaho Indian Education Committee for more than a decade, there are several themes that consistently come up in our discussions. I wanted to evaluate the themes/concepts to determine if certain factors held true in these two school districts. As previous research has supported (Wright et al., 1998; Monk, 2007), failure to recognize the unique and nuanced elements of school(s) and districts does them a disservice. I was quickly reminded that each community was very unique and the historical relationship with the local tribe added an additional layer of complexity. There were existing sentiments of tension and racism between the tribes/tribal members and other non-native community members, as explored in Chapter 4. Preliminarily it may 
appear that the passive representation of American Indian teachers might lead to culturally relevant curriculum and teaching practices in District 2. However, presence of the STEP grants in both districts are also demonstrating mechanisms to establish culturally relevant curriculum practices being conducted to varying degrees. Evaluation of the significance of the STEP grants on representation warrants further research.

\section{Tribal Education Department (TED) Interview Observations}

My interview questions with TEDs focused on three themes, determined to ascertain perceptions of their ability to influence policies that impact American Indian students in their local school district; to understand the TEDs' perspective of whether or not academic grouping of American Indian students was actively happening in the school district; and whether or not TEDs believed teachers and district administrators had a vested interest in the communities.

Overall, the TED in District 1 was passionate about evaluating educational opportunities and tracking the progress of their tribal students through the education pipeline (K-20). They had developed a visual representation of the Tribe's education pipeline. While they felt like they had a strong working relationship with the Superintendent, their relationship with the school board and the principals did not seem as strong, and those perceptions seemed to be felt on both sides. They shared repeated concerns about the equity of educational offerings and the quality of facilities for their students in District 1 . They felt that the condition of the facilities was appalling, and this concern was shared by other administrators in the district. The TED and an administrator shared that the Tribe conducts an annual Communities that Care survey, and student perceptions were that the community doesn't support them and the condition of their 
school is indicative of that lack of support. The TED also believes the school district needs to be more intentional about parent engagement, and having parents at the table for process discussions, particularly in mental health matters.

Overall, the TED in District 2 wanted to see TEDs, LEAs, and SEAs working more intentionally regarding decisions that impact American Indian students. They shared frustrations that one of their own American Indian school board members didn't send their child to the school district, but sent them to the next town over. Trying to educate school board members and teachers what it meant to teach culturally was one of their most important and challenging work. While they felt like their best relationships were with all administrators in the school district, they did not appear to have a strong relationship with the school board. They felt like administrators in the school district understood the importance of teaching culturally.

\section{1) Collaboration with School District}

The TED expressed having built a strong relationship over the years with the Superintendent in District 1. The TED is asked to be part of search committees for principal positions, but not teachers. They shared that even if they were asked to be part of teacher searches, they would likely not have time. Based on interviews, it appears that the TED, which has 15 employees (not including the 35 employed at the early childhood program), is in direct competition with the school district for American Indian teacher positions, as the TED requires a bachelor's degree and teaching licensure for many of the positions in their department. While they have attempted to work collaboratively with the school district in recruiting tribal students, the TED indicated that there is a fundamental lack of interest by tribal members in pursuing teaching as a profession. The Tribal 
Chairman has directed the TED to do whatever necessary to increase the number of Tribal members who become teachers, but that it has been extremely difficult, especially given teacher salaries in Idaho.

The TED provides and annual report to the school board, and provides updates on any new grants received that support students in District 1 . The TED is able to receive student-level data for any student who signs a waiver in District 1 , and this has helped increase their awareness of the diversity of student needs across the district. The Education Pipeline report prepared by the TED has helped guide conversations with the district administration, and allowed them to better self-govern education as a tribe. The focus of the STEP grant in District 1 is primarily on developing $4^{\text {th }}$ grade curriculum that is specific to the local tribe. There are two teachers in District 1 who are engaged in these efforts. In addition, the TED shared the use of traditional language and the Tribe's Five Pillars (stewardship, guardianship, membership, scholarship, and spirituality) in the classes that are part of the STEP project is a demonstration of increased engagement. One school district principal shared that there are efforts in progress to better integrate the Tribe's Five Pillars into their school's philosophies and that it is a priority for them.

The TED in District 2 believes they have a successful relationship with administrators in the district. They employ approximately 65 employees. They occasionally provide updates to the school board and have invited school board members multiple times to attend their annual STEP education summit, but none have attended. The TED meets monthly with the school district superintendent and principals in District 2. Sometimes the TED is invited to participate in hiring administrator positions, and most recently the music teacher, but that they were generally not involved in hiring teachers. 
The TED shared that they have been told American Indian teachers are not competitive for the few teaching jobs that become available in the school district. They were told it was because the American Indian teachers applying did not have teaching experience. However, the TED would then observe the school district hiring non-native teachers who were first-year teachers just out of college. The TED supported training on the Charlotte Danielson framework as part of their STEP grant for all certified teachers in the school district and American Indian teachers who were licensed but not teaching in District 2, in effort to help their local American Indian teachers become more competitive.

While the TEDs are engaged in increasing the passive representation of American Indian teachers in their respective school districts, there appears to be greater interest by American Indians to become teachers in District 2.

\section{2) Perceptions of American Indian Student Success}

The TED in District 1 indicated that success for their students meant successfully progressing through the education pipeline (graduating high school and receiving some form of postsecondary certificate or degree). The TED believes there are significant equity issues for students in District 1 . They shared concerns about the age and condition of the middle/high school facility, the lack of science equipment, and Career Technical Education (CTE) program offerings for students. The TED indicated there is a lack of career options for students who cannot, or choose not to, pursue postsecondary academic degrees.

In addition to the STEP grant, the TED in District 1 has a number of federal grants that support students in District 1 . They have a Native Youth Community Project (NYCP) grant that supports college and career preparation for $5^{\text {th }}$ through $8^{\text {th }}$ grades, and 
has both a day and afterschool component. They were recently awarded another NYCP grant focused on career preparation and dual enrollment for 9-12 grade students. They offer a summer leadership camp for youth ages 14-18. They have a Mentor Artist Program where 10 students are accepted to work with a mentor and write a play where American Indian actors from Hollywood will travel to the communities and perform their plays. They are in their last year of the Native American Career Technical Education Program, which they have had for 11 years. This has supported students who want to earn a certificate or two-year degree post-high school. This grant has allowed the Tribe to use their own funds to provide increased support for students wishing to earn bachelor's or graduate degrees. The grants obtained by the TED provide increased educational support to students in the district.

The TED in District 2 is working with their Advisory Board to help define benchmarks for success, but they would define success as students becoming engaged in their own education. They believe that in order for students to realize success, teachers must be engaging the students and ensuring that students see the relevance of their education to their lives, and how the education will enable them to support their community. The TED in District 2 shared concerns about American Indian boys receiving greater disciplinary actions and observing more American Indian boys in the front office cubicles where students who are in trouble are placed. To address concerns that half as many of their tribal boys as tribal girls are going to college, they established a mentoring program, supported by a grant, targeted at middle/high school American Indian boys. The TED in District 2 is concerned that the middle/high school is offering fewer advanced opportunities than in the past as result of loss of staffing. They felt this 
created an access and equity gap for American Indian students. The ability to partner together with the school district and bring in elders, who work with a teacher of record, to offer the local Tribe's language is an incredible value to their students.

In addition to the two STEP grants, the TED in District 2 also has a number of federal grants that support students in District 2. They have a Head Start program; a vocational rehabilitation program that supports students 16 years or older who have disabilities; a student success program focused on health promotion and prevention programs; a middle/high school college and career mentoring program focused on mentoring American Indian boys; and postsecondary scholarships for students who are tribal members.

\section{3) Perceptions of Teacher/Administrator Engagement with Community}

The TED in District 1 did not share perceptions of teacher or administrator engagement with the community. While they grew up outside the community, they currently only lived in the community during the week, traveling home each weekend (more than an hour away). According to the TED, historically their Tribe was distributed in bands, and the bands were established around the river and the lake. Now, the bands are more defined in terms of communities, and there are various characteristics and politics that make up each of those communities. They believe this creates challenges in building a more unified community concept to support the students. One of the major elements of their STEP grant was to ensure that their tribal history, as told by their elders, becomes part of Idaho history. They are trying to undo the mindset that students are bringing in from the community and their families, which is why the STEP grant is also 
focused on infusing the Tribe's Five Pillars into the school district lessons. They are trying to create better citizens who are more engaged in the success of their communities.

The TED in District 2 talked about the importance of teachers being tied to the community and that American Indian teachers generally had that advantage over nonnative teachers. They shared that the concept of families having children and family members all over the country was foreign to their own concept of family and communities. Their family (which extends beyond parents and children) almost all live within a few hours of each other, and being part of the community was very important. Their STEP grants have a significant community engagement component and recognition that families are the first educators.

Overall, both TEDs believe they have strong working and collaborative relationships with Superintendents. The STEP grants have provided a framework to build on their relationships in ways they believe will better support students. Both TEDs shared concerns about lack of access to programs in the high schools that would better support American Indian student opportunities for postsecondary training/education after high school. Neither TED expressed concerns that their students were given less access than students of other ethnic groups. However, the TED in District 1 shared significant concerns over the facilities for the middle/high school. The TED in District 2 expressed a greater emphasis on the importance of representation of teachers and administrators being part of the local community.

While there is passive representation (presence of American Indian teachers) in District 2, the success of the STEP grant in integrating the Tribe's cultural standards and the Tribe's ability to provide increased professional development related to teaching 
culturally appears to be taking on the form of active representation. While to a somewhat lesser degree, there are also instances of active representation in District 1 as a result of the STEP grant (see Chapter 4 for specifics). The STEP grants in both districts articulate a clear role for the tribes to have a voice in the education of American Indian students attending public schools on their reservations. The representation of the tribes through these grants goes beyond supporting engagement between districts and tribes, but provides a mechanism for non-native teachers to work with tribal education leaders to develop culturally relevant curriculum.

\section{Administrator Interview Observations}

District 1 administrators all shared that their school is perceived externally as being a challenging or troubled school, and those perceptions impact hiring and availability of substitute teachers. The substitute teacher pool for the entire district consists of 11 potential substitutes. One of the days of my interviews, six teachers across the district were out sick and none of the 11 substitute teachers were available. The District was also struggling to fill three vacant positions that provide critical student support services for various programs across the district. I was able to attend a school board meeting during the week I conducted interviews. They discussed the challenges with staffing and concerns they had about teachers coming to work sick because they understand there is no one to cover their classes if they are absent. There were no discussions of possible solutions or strategies to address these challenges. District 1 administrators shared that their art and music teachers support the entire district, limiting the number of electives offered for middle/high school students. 
From a physical representation, the middle/high school facilities are clearly dated and lack technological currency. The elementary school was built in 2012 and is therefore newer, and from a physical representation, more welcoming. While there were minimal culturally relevant pictures, artwork, or other representation of the local tribe, the elementary school does have a mural of the Heart of the Monster, the creation story for many of the Pacific Northwest tribes.

District 2 administrators spoke highly of their school and the students in the district, often referring to it as a very special place. One school administrator shared that while there were external perceptions that because they were a reservation school it was a dangerous or difficult place, when student teachers came to the school they often do not want to leave. The school district has seen very little turnover of teachers, and one administrator referenced that they are either lifers or leavers. From a physical representation, District 2 facilities appeared less dated, and the District 2 middle/high school walls were full of native paintings and pictures.

\section{1) Recruitment \& Retention for American Indian Teachers}

District 1 administrators shared that up to $80 \%$ of the teachers in one of the schools had historically turned over on a regular basis. They feel that while they still struggle with retention, the turnover is not quite as bad as it was. While District 1 does not have an active strategy in place to recruit American Indian teachers, principals actively support and encourage American Indian paraprofessionals in their schools to pursue earning their teaching credentials. District 1 Superintendent and TED have worked together over the years to try and actively recruit and support American Indian students going into teaching professions, but have not identified successful strategies to 
date. While there are no active strategies for recruiting American Indian teachers, the frequent availability of positions provides an avenue to hire American Indian teachers in District 1 due to their higher turnover of teachers.

District 2 shared that, similar to District 1, the available pool of American Indian applicants has historically been limited or non-existent. District 2 administrators all encourage and support American Indian paraprofessionals in their schools pursuing teaching credentials. District 2 referenced working closely with the University of Idaho's IKeep program, which is an Indian Education Professional Development grant from the Office of Indian Education focused on training American Indian students to complete pre-service education programs with a focus on indigenous and culturally responsive pedagogy.

Administrators in District 2 also shared that they try to be strategic about ensuring teachers hired understand culturally responsive teaching and that they have attitudes and philosophies that would be a good fit for American Indian students. District 2 experiences significantly less turnover than District 1, particularly in the elementary school. While minimal, the middle/high school has seen greater turnover and could be an area of opportunity for recruiting American Indian teachers.

\section{2) Curriculum Development/Cultural Relevance}

District 1 utilizes leadership groups, both at a district level (mostly administrators) and at the school level (combination of administrators, teachers, and other staff) for review of new curriculum proposals. Ultimately the school board has final approval of new curriculum. District 1 leadership shared that their curriculum needed updating and that it was starting to date itself. All administrators mentioned concerns about costs and 
associated teacher time for developing new curriculum as limiting factors. As part of the STEP grant, the District is working closely with the TED and $4^{\text {th }}$ grade teachers as they are developing and piloting the use of culturally relevant curriculum materials. The curriculum is focused on $4^{\text {th }}$ grade history and specific to the local Tribe. While there is eagerness and support for the expansion of this work in more grades across the school district, it's a very labor and time intensive process they believe must be led by the Tribe.

District 2 also uses various leadership groups, at both the district (mostly administrators) and at the school level (combination of administrators, teachers, and other staff) for review of new curriculum proposals. Ultimately the school board has final approval of new curriculum. District 2 refers to their school-level leadership groups as Professional Learning Communities (PLC). District 2 efforts regarding curriculum are very research based, and the PLCs actively review and assess the impacts of the curriculum. This is likely supported by the three hours each week that the school district devotes to professional development (one hour Wednesday morning and two hours Friday afternoon). All administrators consistently referenced using curriculum models with national recognition that were backed by research. They also discussed evaluating efficacy of curriculum by assessing student performance as part of their weekly professional development time. District 2 has a Culturally Responsive Learning PLC that is a resource to all other PLCs and teachers in general. In addition, as part of the STEP grant they created a Culture and Language team and the Superintendent is a co-lead on that team. Administrators also talked about being a trauma informed school and how that impacts their approach and engagement with students and parents/guardians. 


\section{3) Tribal and Community Engagement}

District 1 has several community/parent advisory groups as a requirement of being in school improvement or related to federal grant requirements. While only one administrator lives in the community, all administrators attended community events when possible. The Superintendent spoke most about the value of the partnership with the TED and the impact of the STEP grant increasing student engagement. They have seen increased participation by students in the classroom, and while it hasn't realized better attendance they are optimistic it will. They recognize much of the tribal curriculum effort must be led by the Tribe, and time and staffing constraints for both the district and the TED appear challenging. They would love to offer a language class, but the lack of availability of native speakers and tribal resources to support this work have made it challenging.

District 2 has several community/parent advisory groups, also as a requirement of being in school improvement or related to federal grant requirements. While only one administrator lives in the community, all administrators attend community events when possible. The Superintendent meets regularly with the Circle of Elders, in addition to the Tribal Council. One school administrator shared that while they commit to long days $(7 \mathrm{am}-8 \mathrm{pm})$ in the school, they are often rated poorly for not being at enough community events. However, almost every teacher and administrator commented on this administrator's commitment to the students, and several shared the example of how this administrator walks students from their school to their nearby homes or the Boys \& Girls Club every day after school. District 2 administrators appear to have strong connections not only with the TED, but also tribal elders and tribal leaders in the community. District 
2 also has one administrator who is from the local tribal community and American Indian.

Administrators in both districts were very passionate about their students and the schools that they serve. While both districts support a grow your own philosophy for paraprofessionals earning teaching credentials, only District 2 is actively working with nearby universities. District 2 administrators all spoke about teaching culturally and that finding teachers who understand what that means and are able to work in the community is more important than representation. In addition, they all discussed being a trauma informed school.

Overall, administrators in both districts were willing and eager to engage with their local Tribes' tribal education department staff. They recognized the value and knowledge contribution that the tribes bring to the schools with regard to culture and connection with the community. Administrator confusion and frustration with student attendance highlighted a greater need for the local understanding of the federal government's historical use of education as a tool for cultural destruction of American Indian communities. Beginning a dialogue between the tribes and the school district boards, administrators, and teachers would create greater awareness of the phenomenon of intergeneration trauma. While this was happening to some degree in District 2, more directly addressing the impacts could positively impact attendance and engagement than may policy changes.

\section{Teacher Interview Observations}

Teachers in both districts were very passionate about working in each of their respective districts, and all expressed commitment to students succeeding. All of the 
teachers who agreed to be interviewed in District 1 had been there four years or less, and had teaching experience that ranged from 2-40 years. Only one teacher talked about professional development time, which consists of an early release every second Wednesday. None of the five teachers interviewed in District 1 were American Indian Teacher experience in District 2 ranged from 1-47 years. Two of the teachers were in their first year teaching in the district and three had been there between 11-47 years. All of the teachers talked about their PLCs and the time they have for professional development and collaboration. One of the five teachers interviewed in District 2 were American Indian.

\section{1) Use of Culturally Relevant Curriculum/Teaching Culturally}

Teachers in the elementary school in District 1 indicated that curriculum is fairly prescribed and they have some flexibility to use supporting materials. However, as part of the STEP grant, District 1 has two elementary teachers who have one day a month where they work with a team to develop culturally relevant curriculum. The TED established a team consisting of university educators, TED staff, and teachers from the district who are collaboratively developing $4^{\text {th }}$ grade curriculum related to the local Tribe's history, and they have developed four of the seven units. In these two elementary classes, the teachers have greater flexibility. In addition to the curriculum the tribal language is being integrated significantly into one of the two classes.

Teachers in the middle/high school in District 1 felt like they had some flexibility in their curriculum as long as they were aligning it to the state assessment standards. All teachers mentioned inheriting prior teacher's textbooks, and that many of them were dated and needing to be updated. All teachers interviewed at the District 1 middle/high 
school try to actively engage tribal leaders or tribal community members in lessons when possible. However, I observed none of the teachers could necessarily distinguished between teaching about the culture versus teaching culturally. ${ }^{7}$

Teachers in the elementary school in District 2 also indicated that their curriculum is relatively prescriptive, but that the District has spent a considerable amount of money updating texts and materials to meet the newer state assessment standards. They indicated that they actively work with tribal language instructors and other tribal elders or tribal leadership on different curriculum units. They approach their teaching with an understanding that their students have a different way of learning and knowing the world based on their cultural experiences. They also work closely with their TED on the use of a pedagogy based on the local Tribe's history.

Teachers in the middle/high school in District 2 felt they had flexibility in determining their curriculum, but also worked to ensure alignment to the state assessment standards. Two of the four teachers interviewed were in their first year of teaching and while interested in engaging tribal elders or leaders in lessons, neither have had the time to do so. They were able to attend the Tribe's annual education summit. Both indicated that they were spending a considerable amount of time developing their lessons plans. The other two teachers had been teaching in the district between 22-47 years and were keenly aware of teaching culturally and use of culturally relevant curriculum.

District 2 teachers and administrators also talked about being a trauma informed school. The non-American Indian teachers and administrators also shared a recognition

\footnotetext{
${ }^{7}$ Teaching culturally is an awareness and inclusion of cultural references, whereas teaching about the culture is something that would happen at home by parents and tribal community members through various events and ceremonies.
} 
that they came to the community with different cultural experiences and ways of knowing and understanding the world. One teacher in District 2 shared the story of a student who had received money from their parents for the school book fair. The student had purchased the books they wanted and as they were leaving to go back to class another class was coming into the library. The student started handing out the remainder of their money to other students. The teacher stopped the student and asked them what they were doing. The student replied that they had gotten the books they wanted and didn't need the rest of the money. The student felt that the other kids might want to get books too. The teacher was exasperated because to them, it was not normal to give away your money. The teacher shared it was their belief you should keep your money for yourself. But to this student, they viewed their relationships outside of the self and more about community. The teacher shared that it was a valuable lesson about the differences in their worldviews.

\section{2) Perceptions of Student Performance}

Teachers in District 1 shared that student success to them was defined by their individual demonstration of growth. All of the teachers felt that students were underprepared and they were trying to help the students make up for lost ground. Some teachers shared that when the students were engaged in any way, whether learning or interacting with peers, those were signs of success. One teacher shared the story of a student who had missed all but a few days of the first several weeks of school and they always sat alone and didn't eat at lunch, and when in class kept their head on their arms on their desk. Then one day during a movie in class, the student was under the desk 
laughing with another classmate. The teacher recounted that they could have gotten angry, but the student was engaged and happy, and to them that was a success.

Teachers in District 2 had varied answers for student success. For some it was about student growth, for others it was about their commitment and passion for learning. One teacher shared that in order for students to succeed it was important that they not alienate them from space and time through cultural ignorance. Meaning that they needed to be aware of the social constructs that they came to the community with. They need to be diligent that they validate and understand the social constructs of the students and support how they fit within society. Another teacher shared that success for them was students seeing the value in themselves and recognizing they bring value to the rest of the world.

Teachers in both districts spoke limitedly about assessments. Most teachers talked about the importance of individual student growth and the students' demonstration of progress in their learning. Multiple teachers in both districts utilize group and cooperative learning strategies.

\section{3) Tribal and Community Engagement}

Teachers in District 1 all expressed participation in school sponsored or school sporting events. Only three of the five teachers talked about attending powwows, community classes, farmer's markets or other community events. All of the teachers interviewed lived outside of the community, anywhere from 30 minutes to an hour and a half away. Teachers in District 1 talked about several of the TED grants and how they support student opportunities. They also believed that the relationship with the TED had helped them better support their students. 
Teachers in District 2 all expressed participation in school sponsored or school sporting events. Only three of the five teachers (two were new to the school this year) talked about attending powwows or other community events. Teachers in District 2 also talked about the TED grants and their impact in supporting students. They also noted that the relationship with the TED had helped them as teachers.

\section{Summary}

District 2 consistently had both American Indian teachers and administrator representation, while District 1 did not. The six data elements analyzed under access demonstrated patterns that support the theoretical model of representative bureaucracy in that American Indian students in District 2 appear to have been positively impacted by the presence of American Indian teachers. Some data analyzed under access were dependent upon the availability of resources to support programs or availability of qualified teachers (math, science, and dual credit) rather than the ethnic representation of teachers. The six data elements analyzed under performance also suggest support for the theoretical framework in that the presence of American Indian teachers in District 2 appears to have positively impacted performance for American Indian students. American Indian students in District 2 appear to have demonstrated more positive outcomes than American Indian students in District 1 in all data categories evaluated except attendance. I believe there is a need for additional research that evaluates grade level data in both districts over time to determine if there are access and performance trends that are not being captured at the aggregate level.

Spending time in both communities and the interviews with TEDs, administrators, and teachers in both districts was most valuable. It is clear that the STEP grants are 
increasing collaboration between LEAs and TEAs. While it is also clear they are also increasing the presence of culturally relevant curriculum in both districts, District 2 teachers and administrators consistently discussed the importance of teaching culturally and how being trauma informed has changed the way they interact and engage with students and parents/guardians. Further research would enhance the preliminary findings, as activities that would normally be demonstrated as active representation are being generated and sustained through the activities identified in the STEP grants in District 2.

Perhaps what stood out most were the challenges both districts experience with regard to student attendance. Neither district could pinpoint why they had such significant challenges with student attendance. Some teachers and administrators shared that students missed school because there was no one home to get them up for school in the morning or because they had to take care of younger siblings while their parents worked. Others shared there seemed to be an overall lack of interest or perceived value in education. Though District 2 recognized being trauma sensitive, neither district discussed the reality that education has historically been a tool of cultural destruction of American Indian communities and culture. I would propose that the legacy of destruction continues to generate distrust by American Indians for the American education system, and thereby creating apathetic attitudes towards the benefit and value of the American education system.

While the data elements I evaluated under access and performance included additional measures beyond the theoretical models used in prior research (Meier et al., 1989; Meier \& Stewart, 1991; Wright et al., 1998), they were selected to provide a larger dataset to determine the impacts of American Indian teacher representation on American 
Indian student access and performance based on my case study model. The interviews were intended to assess perceptions of performance as well as capture whether passive representation (presence of American Indian teachers) lead to active representation (use of culturally relevant curriculum and teaching practices).

Both the statistical data analyzed and qualitative data captured from interviews appear to suggest support that passive representation might lead to active representation in District 2. However my research also revealed that passive representation of American Indian teachers is significantly more complicated for American Indians than for African American and Hispanics as a result of the federal government's use of education as a tool for cultural destruction (as discussed more thoroughly in Chapter 2). The evidence of these impacts are suggested in the chronic problem of American Indian student attendance. Further, my research revealed that tribes assuming a more direct role in administrative decisions in public schools serving American Indian students, as seen in the examples of the two STEP grants, might act as a form of active representation. Again, the ability of tribes to act in this capacity is a direct result of their quasi-sovereign status, whereas this same option does not exist for African Americans and Hispanics. The ability of tribes to act in this capacity has been most recently facilitated by the goals and objectives of their respective STEP grants. 


\section{CHAPTER SIX: CONCLUSIONS AND POLICY RECOMMENDATIONS}

Historically, obtaining an education beyond high school was a gateway to the middle class and a comfortable life, but today having some form of postsecondary certificate or degree has become necessary to even meet basic needs. Attaining only low levels of education adversely impact living conditions as well as the overall health of society. The under-education of American Indians continues to affect their basic living conditions and overall quality of life. American Indians lack access to fundamental services of many kinds. Eleven percent of American Indians live in conditions that lack basic kitchen facilities, $14 \%$ lack access to electricity, and $12 \%$ lack access to complete plumbing, whereas those numbers for the total population remain at only $1 \%$ (NCAI Policy Research Center, 2015 Demographic Profile of Indian Country). Further, 29\% of American Indians live in poverty (13\% for the total population) and have an unemployment rate of $22 \%$ (5\% for the total population) (NCAI Policy Research Center, 2015 Demographic Profile of Indian Country). American Indian youth suffer from the highest rate of suicide among all ethnic groups (62\% higher than all others), and suicide is the second-leading cause of death for American Indian youth aged 15-24 (NCAI Policy Research Center, 2015 Demographic Profile of Indian Country).

Using a cross-comparative case study, the purpose of my research was to determine whether or not the presence of American Indian teachers positively influences access and performance of American Indian students in two rural, Idaho public school districts located within the local Tribe's reservation boundaries. And, did that then lead to 
active representation through the use of culturally relevant curriculum and teaching practices. In this final chapter I will first summarize essential findings of my research and results from the case studies, second I will discuss possible state and local school district policy recommendations, and finally I will provide suggested areas for future research.

\section{Summary of Essential Findings}

My research findings highlight how the social construction of American Indians as undeserving and unentitled, both historically and in an educational policy context, was foundational to the implementation of the U.S. Government's philosophy of using education as a tool to eliminate American Indian communities and their cultural identity. Because education has been a tool used for destruction of tribal cultural and communities, American Indians are wary and distrusting of a system of which they have had little to no participation in the development. The distrust is partially based on an absence of American Indian representation in education policy and politics ranging from school board members through administrators and teachers. But most significantly, the distrust is as a direct result of education being used as a tool for cultural destruction of American Indian tribes. Most notably, however, any application of representative bureaucracy theory to American Indians and education must consider the historical context. Traditional empirical models fail to capture essential qualitative elements of the American Indian experience. Because Hispanics and African Americans do not have the same historical or political relationship with states and the federal government as American Indians, any model to assess representation would likely fail to capture reasons for lack of passive representation. 
Quantitative research conducted over the last twenty to thirty years supports the theory of representative bureaucracy, which is that increased representation of minority teachers limits the impacts of second generation discrimination (Meier, 1984; Meier et al., 1989; Meier et al., 1999; Meier \& Stewart, 1991; Selden, 1997; Wright et al., 1998). However limited case studies have been conducted that evaluate what real challenges and successes exist at the local level. In the research by Wright et al, (1998) they conducted a quantitative analysis using a combination of five case studies of two school districts in Oklahoma and three counties in Alabama. A critical finding of Wright et al.'s, (1998) research was the confirmation that school districts are unique, and therefore strategies supporting American Indian student success can vary in significance based on the communities and their histories. This was highly consistent with my findings as well. Recognizing that there are important differences between tribes, governments, politics, and histories based on regions of the U.S. (southern versus western, eastern versus northern, etc.), taking into account the unique local historical relationships states and neighboring communities have with tribes is important. As a result, I acknowledge that this research may not be applicable to all public school districts with a predominant American Indian student enrollment. However, the framework of this research could be expanded and/or replicated in other communities with the ability to tailor research questions appropriate to the regional environment.

I used descriptive statistics that included American Indian student access and performance data for $4^{\text {th }}, 8^{\text {th }}$, and $11^{\text {th }}$ grades and compared them to their peers over a three-year period in both districts. By not evaluating data from all grades over time, on an individual school-building level (versus district-wide level), I discovered both limitations 
and opportunities in the data. I found that while the targeted grades I was evaluating $\left(4^{\text {th }}\right.$, $8^{\text {th }}$, and $\left.11^{\text {th }}\right)$ did not experience disciplinary actions, there were still disciplinary actions occurring in other grades in the district. And, based on prior research I was aware that evaluating the degree of disciplinary actions across a school by ethnic representation was important because placement in special education often becomes the largest barrier for students to overcome (Meier, 1984; Meier et al., 1989; Meier et al., 1999; Meier \& Stewart, 1991; Wright et al., 1998). To that end, I was able to evaluate Federal Civil Rights data reported by both districts. In addition, because this research was a case study, determining definitive causality between American Indian teacher representation and American Indian student access and performance was not possible. While valuable insights were provided, in order to make definitive conclusions, a more comprehensive statistical analysis would be required.

There were also challenges in validating the legitimacy of de-identified studentlevel data collected from the state. In meetings with administrators they felt the data did not accurately reflect their own realities, and shared that they had experienced many challenges over the years with the state EASI system. Nevertheless, there was rich data at the grade level (versus district-level) warranting further exploration and analysis, which I will discuss in my Recommendations for Further Research section.

I organized student data by access and performance (see Chapter 5 for greater detail). The student-level data elements I evaluated under access were participation in special education, gifted and talented, and dual credit programs, and availability of middle/high school math and science courses. The data elements I evaluated under performance were school attendance, Idaho Standardized Assessments (ISAT) for $4^{\text {th }}$ and 
$8^{\text {th }}$ grades, disciplinary actions, SAT/ACT testing, and graduation rates. While the data available for graduation rates could not be obtained at the local level, the remainder of the data evaluated provided meaningful results.

Assessment of access data across all six categories (as described in Chapter 5) suggest support that American Indian students in District 2 appear to have been more positively impacted by the representation of American Indian teachers. Results of American Indian teacher representation impacting access in some instances were impacted by the lack of access to programs or curriculum as a result of lack of available resources or availability of qualified teachers in the respective district. However, of all of the access data elements analyzed I would recommend that further analysis of the placement of American Indian students in special education across all grades and over time in both districts is necessary, and discussed in greater detail in my Recommendations for Further Research.

Assessment of performance data also suggested supported for the theoretical model of representative bureaucracy in that American Indian students in District 2 appeared to have performed more positively (in the data elements described above) than students in District 1, the district without American Indian teachers. American Indian students in District 2 appear to demonstrate more positive results on all standardized assessments and disciplinary actions than American Indian students in District 1. However, both districts face challenges with regard to student attendance. Attendance was an area I anticipated seeing positive impacts as a result of teacher representation in District 2, but that was not necessarily the case. 
Administrators and teachers shared perceptions that American Indian students and families were generally apathetic towards education. A better understanding of the social construction of American Indian education policy and politics may help administrator and teacher perceptions. It is not that American Indians fail to recognize the value in education, but lack of engagement is likely more a result of distrust based on the origins of American Indian education and a desire for tribal self-determination over education of their people. The distrust of education has been generations in the making and most dramatically played out during the boarding school era. The history and the federal government's use of education as a tool for cultural destruction necessarily impact any application of representative bureaucracy theory with regard to American Indians. However, because the majority of American Indian students attend public schools there has been a demonstrated need, supported by the findings of federal reports, for representation of tribes in the development and delivery of culturally relevant curriculum and teaching practices. However, despite the existence of such recommendations, they have failed to be implemented at the state or district level.

The State Tribal Education Partnership (STEP) grants may be models for how school districts (LEAs), state education agencies (SEAs), and tribal education departments (TEDs) can work more collaboratively for the benefit of American Indian student success. Interviews with district administrators, teachers, and tribal education departments from both districts confirmed that the relationship between TEDs and LEAs were strengthened by the outcomes identified in their respective STEP grants, leaving me to wonder if the STEP grants are a demonstration of a form of active representation, regardless of the presence of passive representation. Could there be another way to 
establish active representation other than the passive representation of American Indian teachers? Both districts demonstrated varying degrees of culturally relevant curriculum and pedagogical practices. However District 2 was significantly more advanced in its efforts to teach culturally, and they appeared to place a significantly higher importance on teacher professional development that supported this philosophy. Without further indepth research it is difficult to ascertain if this is a result of American Indian teacher representation or the fact that District 2 is twelve years into delivering the outcomes identified in their STEP grants. While District 1 lacks American Indian teacher representation, their work with the Tribe on the development of $4^{\text {th }}$ grade social studies curriculum, for example, is providing a mechanism for active representation.

\section{State and District-Level Policy Recommendations}

I am making state and district-level policy recommendations in three areas. The first is to formalize the framework of the STEP grant in districts serving $10 \%$ or more American Indian students; the second is to require training for school boards, administrators, and teachers in districts serving $10 \%$ or more American Indian students; and the third is to increase professional development time.

1. State-level policy recommendation: Formalize the framework used in the STEP grants at the state level in order to build the capacity of TEDs to act in administrative capacities in collaboration with LEAs in schools that serve $10 \%$ or more of students from the local tribes.

I am recommending that $10 \%$ be the threshold of American Indian student representation based on my analysis of Impact Aid and the requirements for a postsecondary institution to be designated as native serving. While there is a $3 \%$ 
American Indian student average daily attendance ${ }^{8}$ requirement to receive federal Impact Aid funding, there are no state or federal designation for a public school district serving American Indian students at the K-12 level. Therefore, I assessed the requirements for a college or university to be designated as a native serving non-tribal institution. To be federally designated as a Native Serving Non-Tribal Institution (NASTI), $10 \%$ of your enrollment must be American Indian/Alaskan Native students. Rather than choosing the lower end of $3 \%$, I selected the higher end of $10 \%$, because many policymakers may perceive $3 \%$ as too low of a threshold which to commit resources. In lieu of a populationbased threshold, an alternative would be to require all school districts located within or near reservation boundaries to formalize the framework of the STEP grants.

All school districts serving $10 \%$ or more American Indian students should be required to establish active agreements with their local tribes in which tribes are allowed more involvement in the administrative decisions impacting their students. Because of tribes' unique quasi-sovereign status they have a legal rationalization for having this authority. As discussed previously, American Indian students in District 2 demonstrated more positive performance than American Indian students in District 1 . This is partially the case because District 2 has adopted the cultural standards of their local tribe and the STEP grant has created opportunities and a framework for the TEDs in both districts to be part of curriculum, professional development, and student success discussions and decisions. As one TED shared "education was done to us," but now the Tribes are able to have a voice in education because of the work in the STEP grants. This is a policy

\footnotetext{
8 The federal Impact Aid funding formula is markedly more complicated based on several other factors (https://www2.ed.gov/about/offices/list/oese/impactaid/whatisia.html).
} 
recommendation that could be carried out through recommendations from the Idaho Indian Education Committee ultimately to the Idaho State Board of Education in either rule or statute. The two Tribes with STEP grants could be models for developing what this partnership might look like for school districts that have not received STEP grants.

2. State-/District-level Policy Recommendation: Require teachers, administrators and school board members in districts serving American Indian students to go through training on culturally responsive teaching and pedagogy.

While observing the School Board meeting in District 1, a school board member shared their experience of visiting the classes in their elementary school. As is customary in their culture, youth respectfully greet their elders when they see them. When the school board member entered the class, a student who ran up to greet their elder was reprimanded by the teacher for leaving their seat. The student stood confused and at a loss, not wanting to be disrespectful to the elder but not wanting to get in trouble with the teacher. This is but one of many observations I made where understanding the cultural customs could support and benefit American Indian students and their growth. Providing regular district-wide training is an easy way to ensure students' histories and sense of self-belonging are valued, that their culture lives on dynamically. Lomawaima (1999), a researcher on culturally relevant teaching, revealed that as American Indians their "cultures have been presented in static dioramas in natural history museums as though we were nonhuman subjects, undeserving of inclusion within museums devoted to ‘American'... history, culture, and civilization" (p. 4). Further, interviews with teachers in District 2 supported that non-American Indian teachers felt they had benefited significantly from training on culturally relevant teaching. 
This recommendation could be carried out through training at the district-level, training at the annual Idaho School Boards Association meeting, or as part of the Idaho Indian Education Committee's annual meetings. The effort by the LEA and TED in District 2 could serve as a model for replication statewide.

3. District-level Recommendation: Increase professional development time in District 1.

Teacher turnover and availability of specialized and substitute teachers in District 1 have been significant challenges. There is no doubt that teacher turnover is impacting stability in the schools. In fact administrators and teachers all expressed a need for stability. Many teachers shared that acting out by students increases significantly around Thanksgiving, Christmas break, spring break, and especially summer break - periods without structure and connectivity with teachers. While all teachers were clearly committed to the students and the schools they served, they needed more time to develop and reflect upon their skills. Because resources are limited and pay is low, providing time to support professional development may be a way to increase job satisfaction and longterm commitment to the communities. District 2 has been providing three-hours of weekly, district-wide time for professional development, and all teachers and administrators expressed how this time helped them professionally as well as their ability to assess student performance whereas District 1only provides one hour every other week for district-wide professional development. District 2 may be able to share ideas for how development and implementation of a professional development model could be accomplished in District 1. 


\section{Recommendations for Further Research}

There are three areas that would benefit from the development of further research. The first is an analysis of American Indian student performance on the new ISAT tool, the second is American Indian student placement in special education, and the third is a longitudinal study of access and performance data elements for all grades over a 3-5 year period.

As part of the federal Every Student Succeeds Act (ESSA), all states are required to have a standardized state assessment, and the ISAT is Idaho's standardized assessment. Idaho was part of the SBAC efforts, and implemented the new assessment tool in 20142015. Four years have passed since the initial implementation. Data should now be more reflective of student knowledge and abilities, and student performance should be assessed over time. Evaluation of students who do not take the ISAT should be part of this assessment. In addition, because Idaho was part of the SBAC efforts, there may be greater possibilities to expand the scope of the research to include school districts of similar size and demographics in other states who also participated in the SBAC.

The second recommendation for further research is in the area of special education. The number of students placed in special education impacts a school districts' state and federal funding, and therefore greater scrutiny should be given to legitimacy of the students placed in those programs. My assessment of state-level data on special education across three years (AYs 2012-2015) in $4^{\text {th }}, 8$ th, and $11^{\text {th }}$ grades in the two districts, revealed that American Indian students comprised the largest percentage of special education participation in all but one instance (District $1,11^{\text {th }}$ grade). Which might be evidence of disproportionate placement of American Indian students in special 
education. This is an example where evaluating all grades over time may yield trends or patterns of American Indian student placement in special education, supporting the research on academic grouping of minority students in low-achieving pathways. Analysis of these data also revealed that in District 1, American Indian students in special education made up the largest number of students receiving in-school or out-of-school suspensions (Chapter 5).

Finally, a longitudinal study of American Indian student access and performance data for all grades over a 3-5 year period may yield valuable results about whether certain grades experience higher placement in special education, experience increased attendance, and achieve proficiency on state standardized testing. This work may also help to evaluate the impact teacher turnover has on American Indian student access and performance. An aggregate assessment of school-wide data over time may provide insight into what policies result in success, and those that suffer challenges.

Education is no longer an issue of expanding opportunity, it has become necessary to attain even minimal standards of living. According to Georgetown University's Public Policy Institute Center on Education and the Workforce, by 2020 more than $60 \%$ of jobs in Idaho will require some form of postsecondary training (includes certificates, undergraduate or graduate degrees). This makes the undereducation of American Indians a crisis more pressing now than ever. Greater attention and analysis of American Indian student access and performance is necessary. American Indians lag behind their white and non-white minority peers in educational attainment, both in Idaho and the nation. According to research conducted in 2016 by the University 
of Idaho’s James A. and Louise McClure Center for Public Policy Research (2016), American Indian adults in Idaho have lower levels of educational attainment as follows:

- the high school graduation rate for American Indians in Idaho was 56\% compared to $77 \%$ for the total Idaho population;

- $\quad$ only $22 \%$ of American Indians in Idaho have an Associate's degree, compared to $34 \%$ of all adults in Idaho; and

- only $14 \%$ of American Indians in Idaho have a Bachelor's degree, compared to $25 \%$ of all adults in Idaho.

National reports spanning generations (1928 Meriam, 1969 Kennedy, and 1991 Indian Nations at Risk Task Force) have repeatedly concluded that our nation's educational policies, which were perceived to meet the educational needs of American Indian students, have actually been a failed approach for centuries. Education intended to acculturate American Indians has been devastating for tribal communities and unsuccessful at its intended goals. We have made very little progress in recognizing or implementing the many recommendations from the various legislative committee reports and task forces in the last century when it comes to American Indian education. There are models in Idaho where increased partnership between LEAs and TEDs is resulting in increased American Indian student engagement and performance. In a state with a single governing board responsible for educational policies throughout K-20 public education, and the existence of an Indian Education Committee that is advisory to the Board, change can happen. 


\section{REFERENCES}

American Indian Policy Review Commission (1976). Report on Indian Education: Task Force Five: Indian Education: Final Report. U.S. Government Printing Office.

Atkins, D.N., Fertig, A.R., \& Wilkins, V.M. (2014). Connections and expectations: How minority teachers can improve educational outcomes for minority students. Public Management Review. Vol. 16, No. 4, pp. 503-526.

Balfanz, R., \& Byrnes, V. (2012). Chronic absenteeism: Summarizing what we know from nationally available data. Baltimore: John Hopkins University Center for Social Organization of Schools.

Barton, R. (2012). Recruiting and retaining rural educators: Challenges and strategies. Principal's Research Review, Vol 7(6). National Association of secondary school principals.

Berger, P.L. \& Luckmann, T. (1966). The social construction of reality: A treatise in the sociology of knowledge. New York: NY, Random House.

Biolsi, T. (2001). Deadliest enemies: Law and the making of race relations on and off the Rosebud Reservation. Berkley, CA: University of California.

Calloway, C. G. (2016). First peoples: A Documentary survey of American Indian history, $5^{\text {th }}$ ed. Boston, MA: Bedford/St. Martin's.

Coeur d'Alene Tribe, (2018). Retrieved from http://www.cdatribensn.gov/cultural/Overview.aspx.

Congress of the U.S., W. D. S. C. on L. and P. W. (1969). Indian Education: A National Tragedy--A National Challenge. 1969 Report of the Committee on Labor and Public Welfare, United States Senate, Made by Its Special Subcommittee on Indian Education. Retrieved from 
http://libproxy.boisestate.edu/login?url=http://search.ebscohost.com/login.aspx?di rect $=$ true $\& d b=$ eric $\& A N=E D 034625 \&$ site $=$ ehost-live

Conner, T. W. (2014). Collaboration and Indian education: Exploring intergovernmental partnerships between tribes and public schools. Journal of American Indian Education, Vol. 53, No. 2, pp. 45-62.

Corntassel, J. \& Witmer R.C., II. (2008). Forced federalism: Contemporary challenges to indigenous nationhood. Norman, OK: University of Oklahoma.

Cotterell, A. (2014). Rural Idaho community divided over failed school levy. Boise State Public Radio. Retrieved from: http://www.boisestatepublicradio.org/post/ruralidaho-community-divided-over-failed-school-levy\#stream/0

Creswell, J.W. (2009). Research design: Qualitative, quantitative, and mixed methods approaches, $3^{\text {rd }}$ ed. Thousand Oaks: CA. Sage Publishing.

Deloria, V. \& Wildcat, D. (2001). Power and place: Indian education in America. Golden, CO: Fulcrum Publishing.

Deloria, V. \& Wilkins, D.E. (1999). Tribes, treaties and constitutional tribulations. Austin, TX: University of Texas.

Dolan, J. \& Rosenbloom D.H. (2003). Representative bureaucracy: Classic readings and continuing conversations. Armonk, NY: M.E. Sharpe.

Duran, E. \& Duran, B. (1995). Native American postcolonial psychology. New York. NY, State University of New York Press

Echo-Hawk. W. R., (2010). In the courts of the conqueror: The 10 worst Indian law cases ever decided. Golden, CO: Fulcrum. Kindle version.

Fletcher, M. L.M., (2008). American Indian education: Counternarratives in racism, struggle, and the law. New York: NY: Routledge.

Fox, S.J. (1999). Student assessment in Indian education or what is a roach? In Swisher, K.C. \& Tippeconnic, J.W.III (1999). Next Steps: Research and practice to advance Indian education. Charleston, WV: Appalachia Educational Laboratory. 
Fraga, L.R., Meier, K.J., and England, R.E. (1985). Social comparison, task motivation, and the development of self-evaluative standards in children. Developmental Psychology. Vol.21, pp-1080-89.

Fredericksen, E.D., Witt, S.L., \& Nice, D.C. (2016). The Politics of intergovernmental relations, $3^{\text {rd }}$ ed. San Diego, CA: Birkdale.

Fredrickson, G. H. \& Smith, K. B. (2003). The Public administration theory primer: Essentials of public policy and administration. Cambridge, MA: Westview.

Georgetown University Public Policy Institute Center on Education and the Workforce Retrieved from https://1gyhoq479ufd3yna29x7ubjn-wpengine.netdna-ssl.com/wpcontent/uploads/2014/12/fullreport.pdf October 17, 2017

Goodrick, D. (2014). Comparative Case Studies, Methodological Briefs: Impact Evaluation 9. UNICEF Office of Research, Florence: Italy.

Grover, K. (2017). Five myths about American Indians: Did one tribe really sell Manhattan for some beads. Washington Post. Retrieved from https://www.washingtonpost.com/outlook/five-myths/five-myths-about-americanindians/2017/11/21/41081cb6-ce4f-11e7-a1a30d1e45a6de3d_story.html?utm_term=.09ed01403418.

Hamilton Project (2018). Where work pays: Occupations \& earnings across the United States. Brookings Institute. http://www.hamiltonproject.org/charts/where_work_pays_interactive Idaho Center for Fiscal Policy (2018). Teacher Compensation. Retrieved from http://idahocfp.org/new/wp-content/uploads/2018/07/ICFP-TeacherCompensation-Issue-Brief.pdf

Idaho Center for Fiscal Policy (2018). Investments in education: Trends in Idaho's public school funding. Retrieved from http://idahocfp.org/new/wpcontent/uploads/2018/05/ICFP-2018-Education-Funding-Report.pdf

Idaho State Department of Education (2018). Public School Finance. http://www.sde.idaho.gov/finance/ 
Idaho State Department of Education (2018). School Finder. https://idahoschools.org/

Indian Nations at Risk Task Force (1991). Indian Nations at risk: An educational strategy for action. Final Report. Washington, D.C.: U.S. Department of Education.

Ingram, H.M., Schneider, A.L. \& deLeon, P. (2007). Social construction and policy design. In Sabatier, P.A. (Ed.). Theories of the policy process, $2^{\text {nd }}$ ed., (pp.93126). Boulder, CO: Westview.

Krislov, S. (1974). Representative bureaucracy. Englewood Cliffs, NJ: Prentice Hall.

Ladson-Billings, G. (1995). The Case for culturally relevant pedagogy. Theory Into Practice. Vol. 34, Summer, pp. 159-165.

Leiding, D. (2006). Racial bias in the classroom: Can teachers reach all children. Innovations in Education, No. 8. Lanham, MD: Rowman \& Littlefield Education.

Lomawaima, K.T., (1999). The unnatural history of American Indian education. In Swisher, K.C. \& Tippeconnic, J.W. (Eds). Next steps: Research and practice to advance Indian education (pp. 3-31). Huntington, WV: Chapman Printing.

Meier, K. J. (1984). Teachers, students, and discrimination: The Policy impact of black representation. The Journal of Politics, Vol. 46, No. 1, pp. 252-263. Retrieved from: http://www.jstor.org/stable/2130443. Meriam, L. (1928). The Problem of Indian Administration. Baltimore, MD: Johns Hopkins University.

Meier, K.J. (1993). Latinos in representative bureaucracy: testing the Thompson and Henderson hypotheses. The Journal of Public Administration Research and Theory. Vol. 3(4), pp393-414. In Wright, D.E., Hirlinger, M.W., \& R.E. (1998). The Politics of second generation discrimination in American Indian education: Incidence, explanation, and mitigating strategies. Westport, CT: Bergin \& Garvey.

Meier, K. J., \& Bohte, J. (2007). Politics and the bureaucracy: Policymaking in the fourth branch of government. Belmont, CA: Thomson Wadsworth.

Meier, K.J. \& Nigro, L.G., (1976). Representative bureaucracy and policy preferences: A study in the attitudes of federal executives. In Dolan, J. \& Rosenbloom D.H. 
(2003). Representative bureaucracy: Classic readings and continuing conversations. Armonk, NY: M.E. Sharpe.

Meier, K.J. \& Stewart, J., (1991). The politics of Hispanic education. Albany, NY: State University Press.

Meier, K. J., Stewart, J., \& England, R. E. (1989). Race, class, and education: The Politics of second-generation discrimination. Madison, WI: Wisconsin.

Meier, K. J., Wrinkle, R. D., and Polinard, J. L., (1999). Representative bureaucracy and distributional equity: Addressing the hard question. The Journal of Politics, Vol. 61, No. 4, pp. 1025-1039. Retrieved from: http://www.jstor.org/stable/2647552.

Meriam, L. (1928). The Problem of Indian Administration. Baltimore, MD: Johns Hopkins University.

Momaday, N.S. (1997). The Man made of words. New York, NY: St. Martin’s Griffin.

Monk, D. H. (2007). Recruiting and Retaining High-Quality Teachers in Rural Areas. Future of Children, 17(1), 155-174. https://doiorg.libproxy.boisestate.edu/10.1353/foc.2007.0009

Mosher, F. (1968). Democracy and the public service.New York, NY: Oxford University. Nabokov, P. (1999). Native American testimony: A chronicle of Indian-white relations from prophecy to the present. 1492-2000. New York, NY: Penguin.

National Congress of American Indians, Policy Research Center (2012). Demographic profile of Indian country. Retrieved from http://www.ncai.org/resources/ncai_publications.

National Congress of American Indians, Policy Research Center (2015). Demographic profile of Indian country. Retrieved from http://www.ncai.org/resources/ncai_publications.

National Indian Education Association (2017). Is education equal: How Federal funding shortages impact Native students. http://www.niea.org/wpcontent/uploads/2016/02/NIEA-BIESchoolConstructionNarritive-FINAL.pdf 
Nez Perce Tribe (2010). Information Systems Department. Retrieved from http://www.nezperce.org/Official/Nimiipuu.htm.

Nuby, J. F. \& Smith J. (2012). From federal intervention to self-determination: Looking forward. In Klug, B. J. (Ed.). Standing together: American Indian education as culturally responsive pedagogy (pp. 3-12). Plymouth: United Kingdom. Rowman \& Littlefield Education.

Reyhner, J. (2018). American Indian boarding schools: What went wrong? What is going right? Journal of American Indian Education, Vol. 57, No.1, pp. 58-78.

Reyhner, J.A. \& Eder, J. (2004). American Indian education: A history. Norman, OK: University of Oklahoma Press.

Roch, C.H., Pitts, D.W., \& Navarro, I. (2010). Representative Bureaucracy and policy tools: Ethnicity, student discipline, and representation in public schools. Administration \& Society. Vol. 42, 1: pp. 38-65. Sage Publishing.

Schneider, A.L. \& Ingram, H.M. (1993). Social Construction of target populations: Implications for politics and policy. American Political Science Review, Vol. 87, No. 2, pp. 334-347.

Schneider, A.L. \& Ingram, H.M. (Eds.). (2005). Deserving and entitled: Social constructions and public policy. Albany, NY: State University of New York.

Selden, S. (1997). The Promise of representative bureaucracy: Diversity and responsiveness in a government agency. Armonk, NY: M.E. Sharpe, Inc.

Steinman, E. (2004). American Federalism and intergovernmental innovation in statetribal relations. Publis, Vol. 34, No. 2, pp. 95-114. Retrieved from http://www.jstor/stable/3331208.

Swisher, K.C. \& Tippeconnic, J.W. (Eds). (1999). Next steps: Research and practice to advance Indian education. Huntington, WV: Chapman Printing.

Szasz, M. (1974). Education and the American Indian: The road to self-determination, 1928-1973. Albuquerque, NM: University of New Mexico Press. 
University of Idaho, James A. \& Louise McClure Center for Public Policy Research (2016). Idaho at a glance: American Indian education. Retrieved from http://sde.idaho.gov/indian-ed/files/general/Idaho-at-a-Glance-American-IndianEducation.pdf.

U.S. Census (2018). Community Fact Finder. https://factfinder.census.gov/faces/nav/jsf/pages/community_facts.xhtml

U.S. Department of Education (2017). About Impact Aid. Retrieved from https://www2.ed.gov/about/offices/list/oese/impactaid/whatisia.html

U.S. Department of Education (2013). Civil Rights Data Collection. https://ocrdata.ed.gov/Home

U.S. Department of Education (2015). Civil Rights Data Collection. https://ocrdata.ed.gov/Home

U.S. Department of Education (2018). Individuals with disabilities education act. https://sites.ed.gov/idea/statuteregulations/

U.S. Department of Education (2018). Office of Indian Education. https://www2.ed.gov/programs/step/index.html

Weeks, P. (2006). They made us many promises: The American Indian experience 1524 to the present, $2^{\text {nd }}$ ed. Wheeling, IL: Harlan Davidson, Inc.

Weeks, P. (2016). Farewell, my nation: American Indians and the United States in the nineteenth century, $3^{\text {rd }}$ ed. West Sussex, UK: John Wiley \& Sons, Ltd.

Weinberg, M. (1977). A Chance to learn: The History of race and education in the United States. New York, NY: Cambridge.

Wilkins, D.E. (2002). American Indian politics and the American political system. Lanham, MD: Rowan \& Littlefield.

Wilkins, D.E. \& Stark, H.K. (2011). American Indian politics and the American political system. ( $3^{\text {rd }}$ ed.). Lanham, MD: Rowan \& Littlefield.

Wilkins, D.E. \& Lomawaima, K.T. (2001). Uneven ground: American Indian sovereignty and federal law. Norman, OK: University of Oklahoma. 
Wright, D.E., III, Hirlinger, M.W., \& England, R. (1998). The politics of second generation discrimination in American Indian education: Incidence, explanation, and mitigating strategies. Westport, CT: Bergin \& Garvey. 
APPENDIX A 


\section{Tribal Education Department Director/Manger Interview Questions}

1. To what extent are your education departments involved in hiring decisions in the school district?

2. Do you recruit teachers who are tribal members to apply in the local public school districts?

3. What are the barriers to recruiting and retaining American Indian teachers?

4. What are your perception of American Indian student performance compared to their peers? Why?

a. How do you define success?

5. What metrics do you use to define success (i.e., grades, test scores)?

6. Do you see teachers and school administrators at community events?

7. Do you receive aggregate or student-level data from the districts for your students?

8. Share about your relationship with the school board and district administrators?

9. Can you share some of the programs or services that you the tribe provides to the community and/or school district?

10. Do you see ways of building or increasing collaboration with the school district? 
APPENDIX B 


\section{Superintendent/Principal Interview Questions}

1. How do you recruit and retain American Indian teachers?

a. What are the challenges/successes?

b. What about general teacher retention?

2. Are there opportunities for growing your own American Indian teachers through paraprofessional, or other opportunities?

3. Who is responsible for approving content and curriculum within your school district?

4. What is the process schools must follow for the development of curriculum within your school district?

5. Are there any requirements about representation from the community that includes parents, elders, or community leaders (use of parent councils as a form of representation)?

6. How is the curriculum vetted within the school district?

7. Are curriculum evaluated for cultural relevance? If so, who is involved in that process?

8. Are you involved in community events?

9. How are disciplinary actions reported in your state reporting?

10. What role do counselors play in working with students - career advising, guidance into special ed, gifted and talented, advanced opps?

11. What are your thoughts on the STEP grant? 
APPENDIX C 


\section{Teacher Interview Questions}

1. How are texts and curriculum materials selected for your class?

2. Do you work with other teachers (in the school or throughout the state) in the development of content materials?

3. Do you work with community members that include parents, elders, or community leaders in the development or presentation of content?

4. What does culturally relevant pedagogy mean to you?

5. Do you use tribal culture, history, and/or governance in your content materials?

6. What autonomy do you feel you have in the classroom?

7. What metrics do you use to define success (i.e., grades, test scores)?

a. Are they consistently assessed and applied across all population of students?

b. How do you evaluate students?

8. What is your perception of American Indian student performance in comparison to their peers? Why?

9. Are you involved in community events?

10. What types of actions might cause a student to receive an out of school suspension (OSS)? Why do you believe there are no disciplinary actions for your school?

11. What are your perceptions of programs like gifted and talented, special education, or advanced opportunities?

12. Do you employ cooperative learning strategies 